\title{
Studien zu den biochemischen und strukturellen Eigenschaften von Snapin und zu seiner Rolle in der neuronalen Exozytose
}

Dissertation zur Erlangung des Doktorgrades der Mathematisch-Naturwissenschaftlichen Fakultäten der Georg-August-Universität zu Göttingen vorgelegt von Olga Vites aus Odessa (Ukraine)

Göttingen 2004 
D7

Referent: Prof. Dr. R. Jahn

Koreferent: Prof. Dr. R. Ficner

Tag der mündlichen Prüfung: 04.11.2004 


\section{Inhaltsverzeichnis}

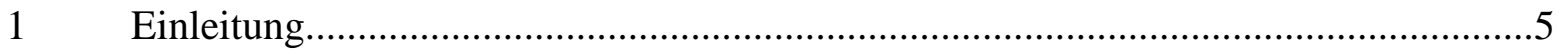

1.1 Membranfusion, Proteine der SNAP-25-Familie und Snapin..........................6

1.2 Sekretorische Lysosomen, BLOC-1 Komplex und Snapin............................10

1.3 cAMP-Signaling, Adenylatcyclase VI, RGS7 und Snapin..................12

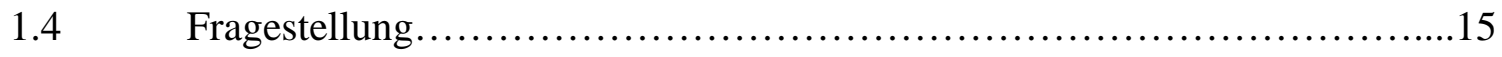

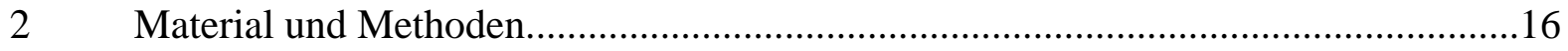

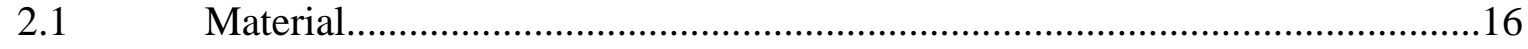

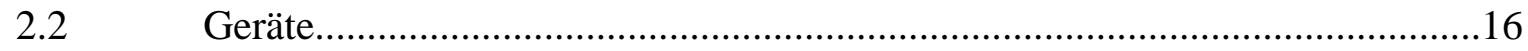

E. coli Stämme und Zellinien....................................................................... 16

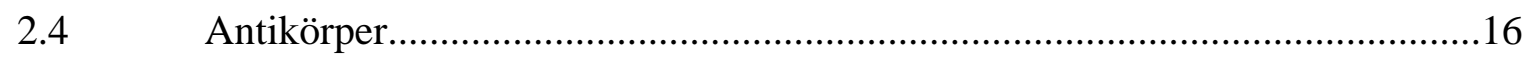

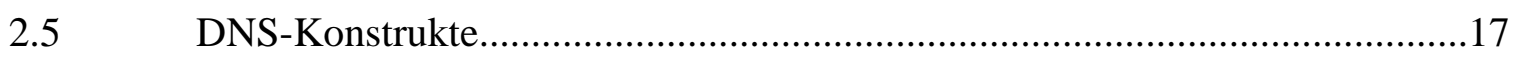

2.6 Expression und Aufreinigung von rekombinanten Fusionsproteinen..............19

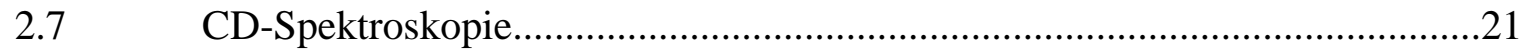

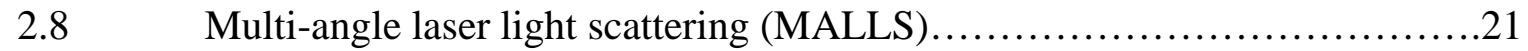

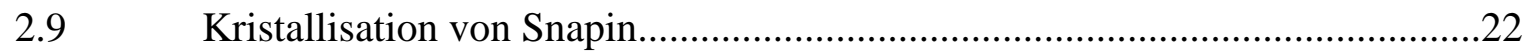

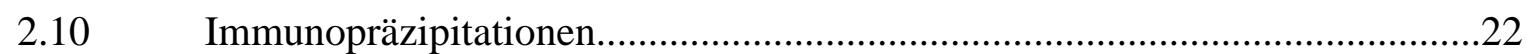

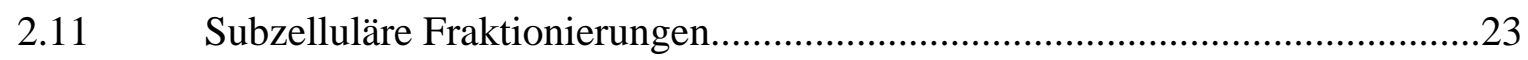

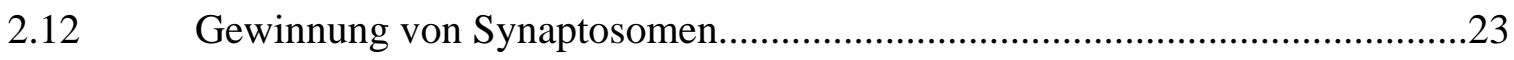

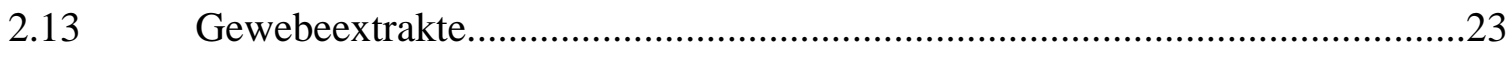

2.14 Interaktionsstudien mit GST-Fusionsproteinen und Hirnextrakten.................24

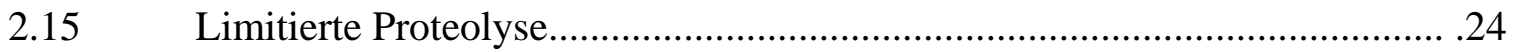

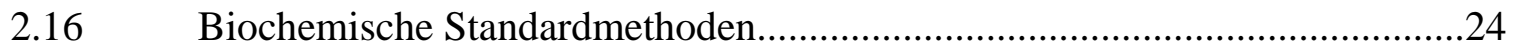

2.17 Computergestüzte Sequenzanalyse............................................................25

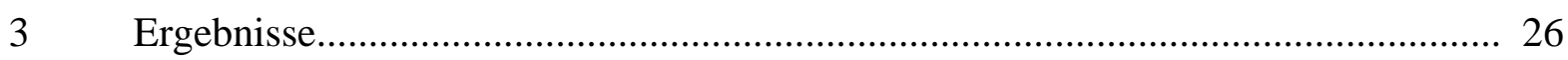

3.1 Reinigung von rekombinantem Snapin und Snapinfusionsproteinen..............26

3.2 Antikörper gegen Snapin und Snapinfragmente............................................29

3.3 Gewebeverteilung und subzelluläre Verteilung von Snapin............................31

3.4 Unterusuchungen zur Struktur von Snapin: von der Primärstruktur

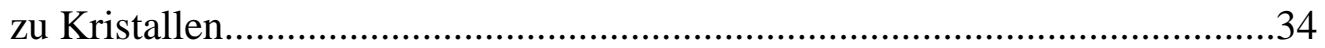

3.4.1 Primäre Struktur: Konservierung von Snapin im Tierreich...........................34

3.4.2 Sekundäre Struktur: computergestützte Analyse der Aminosäurensequenz von Snapin und Studien mittels CD- Spektroskopie.......................37

3.4.3 Tertiäre Struktur: limitierte Proteolyse........................................................40 
3.4.4 Quartiäre Struktur: Dimerisierung von rekombinantem Snapin....................41

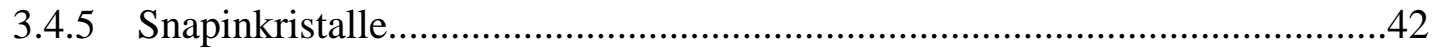

3.5 Interaktion zwischen Snapin und SNARE-Proteinen....................................45

3.5.1 Immunopräzipitationen aus Lysaten von PC12 Zellen und Rattenhirnen......45

3.5.2 Interaktionsstudien mit GST-Fusionsproteinen und Rattenhirnlysaten.........47

3.5.3 Untersuchungen mittels CD-Spektroskopie.................................................48

3.5.4 Vergleichsstudien mit Wildtyp-Snapin und SnapinsS50D............................50

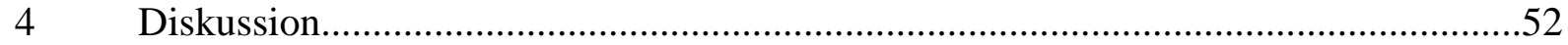

4.1 Gewebeverteilung und subzelluläre Lokalisation von Snapin..........................52

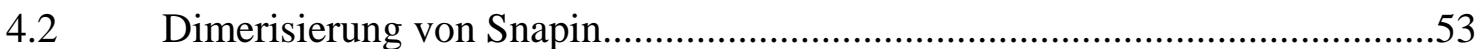

4.3 Rolle von Snapin in der neuronalen Exozytose.............................................53

4.3.1 Interaktionsstudien mit rekombinanten und nativen Proteinen.....................53

4.3.1.1 Unteruchungen mit Ungleichgewichtsassay.......................................53

4.3.1.2 Untersuchungen mit Gleichgewichtsverfahren..................................55

4.3.2 Elektrophysiologische Daten.......................................................................56

4.4 Snapin-Homologe in anderen Organismen.................................................59

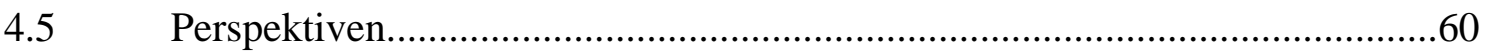

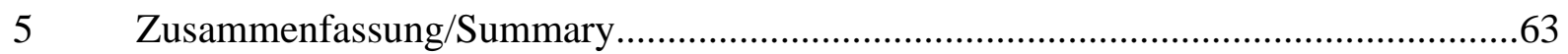

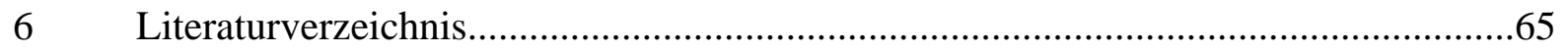

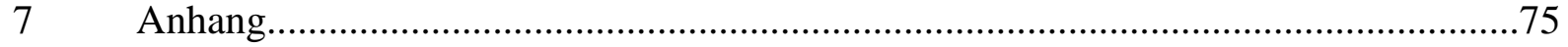

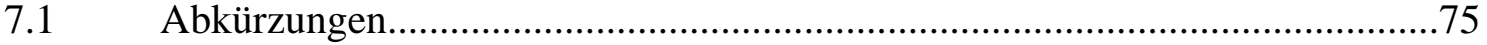

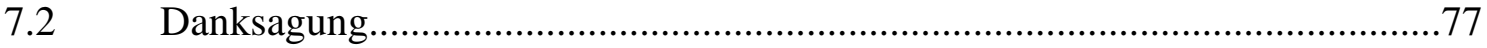

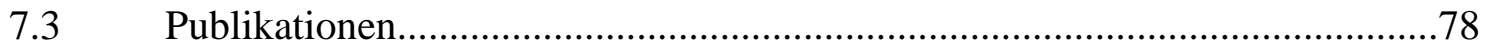

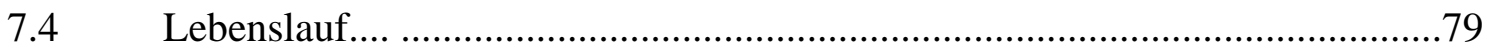




\section{Einleitung}

In der postgenomischen Ära liegt einer der wichtigsten Schwerpunkte der biologischen Forschung in der Charakterisierung von Protein-Protein-Interaktionen. Zusammen mit den grundlegenden Daten wie zeitlich und räumlich aufgelöste Expressionsmuster, zelluläre Lokalisation und Domänenstruktur kann das Wissen über Interaktionspartner zum Verständnis der Funktion eines Proteins führen. Zur Identifikation neuer Interaktionspartner werden Verfahren wie massenspektrometrische Analyse von gereinigten Proteinkomplexen (Übersicht bei Aebersold und Mann, 2003), Proteinmikroarrays auf Chip- oder Glasoberflächen (Übersicht bei Phizicky et al., 2003) und Zwei-Hybrid-Verfahren angewandt (Übersicht bei Causier, 2004). Zwei-Hybrid-Verfahren haben zwei entscheidende Vorteile gegenüber anderen Verfahren zur Identifikation von neuen Interaktionspartnern. Erstens sind sie extrem sensitiv und können niedrig affine Interaktionen (bis $10^{-7} \mathrm{M}$ ) identifizieren. Zweitens bedarf ihre Durchführung nur einer Standardausstattung eines molekularbiologisch oder biochemisch ausgerichteten Labors. Die Grundlage jedes Zwei-Hybrid-Verfahrens besteht darin, dass zwei Proteine $\mathrm{X}$ und $\mathrm{Y}$, deren Interaktion man überprüfen möchte, an zwei sich in ihrer Funktion ergänzende Domänen eines Proteins gebunden sind. Im Standardfall sind es die DNS-bindende und die aktivierende Domäne eines Transkriptionsfaktors. Wenn X und Y miteinander interagieren, kommen die zwei Domänen des Transkriptionsfaktors in räumliche Nähe und können so ihre Funktion ausführen, indem sie ein Reportergen aktivieren. Die hohe Sensitivität dieser Methode rührt daher, dass Proteine in vivo überexprimiert werden und zusätzlich durch die Domänen des Transkriptionsfaktors im Nukleus der Zelle lokalisiert sind. Dieser Vorteil konnte nur auf Kosten von falsch positiv detektierten Interaktionen erkauft werden. Die Anzahl von falsch positiven Interaktionen bei Zwei-Hybrid-Verfahren wurde auf über 50\% geschätzt (von Mering et al., 2002). Auch falsch negative Ergebnisse sind möglich, wenn es sich um Membranproteine oder Proteinkomplexe aus mehreren Komponenten handelt.

Unabhängig davon, durch welche Methode eine Protein-Protein-Interaktion ursprünglich gefunden wurde, muss diese Interaktion der Überprüfung auf biologische Signifikanz durch andere Verfahren standhalten. Sowohl indirekte Indizien wie Koexpression im gleichen Zelltyp, Kolokalisation im gleichen Zellkompartiment, Interaktion orthologer Proteine in anderen Spezies, wie auch direkte Interaktionsstudien wie Immunopräzipitationen und andere Koreinigungen aus nativem Material und quantitative Studien an rekombinanten Proteinen sollten mit der neu entdeckten Interaktion konsistent sein. 
Diese Studie beschäftigt sich mit einem Protein, das ebenfalls ursprünglich durch ein ZweiHybrid-Verfahren identifiziert wurde (Ilardi et al., 1999). In diesem Screen wurde nach Interaktionspartnern von SNAP-25, einem der zentralen Proteine der neuronalen Exozytose gesucht, einem Vorgang, bei dem mit Neurotransmitter gefüllte synaptische Vesikel mit der Zellmembran fusionieren. Als Interaktionspartner von SNAP-25 wurde das gefundene Protein Snapin genannt. Mittlerweile sind noch andere Fachartikel erschienen, die verschiedene ebenfalls über Zwei-Hybrid-Verfahren gefundene Interaktionspartner für Snapin vorschlagen. Dazu zählen an der kostitutiven Exozytose beteiligtes SNAP-23 (Buxton et al., 2003), Regulator von G-Protein gekoppelten Signalstransduktion RGS-7 (Hunt et al., 2003), für die Wahrnehmung von hitze- und entzündungsinduzierten Schmerzen verantwortlicher Vanilloidrezeptor-1 (Morenilla-Palao et al., 2004) und Adenylatcyclase Typ VI (Chou et al., 2004). Außerdem wurde Snapin als eine Komponente des BLOC-1-Komplexes durch Massenspektrometrie identifiziert. Der BLOC-1-Komplex ist an der Biogenese spezialisierter Organellen des endosomal-lysosomalen Systems wie Melanosomen und dichte Granulen der Blutplättchen beteiligt (Starcevic und Dell’Angelica, 2004).

In den folgenden Kapitel der Einleitung soll genau auf die unterschiedlichen biologischen Vorgänge eingegangen werden, mit denen Snapin in Zusammenhang gebracht wurde.

\subsection{Membranfusion, Proteine der SNAP-25-Familie und Snapin}

Die Membranfusion ist ein in der eukaryontischen Zelle weitverbreitetes Phänomen. Alle Kompartimente sind gegeneinander durch Membranen abgegrenzt, damit sie ihre Funktion ausführen können. Diese basiert auf der einmaligen Struktur und Zusammensetzung von Kompartimenten. Kompartimente stehen miteinander im regen Austausch, der jedoch genau reguliert und kontrolliert werden muss. Der Austausch zwischen den Kompartimenten wird durch Transportvesikel durchgeführt, die ebenfalls von einer Lipidmembran umschlossen sind. So werden zum Beispiel sekretorische Proteine am endoplasmatischen Retikulum synthetisiert, im Golgi-Apparatus modifiziet und in sekretorische Granulen verpackt (Palade, 1975). Sekretorische Granulen fusionieren später mit der Plasmamembran der Zelle, ein Vorgang, der als Exozytose bezeichnet wird. Der umgekehrte Vorgang, bei dem die Zelle Materie (von Molekülen bis einzelligen Organismen) aufnimmt, wird Endozytose genannt (de Duve, 1963). Der klassische endozytotische Weg verläuft über „clathrin-coated” Vesikel, frühes endosomales Kompartiment, spätes endosomales Kompartiment und Lysosomen (Übersicht bei Maxfield und McGraw, 2004). Dieser Weg ist durch Reifung von einzelnen Kompanenten ineinander, Austausch mit dem Trans-Golgi-Netzwerk und Recycling- 
Endosomen, homo- und heterotypische Fusion von den endosomalen Kompartimenten mehrfach verzweigt. Außerdem ist auch eine clathrin-unabhängige Endozytose möglich. So wird zum Beispiel diskutiert, dass Recycling von sekretorischen Organellen, wie synaptische Vesiklel und dichte Granulen zumindest teilweise nach dem sogenannten „kiss-and-run”’ Mechanismus verläuft (Übersicht bei Schneider, 2001). Dabei fusioniert die Vesikelmembran mit der Plasmamembran nur für kurze Zeit ohne zu kollabieren, und die Fusionspore wird schnell wieder verschlossen.

Drei Proteinfamilien scheinen in jeden einzelnen Membranfusionsschritt involviert zu sein. Dies sind Proteine der Rab-Familie, die SM- und die SNARE-Proteine. Rab/ypt-Proteine sind monomere GTPasen, die in ihrer GTP-gebundenen Form aktiv sind. Aktive Rab-Proteine binden an eine Reihe von löslichen Faktoren (so genannte Effektoren), die das Signal von aktivierten Rab-Proteinen auf die Fusionsmachinerie übertragen (Übersicht bei Zerial \& und McBride, 2001). Rab-Proteine sind in erster Linie am Docking von Transportvesikeln an ihre Zielmembranen beteiligt und kontrollieren vermutlich die Fusionsspezifität. Die Munc/sec-Proteine, auch als SM-Proteine bezeichnet, spielen eine noch nicht ganz geklärte Rolle in einem späteren Stadium der Vesikelfsuion (Übersicht bei Gallwitz und Jahn, 2003). Die Deletion von diesen Proteinen in Hefe, Invertebraten oder Säugern führte zur Blockade der Exozytose, was auf die aktivierende Funktion von SM-Proteinen hindeutet. Biochemische Studien zeigten, dass SM-Proteine auf verschiedene Arten mit freien Syntaxinen (einer Familie der SNARE-Proteinen) oder SNARE-Komplexen interagieren können. Besonders im Fall der neuronalen SNAREs scheint sich die Bindung von Munc18 an Syntaxin negativ auf die Formation des SNARE-Komplexes auszuwirken. Dies macht die Aufstellung eines Modells, das eine aktivierende Funktion von Munc18 in der neuronalen Exozytose beschreiben soll, wegen der zentralen Rolle des SNARE-Komplexes in der Membranfusion besonders schwierig. Die SNARE-Hypothese wurde von Rothman und seinen Kollegen 1993 formuliert. Dabei sollten SNAREs die Spezifität des Fusionsschrittes vermitteln (Söllner et al., 1993a) und die ATPase NSF im Komplex mit $\alpha$-SNAP die eigentliche Fusion ausführen (Söllner et al., 1993b). Nachfolgende intensive Forschung führte dazu, dass die Rollen unter denselben Hauptdarstellern anders verteilt wurden. Die moderne Version der SNAREHypothese besagt, dass die Formation des SNARE-Komplexes zur Membranfusion führt und dass der SNARE-Komplex anschließend von NSF im Komplex mit $\alpha$-SNAP in einzelne Proteine zerlegt wird, um sie für eine weitere Fusionsrunde bereitzustellen.

Wie funktioniert dieser Vorgang im einzelnen und auf welche experimentellen Daten stützt sich der vorgeschlagene Fusionsmechanismus? SNAREs sind kleine membrangebundene 
Proteine, deren zelluläre Verteilung auf der vesikulären und der „target” Membran zur ursprünglichen v- und t-SNARE Nomenklatur geführt hat. Sie haben alle die sogenannte SNARE-Domäne gemeinsam, einen nicht sehr stark konservierten Abschnitt aus ungefähr 60 Aminosäuren, der zur Bildung von Coiled-Coil-Interaktion fähig ist und somit für die Heterooligomerisierung von SNARE-Proteinen verantwortlich ist. Die Kristallstruktur des neuronalen SNARE-Komplexes (Sutton et al., 1998) und der Sequenzvergleich von SNAREMotiven anderer Mitglieder der SNARE-Familie (Fasshauer et al., 1998) zeigten, dass insgesamt 16 Positionen, an denen sich Kontakte zwischen den einzelnen Helicies der CoiledCoil-Struktur ausbilden, stark konserviert sind. Außer dem zentralen „,0-layer’' handelt es sich um unpolare Aminosäuren, angeordnet in den a- und d-Positionen aneinander gereihter Heptadwiederholungen. Der „,0-layer’' beinhaltet entweder ein Arginin (R) oder ein Glutamin (Q). Dies führte zu einer neuen SNARE-Klassifikation in R- und Q-SNAREs. Man geht davon aus, dass jeder fusogene SNARE-Komplex in der Zelle aus einem R-SNARE und 3 QSNAREs besteht. Manchmal, wie im Falle vom neuronalen t-SNARE, SNAP-25, werden zwei Q-SNARE-Motive von einem Protein beigetragen. Monomere SNARE-Motive liegen unstrukturiert vor und die Formation des SNARE-Komplexes verursacht einen enormen Anstieg im $\alpha$-helikalen Gehalt (Fasshauer et al., 1997). Der entstandene SNARE-Komplex ist extrem stabil (hohe Schmelztemperatur, SDS-Resistenz) und kann in der Zelle erst unter ATP-Verbrauch durch NSF dissoziiert werden (Söllner et al., 1993b). Zusammengenommen führten diese Eigenschaften des SNARE-Komplexes zu der Vorstellung, dass die vom zytosolischen N-Terminus zum membranständigen C-Terminus hin verlaufende Komplexbildung nach dem Reisverschlussmechanismus gegenüberliegende Membranen zweier Kompartimente in eine räumliche Nähe bringt und eventuell somit eine Fusion verursacht. Es wird immer noch diskutiert, ob zusätzliche Proteine in der Zelle den letzten Schritt katalysieren, der zur Membranfusion nach der Formation des trans-SNAREKomplexes führt. Aus diesem Grund, und aus der Sicht der strikten Regulation von intrazellulären Membranfusionen, sind mit SNAREs interagierende Proteine von besonderem Interesse.

Die neuronale Exozytose ist die am besten studierte intrazelluläre Membranfusion (s. Abb.1). Der erste kristallisierte SNARE-Komplex bestand aus den neuronalen SNAREs Synaptobrevin 2, Syntaxin 1a und SNAP-25a. Für diese Proteine, in erster Linie für Syntaxin sind über 50 Interaktionspartner beschrieben worden (Jahn, 2004). Nur wenige von diesen Interaktionen sind detailliert und zuverlässig charakterisiert worden. 


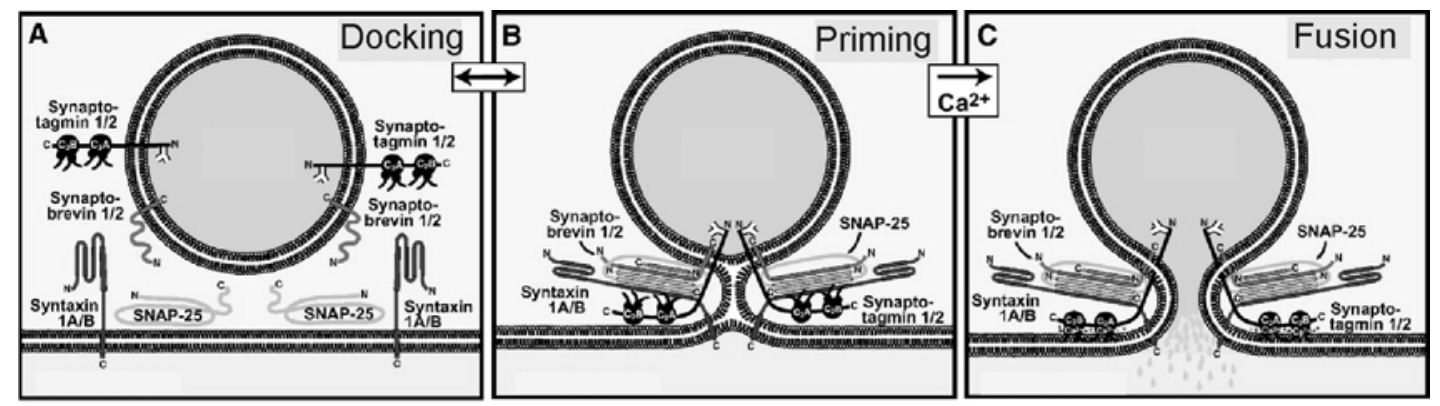

Abb.1 Modell der SNARE-vermittelten Fusion von synaptischen Vesikeln an die Plasmamembran. A, SNARE befinden sich im reaktiven Zustand, Syntaxin und SNAP-25 (tSNAREs) auf der Plasmamebran und Synaptobrevin (v-SNARE) auf den synaptischen Vesikeln. B, Bildung eines Trans-Komplexes, v-SNAREs und t-SNAREs befinden sich noch auf verschiedenen Membranen. C, Membranfusion und Formation eines Cis-Komplexes, vund t-SNAREs sind in einer Membran verankert. Verändert nach Südhof, 2004

Zu den etablierten Regulatoren (Übersicht bei Südhof, 2004) gehören der Kalziumsensor Synaptotagmin, die oben beschriebenen SM-Proteine und das kleine zytosolische Protein Complexin, das vermutlich formierte trans-SNARE-Komplexe stabilisiert. Eine andere Regulationsmöglichkeit der SNARE-Funktion besteht in der Modifikation der SNAREProteine selber, zum Beispiel durch Phosphorylierung (Nagy et al., 2002 und 2004) oder durch Expression verschiedener Isoformen (Sorensen et al., 2003).

Ilardi et al., 1999 beschrieben die Identifizierung eines neuen SNARE-interagierenden Proteins namens Snapin. Sie beobachteten, dass dieses Protein an ein monomeres SNAP-25 bindet und die Interaktion zwischen Synaptotagmin und dem SNARE-Komplex verstärkt. Die Injektion von Snapin-Fragmenten, die mit den SNAP-25 interagieren können, in Neuronen, verursachte eine transiente Inhibition der Exozytose. Die darauf folgende Arbeit der gleichen Arbeitsgruppe (Chheda et al., 2001) berichtete, dass Snapin ein physiologisches Substrat für die PKA darstellt und das die Phosphorylierung durch PKA an Ser50 die Interaktion zwischen Snapin und SNAP-25 verstärkt und den SNARE-Synaptotgmin-Komplex zusätzlich stabilisiert. Buxton et al., 2003 zeigten in ihrer Publikation, dass im Widerspruch zu den Daten von Ilardi et al., 1999, Snapin nicht nur spezifisch an SNAP-25 sondern auch an SNAP-23 bindet, eins bei konstitutiver Exozytose beteiligtes SNARE-Protein. Daten von Morenilla-Palao et al., 2003 wiesen auch indirekt darauf hin, dass Snapin an der neuronalen Exozytose beteiligt ist. In ihren Versuchen wurde gezeigt, dass die Koexpression von Snapin und Vanilloidrezeptor, die möglicherweise miteinander interagieren, zu einer Verminderung 
der SNARE-abhängigen Vanilloidrezrptorexpression auf der Zelloberfläche führt, die durch PKC reguliert wird.

\subsection{Sekretorische Lysosomen, BLOC-1 Komplex und Snapin}

Neben den Zellen, die sich auf regulierte Exozytose spezialisieren (Neuronen, Chromafinzellen, pankreatische ß-Zellen) und ihre Mediatoren in sekretorischen Vesikeln oder Granulen lagern, existiert eine Reihe von Zellen, die ihre Sekretionsprodukte in einem endosomal-lysosomalen Kompartiment speichern. Dieses Kompartiment wird oft als sekretorische Lysosomen bezeichnet (Übersicht bei Blott und Griffiths, 2002). Zellen, die solche sekretorische Lysosomen besitzen, stammen meist aus der hämatopoetischen Linie. Dazu zählen zum Beispiel Blutplättchen (Thrombozyten), B- und T-Zellen, Makrophagen, TZellen und Osteoklasten. Eine Ausnahme von der Regel stellen Melanozyten dar, die neuronalen Ursprungs sind. Sekretorische und konventionelle Lysosomen unterscheiden sich voneinander durch mehrere Eigenschaften.

1. Morphologie: während konventionelle Lysosomen einheitlich multivesikuläre Strukturen darstellen, können sekretorische Lysosomen außer multivesikulärer Erscheinung auch dichte Granulen oder andere Strukturen wie zum Beispiel Melanosomen haben.

2. Zusammensetzung: beide Lysosomenarten beinhalten degradierende Enzyme wie sauere Hydrolasen und andere typische lysosomale Marker wie Proteine der LAMPFamilie. Sekretorische Lysosomen besitzen zusätzlich noch zelltypspezifische Komponenten wie Serotonin, Histamin oder Melanin, die sie sezernieren können.

3. Exozytose: vor einiger Zeit wurde klar, dass auch konventionelle Lysosomen mit der Plasmamembran fusionieren können. Anscheinend benutzen auch nicht exozytotische Zellen diesen Vorgang zur Reparatur von Plasmamembranschäden (Übersicht bei Andrews, 2000). Die zellulären Mechanismen, die der Exozytose der beiden Lysosomenarten zugrunden liegen, müssen zumindest in einigen Komponenten unterschiedlich sein, da genetische Krankheiten bekannt sind, die speziell die Funktion von sekretorischen Lysosomen beeinträchtigen.

Von welchen Schlüsselkomponenten der Membranfusion wurde in Verbindung mit der Exozytose von sekretorischen Lysosomen berichtet? Die Sekretion von spezialisierten Lysosomen wird genauso wie die Sekretion von Neurotransmittervesikeln durch Mitglieder der Rab-, Munc-, Synaptotagmin- und SNARE-Familie (s. Abb.2 und Übersicht bei Stinchcombe et al., 2004) vermittelt. 


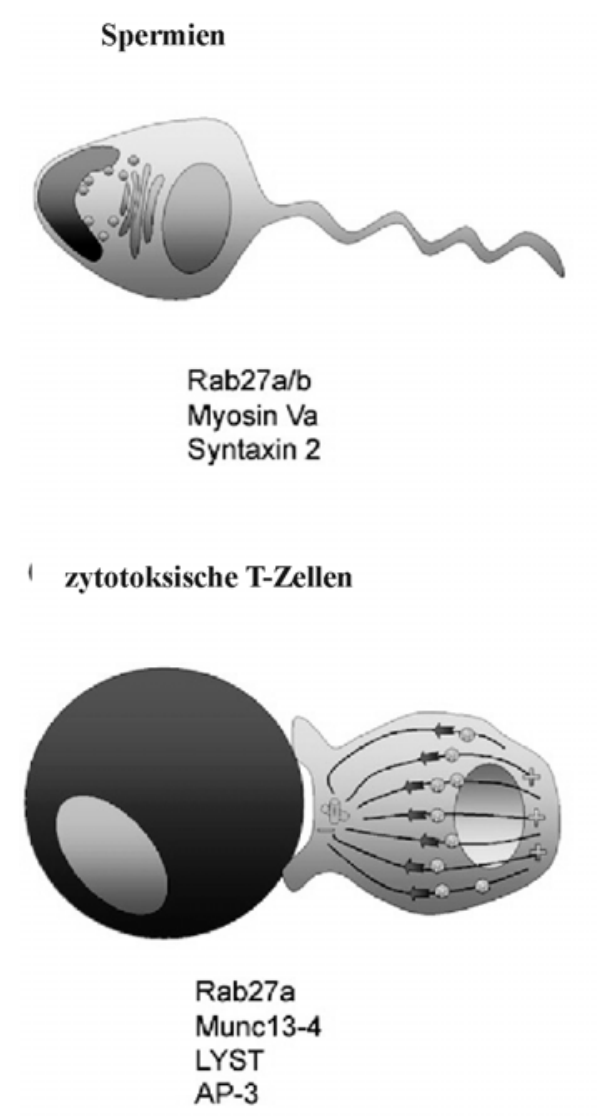

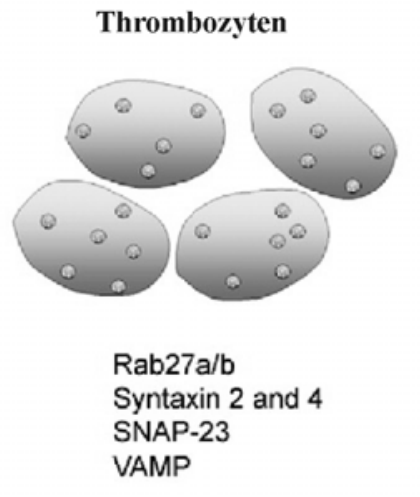

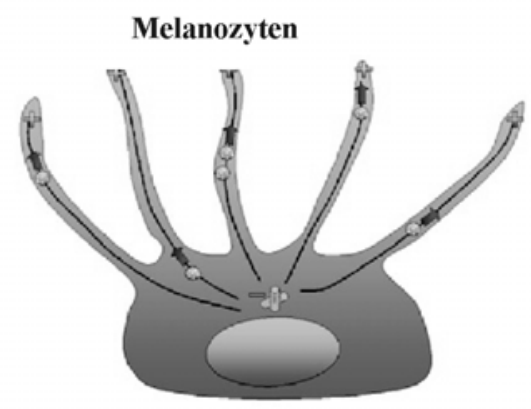

\section{Rab27a}

Myosin Va

Syntaxin 4

SNAP-23 and 25

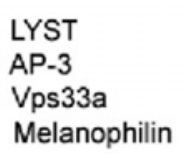

Fibroblasten

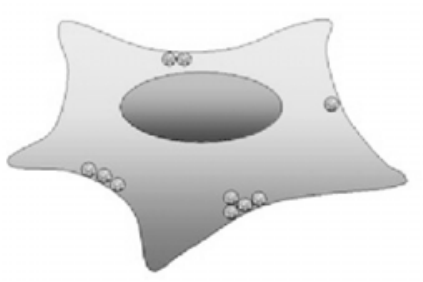

Syntaxin 4

SNAP-23

VAMPNAMP7

Synaptotagmin VII

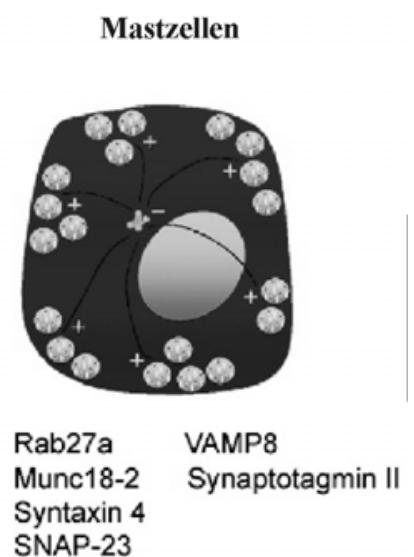

Abb.2 An der Sekretion von exozytotischen Lysosomen beteiligte Proteine. Verändert nach Blott und Griffiths (2004).

Auf die Beteilung von vielen dieser Proteine wiesen Studien von solchen genetischen Kranktheiten wie Chediak-Higashi-Syndrom, Girscelli-Syndrom und Hermansky-PodlakSyndrome hin. Für das Hermansky-Podlak-Syndrom existiert ein gut ausgearbeitetes MausModell (Übersicht bei Li et al., 2004). Dieses Syndrom äußert sich im partiellen Albinismus und Blutungsneigung. Es existieren vier Subtypen, die auf Mutationen in verschiedenen Genen zurückzuführen sind. Sieben mit dieser Krankheit assoziierte Gene wurden beim Menschen (Li et al., 2003) und 16 bei der Maus (Übersicht Swank et al., 1998) identifiziert. Für viele dieser Gene gibt es keine homologen Gene in Hefe, im Gegensatz zu den Genen, die für die Standardausrüstung der Membranfusion kodieren. Mittlerweile ist es klar, dass ihre Genprodukte 3 verschiedene Komplexe ohne gemeinsame Komponenten formieren können. Diese Komplexe heissen BLOC für „,biogenesis of lysosomal-related organelle complex’.

Zuerst wurden die Komponenten des BLOC-3 Komplexes entdeckt (Nazarian et al., 2003, Martina et al., 2003, Chiang et al., 2003). Dieser Komplex besteht aus HPS-1 und HPS-4 und 
kommt im Zytosol und in kleinen Mengen membranassoziert vor. Mutationen in einem der Gene führen zu den typischen Syndromen von HPS und auf der zellulärer Ebene zu den Transportdefekten von lysosomalen und endosomalen Vesiklen (Nazarian et al., 2003). Es gibt Hinweise darauf, dass HPS-1 und HPS-4 noch in weiteren Komplexen vorliegen (Chiang et al., 2003). HPS-3, HPS-4 und HPS-6 bilden den BLOC-2 Komplex (di Pietro et al., 2004, Gautam et al., 2004). Mutationen in den Genen des BLOC-2 Komplexes führen zu einer relativ milden Form von HPS (Nguyen et al., 2002), die sich in erhöhter Anzahl von unreifen Melanosomen manifestiert. Der BLOC-1 Komplex (Starcevic und Dell'Angelica, 2004) besteht aus Pallidin, Muted, Cappuccino, Dysbindin, Snapin und BLOS-1, BLOS-2, BLOS-3. Interessanterweise können alle an dem BLOC-1 Komplex beteiligte Proteine Coiled-CoilInteraktionen eingehen, kommen zytosolisch und membranassoziiert vor und sind konserviert unter Vertebraten und Invertebraten, haben aber keine Homologen in Hefe. Deletion einer der Komplexkomponenten führt zum reduzierten Expressionsniveau anderer Proteine, die an dem Komplex beteiligt sind. Die Funktion dieses Komplexes ist nicht klar, obwohl Mutationen in seinen Komponenten zu stark ausgeprägten HPS-Syndromen führen. Von zwei Komponenten des Komplexes wurde berichtet, dass sie mit SNARE-Proteinen interagieren können. Pallidin interagiert mit Syntaxin 13 und zeigt eine deutliche Kolokalization mit ihm in einem vesikulärem Kompartiment (Huang et al., 1999). Syntaxin 13 ist ein SNAREProtein, das an der Fusion von frühen Endosomen (McBride et al., 1999, Sun et al., 2003) beteiligt ist und auch eine Rolle bei Recycling-Endosomen spielt (Prekeris et al., 1998). SNAP-25 und SNAP-23 wurden als Interaktionspartner von Snapin beschrieben (Ilardi et al., 1999, Buxton et al., 2003). Interessanterweise wird SNAP-23 mit fast allen exozytotischen Lysosomen in Verbindung gebracht (s. Abb.2) und von einem Komplex zwischen SNAP-25, Syntaxin 13 und VAMP2 wurde in zwei Facharbeiten berichtet (Prekeris et al., 1998, Sun et al., 2003).

\section{3 cAMP-Signaling, Adenylatcyclase VI, RGS7 und Snapin}

c-AMP dient als ,,second messanger”' bei der Übertragung vieler Hormonsignale und Sinnesreize. Es wird vom Enzym Adenylatcyclase aus ATP hergestellt. Bei Säugern wurden bis jetzt 9 verschiedene Mitglieder der Adnenylatcyclasen-Familie identifiziert (Übersicht bei Chern 2000). Alle Isoformen außer der hodenspezifischen Isoform sind Membranproteine mit 12 Transmembrandomänen und 3 zytoplasmatischen Einheiten N, C1 und C2. C1 und C2 besitzen die katalytische Funktion und sind stark unter den Isoformen konserviert. Die Nterminale Domäne ist variabel und spielt eine regulatorische Rolle. Adenylatcyclasen werden 
von verschieden G-Proteinen reguliert. Hierbei unterscheidet man einen positiven und einen negativen Regulationsmodus. Nach der Bindung des primären Stimulus (Neurotransmitter, Hormon) an seinen Rezeptor an der Zelloberfläche induziert dieser Rezeptor den GDP-GTPAustausch in der $\alpha$-Untereinheit des Gs-Proteins. In der GTP-gebundenen Form dissoziiert die $\alpha$-Untereinheit ab, bindet an die Adenylatcyclase und aktiviert sie. Die Hydrolyse von GTP durch die $\alpha$-Untereinheit beendet die Aktivierung. Dies ist der positive Regulationsmodus von Adenylatcyclasen durch G-Proteine. Der negative Modus besteht in einer indirekten Wirkung über die $\beta \gamma$-Untereinheit von Gi-Proteinen.

Adenylatcyclase VI stellt einen besonders interessanten Fall dar. Sie ist in mehreren Geweben darunter auch im Hirn exprimiert (Premont et al., 1992). Außergewöhnlich bei dieser Adenylatcyclase ist, dass sie eine 10 bis 15 fach niedrigere basale Aktivität als zum Beispiel Adenylatcyclase II hat (Pieroni et al., 1995) und von $\mathrm{Ca}^{2+}$, PKA und PKC inhibiert wird (Mons et al.,, 1994, Chen et al., 1997, Lai et al., 1997). Soweit bekannt, wird sie nur durch die Stimulation des $ß 2$ adrenergen Rezeptors aktiviert (Chern, 2000).

Chou et al., 2004 beschrieben einen weiteren Regulator der Adenylatcyclase VI. Sie identifizierten Snapin durch ein Zwei-Hybrid-Verfahren als Protein, das an den regulatorischen N-Terminus der Adenylatcyclase VI bindet. Kolokalisationsstudien und Bindungsexperimente bestätigten die Möglichkeit der in vivo Relevanz dieser Interaktion. Allerdings gelang den Autoren keine Koimmunopräzipitation. Interessanterweise wurde die Bindungsdomäne von Snapin nicht der C-terminalen Coiled-Coil-Domäne wie im Falle von SNAP-23 und SNAP-25 Interaktion zugeordnet, sondern einem zentralen Fragment zwischen den Aminosäuren 33 und 51. Koexpression von Snapin und Adenylatcyclase VI modulierte spezifisch die Inhibition der Adenylatcyclase VI durch PKC, aber nicht die basale Aktivität oder die inhibitorischen Effekte von PKA und $\mathrm{Ca}^{2+}$.

Hunt et al., 2003 schlugen noch einen weiteren über Zwei-Hybrid-Verfahren gefundenen Snapin-Interaktionspartner vor, der an cAMP-Signaling beteiligt ist. Es handelt sich um RGS7 (,,regualtor of G-protein signaling’), ein hirnspezifisches Mitglied der RGSProteinfamilie. RGS-Proteine verstärken die intrinsisch schwache GTPase-Aktivität der $\alpha$ Untereinheit von G-Proteinen und desaktivieren sie somit. Außer der RGS-Domäne besitzen RGS-Proteine hauptsächlich N-terminal weitere Domänen, mit denen sie mit anderen Proteinen interagieren können. 


\section{Stimulus}

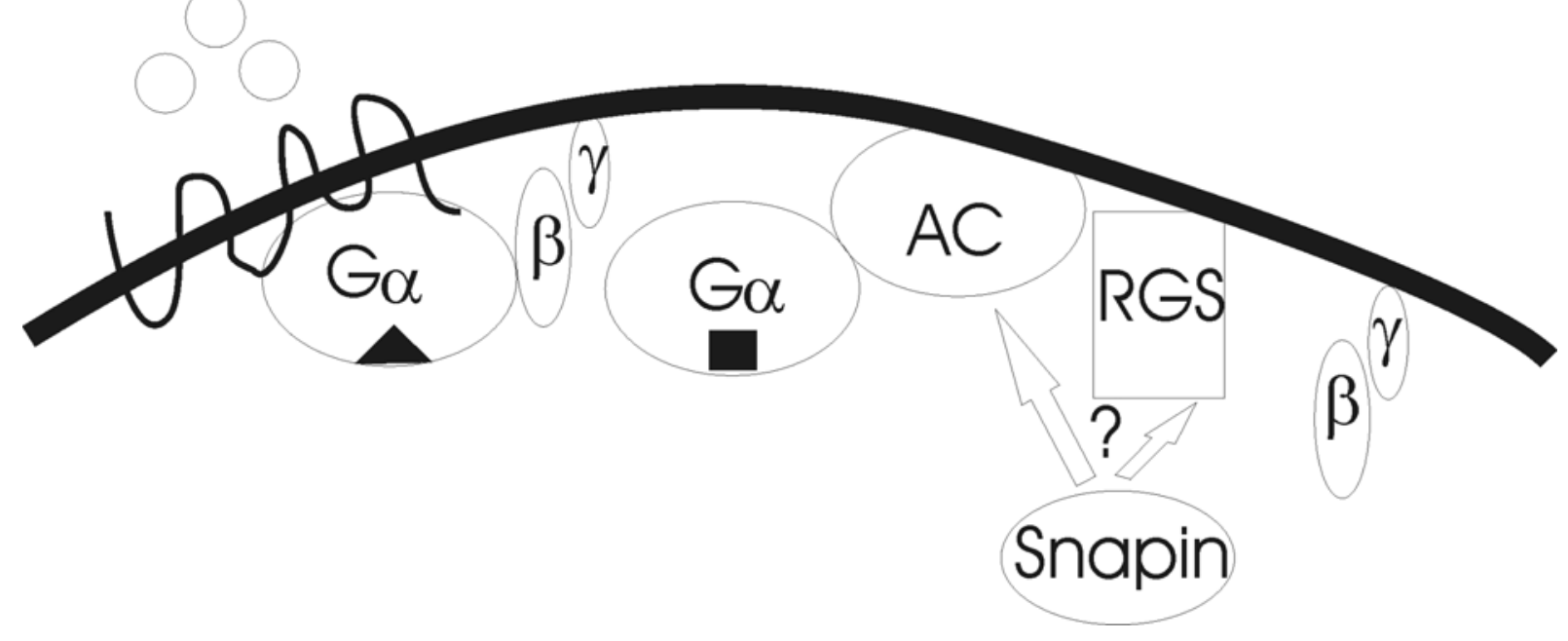

Abb.3 Snapin im Zusammenhang mit G-Protein-Signaling. $G \alpha, \beta, \gamma$ - entsprechende Untereinheiten eines G-Proteins, AC - Adenylatcyclase, RGS - ,regulator of G-protein signaling', Das Dreieck in Assoziation mit der $\alpha$-Untereinheit des G-Protein bedeutet GDP, das Rechteck bedeutet GTP.

Anhand dieser Domänen werden sie in 5 Unterfamilien eingeteilt (Übersicht bei Ishii und Kurachi, 2003). Die ersten 19 Aminosäuren von RGS2 interagieren mit Adenylatcyclase V (Salim et al., 2003). Grundsätzlich scheint die RGS-Adenylatcyclase-Interaktion nicht auf RGS2 und Adenylatcyclase V beschränkt sein. Sinnarajah et al., 2001 zeigten, dass auch RGS3 und 1, aber nicht 4 und 5 verschiedene Adenylatcyclasen inhibieren können. Die Aktivität von den Adenylatcyclasen III, V und VI, aber nicht I und II konnten durch RGS2 moduliert werden. Hunt et al., 2003 zeigten, dass die N-terminale DEX-Domäne von RGS6 und RGS7 mit Snapin im Zwei-Hybrid-Verfahren interagieren kann. Bei Snapin wurde die Bindungsstelle der Coiled-Coil-Domäne zugeordnet. Physiologische Folgen dieser Interaktion sind in der Arbeit nicht untersucht worden.

Eine schematische Darstellung der Zusammenhänge zwischen Snapin und den an G-ProteinSignaltransduktion beteiligten Proteinen ist auf der Abb. 3 zu sehen. 


\subsection{Fragestellung}

Die Bindung von Snapin an SNAP-25 und im demselben Fachartikel (Ilardi et al., 1999) beschriebene Effekte auf Interaktionen von anderen exozytotischen Proteinen machten Snapin besonders interessant für die Arbeitsgruppe von Professor Jahn, die sich mit Membranfusion in eukaryontischen Zellen und speziell mit der neuronalen Exozytose auseinandersetzt. Das Ziel dieser Arbeit war, zum Verständnis der Funktion von Snapin durch umfassende Charakterisierung von diesem Protein und seinen Interaktionen beizutragen. $\mathrm{Zu}$ Beginn dieser Studie war nur die Arbeit von Ilardi et al., 1999 bekannt. Die Qualität der im Fachartikel publizierten Daten veranlasste uns, erneut die Frage nach dem Expressions- und Zellokalizationsmuster von Snapin zu stellen. Außerdem sollte seine Bindung an SNAP-25 und andere Proteine der neuronalen Exozytose quantitativ erfasst werden, um diese in den Kontext der vermuteten regulatorischen Rolle von Snapin bei der Neurotransmitterfreisetzung zu bringen. 


\section{Matherial und Methoden}

\subsection{Material}

Standardchemikalien wurden von den Firmen Sigma, Roth und Merck bezogen. Klonierungsarbeiten (Restriktionsverdau, Dephosphorylierung und Ligation) wurden mit Enzymen von New England Biolabs und von Fermentas durchgeführt und die Plasmid-DNS mit den Kits von Qiagen oder Macherey-Nagel aus Bakterien gewonnen. Für alle PCRReaktionen wurde die Pfu-Polymerase von Stratagene verwendet. Materialen und Säulen für die Chromatographie stammen von Qiagen ( $\mathrm{Ni}^{2+}$-NTA-Agarose) und Amersham Pharmacia Biotech (Glutathion-Sepharose-4B, monoS- und monoQ-Säulen, ProteinG- und ProteinASepharose 6B, CNBr-Sepharose 4B). Plasmide für Molekularbiologie wurden bei Amersham Pharmacia Biotech (pGEX-Serie) und Novagen (pET-Serie) bezogen. Medien für die Zellkultur wurde bei Life Technologies bezogen.

\subsection{Geräte}

Ionenaustauschchromatographie: ÄKTA -System, Amersham Pharmacia Biotech

MALLS: Dawn DSP mit Optilab DSP, Wyatt Technology Corporation

CD-Spektroskopie: Spektropolarimeter J-720, Jasco

\subsection{E. coli Stämme und Zellinien}

Für Klonierungen wurde der E. coli Stamm XL1blue und für Expressionen der E. coli Stamm BL21(DE3) verwendet.

PC12-Zellen (eine Pheochromozytom-Zellinie aus Rattennebennierenzellen (Greene and Tischler, 1976)) wurden auf kollagenbeschichteten (Kollagenkonzentration ca. $2 \mu \mathrm{g} / \mathrm{cm}^{2}$ ) Petrischalen in RPMI 1640 Medium (Life Technologies) mit 10\% hitzedesaltiviertem Pferdeserum, 5\% FCS, 2 mg/ml L-Glutamin, Penizillin-Streptamyzin-Mischung $60 \mathrm{U} / \mathrm{ml}$ kultiviert.

\subsection{Antikörper}

Folgende in dieser Arbeit verwendete Antikörper sind bereits beschrieben: $\alpha$ GDI (monoklonaler Antikörper Cl 81.2 (Chou et al., 2000)), aSynaptophysin (monoklonaler Antikörper Cl 7.2 (Jahn et. al., 1985), aNMDAR (monoklonaler Antikörper Cl 54.2 (Brose et al., 1994), aSynaptobrevin 2 (monoklonaler Antikörper, Cl 69.1 (Edelmann et al., 1995)), aSNAP-25 (monoklonaler Antikörper Cl 71.1 und Cl 71.2 (Bruns et al., 1997)), aSyntaxin 1a 
(monoklonaler Antikörper HPC-1 (Barnstable et al., 1985), $\alpha$ Complexin I und II (polyklonaler Antikörper 942). Die meisten Antikörper sind bei Synaptic Systems erhältlich. Im Rahmen dieser Arbeit wurden drei Antiseren gegen Snapin aus $R$. norvegicus in Kaninchen erzeugt. Das erste Antiserum ist gegen die komplette Sequenz von Snapin gerichtet. Das Antigen wurde rekombinant in E.coli als 6xHis-Fusionsprotein exprimiert und im ersten Aufreinigungsschritt über $\mathrm{Ni}^{2+}$-Affinitätschromatographie angereichert. Nach dem Abschneiden des Tags mit Thrombin wurde das Protein zusätzlich über die Kationenaustauschchromatographie gereinigt.

Das zweite Antiserum ist gegen das C-terminale Peptid gerichtet, das ursprünglich als die Bindungsstelle von SNAP-25 identifiziert worden ist (Ilardi et al., 1999). Dieses Peptid, das den Aminosäuren 117 bis 136 von Snapin entspricht, wurde chemisch mit einem zusätzlichen C-terminalen Cystein synthetisiert. Das Peptid wurde mit MBS an KLH (Calbiochem) gekoppelt.

Das dritte Antiserum ist gegen das Fragment von Ala26 bis Tyr81 gerichtet und interagiert somit nicht mit der putativen Bindungsstelle von SNAP-25. Das Fragment wurde als GSTFusionsprotein exprimiert, an der Gluthationsepharose gereinigt und zusammen mit dem GST-Tag als Antigen eingesetzt.

Nach der Herstellung wurden die Antigene durch Dialyse in PBS überführt und bei $-80^{\circ} \mathrm{C}$ gelagert. Für die ersten zwei Injektionen wurden $300 \mu$ g Protein gemischt mit dem kompletten Freundschen Adjuvant, für alle weiteren $150 \mu$ g Protein gemischt mit dem inkompletten Freundschen Adjuvant verwendet. Das Antiserum gegen das komplette Protein und gegen das C-terminale Peptid sind bei Synaptic Systems erhältlich.

Zur Affinitätsaufreinigung vom Snapin-Antiserum wurden 10 mg GST-Snapin an CNBrSepharose wie vom Hersteller empfohlen gekoppelt. $15 \mathrm{ml}$ Antiserum wurden über Nacht mit dem gekoppelten Antigen inkubiert. Die CNBr Sepharose mit dem gebundenden AntikörperAntigen-Komplex wurde mehrmals mit PBS (40 mM NaCl pH=7,4, $150 \mathrm{mM} \mathrm{NaCl}$ ) mit 0,1\% Tween20 und anschließend mit PBS gewaschen. Die Antikörper wurden mit 0,2 M Glyzin $\mathrm{pH}=2,3$ in $150 \mathrm{mM} \mathrm{NaCl}$ eluiert und sofort mit Tris auf den $\mathrm{pH}$-Wert zwischen 7,2 und 7,5 eingestellt. Anschließend wurden die aufgereinigten Antikörper gegen PBS dialysiet und bei $80^{\circ} \mathrm{C}$ gelagert.

\subsection{DNS-Konstrukte}

Folgende Konstrukte stammen aus dem Labor von Prof. Reinhard Jahn und wurden bereits beschrieben: 
pGEX-KG: SNAP-23, SNAP-29;

pGEX-1T: Syntaxin 1a, zytoplamatische Domäne (Aminosäuren 1-264), SNAP-25a;

pET28a: SNAP-25a, in dem alle Cysteine durch Serine ersetzt worden sind (Fasshauer et al., 1999), Syntaxin 1a, zytoplasmatische Domäne (Aminosäuren 1-262), Synaptobrevin 2, zytoplasmatische Domäne (Aminosäuren 1-96). Alle cDNS-Sequenzen stammen aus $R$. norvegicus.

Die Snapin-Sequenz wurde in den pET28a-Vektor mittels NdeI und XhoI, in den pGEX-KG mittels BamHI und XhoI Schnittstellen kloniert.

SNAP-25b wurde aus dem Vektor pQE9 mittels BamHI und XhoI Schnittstellen in den pGEX-KG-Vektor subkloniert.

Zur Einführung einer phosphomimetischen Mutation in Snapin (Chheda et al., 2001) wurde das Serin an der Position 50 durch ein Aspartat ersetzt. Dazu wurde das QuickChange Mutagenesis Kit von Stratagene benutzt. Auf diese Weise sind die Konstrukte pET28a SnapinS50D und pGEX-KG SnapinS50D entstanden.

Alle Konstrukte wurden durch Sequenzierung auf beiden DNS-Strängen verifiziert.

\begin{tabular}{|c|c|c|c|c|}
\hline Protein & $\begin{array}{l}\text { Amino- } \\
\text { säuren }\end{array}$ & Primer, falls von mir kloniert & Mutation & Vektor \\
\hline SNAP-25a & $1-206$ & & $\begin{array}{l}\text { Alle Cysteine durch } \\
\text { Serine ersezt }\end{array}$ & pET28a \\
\hline SNAP-25a & $1-206$ & & $\begin{array}{l}\text { Alle Cysteine durch } \\
\text { Serine ersezt }\end{array}$ & pET28a \\
\hline SNAP-25b & $1-206$ & $\begin{array}{l}\text { OV18: } \\
\text { acgctcgagttaaccacttcccagcat, } \\
\text { OV19: } \\
\text { cctggatccatggccgaggacgca }\end{array}$ & Wildtyp & $\begin{array}{l}\text { pGEX- } \\
\text { KG }\end{array}$ \\
\hline SNAP-23 & $1-210$ & & Wildtyp & $\begin{array}{l}\text { pGEX- } \\
\text { KG }\end{array}$ \\
\hline SNAP-29 & $1-260$ & & Wildtyp & $\begin{array}{l}\text { pGEX- } \\
\text { KG }\end{array}$ \\
\hline Syntaxin 1a & $1-262$ & & $\begin{array}{l}\text { Zytoplasmatische } \\
\text { Domäne }\end{array}$ & pET28a \\
\hline Syntaxin 1a & $1-264$ & & $\begin{array}{l}\text { Zytoplasmatische } \\
\text { Domäne }\end{array}$ & $\begin{array}{l}\text { pGEX- } \\
1 \mathrm{~T}\end{array}$ \\
\hline
\end{tabular}




\begin{tabular}{|c|c|c|c|c|}
\hline Synaptobrevin & $1-96$ & & $\begin{array}{l}\text { Zytoplasmatische } \\
\text { Domäne }\end{array}$ & pET28a \\
\hline Snapin & $1-132$ & $\begin{array}{l}\text { OV1: } \\
\text { gcgagcatatggccgcggctggttccgctgc, } \\
\text { OV10: } \\
\text { gcgacctcgagttatttgcttggagaaccagg }\end{array}$ & Wildtyp & pET28a \\
\hline Snapin & $1-132$ & $\begin{array}{l}\text { OV4: } \\
\text { gcgacggatccatggccgcggctggttccgctg, } \\
\text { OV10: } \\
\text { ccggagcactacttggtcttctctgaccgc }\end{array}$ & Wildtyp & $\begin{array}{l}\text { pGEX- } \\
\text { KG }\end{array}$ \\
\hline Snapin & $1-132$ & $\begin{array}{l}\text { OV22: } \\
\text { gcggtcagagaagaccaagtagagctccgg, } \\
\text { OV23: } \\
\text { ccggagcactacttggtcttctctgaccgc }\end{array}$ & S50D & pET28a \\
\hline Snapin & $1-132$ & $\begin{array}{l}\text { OV22: } \\
\text { gcggtcagagaagaccaagtagagctccgg, } \\
\text { OV23: } \\
\text { ccggagcactacttggtcttctctgaccgc }\end{array}$ & S50D & $\begin{array}{l}\text { pGEX- } \\
\text { KG }\end{array}$ \\
\hline
\end{tabular}

\section{Tab. 1 Übersicht der in dieser Studie benutzten Konstrukte}

\subsection{Expression und Aufreinigung von rekombinanten Fusionsproteinen}

Alle Fusionsproteine wurden im E. coli Stamm BL21(DE3) exprimiert. Dieser Stamm zeichnet sich durch Deletion von mehreren Proteasen aus und trägt einen $\lambda$ Prophagen, der für eine T7-Polymerase kodiert. Die T7-Polymerase ist für die Expression von 6xHisFusionsproteinen, deren Gene unter der Kontrolle von einem T7-Promotor stehen, zwingend notwendig.

Zuerst wurden elektrokompetente Bakterien frisch mit dem entsprechenden Plasmid transformiert und eine Übernachtkultur ausgehend von einer einzelnen Kolonie angeimpft. Am nächsten Tag wurde die Übernachtkultur 1:100 verdünnt und die Bakterien wurden bis zur OD zwischen 0,8 und 1,0 bei $600 \mathrm{~nm}$ kultiviert. Danach erfolgte die Induktion der Fusionsproteinexpression mit 0,8 mM IPTG für 3-5 Stunden. Die Bakterien wurden abzentrifugiert, das Pellet in 50 ml Resuspensionspuffer (s. Tab. 2) pro 21 Ausgangskultur 
aufgenommen und bis auf weiteres bei $-20^{\circ} \mathrm{C}$ gelagert. Das Bakterienpellet wurde aufgetaut, mit 4 mg Lysozym pro Liter Ausgangskultur und 0,1 mM PMSF versetzt und 30 min bei $4^{\circ} \mathrm{C}$ inkubiert. Danach erfolgte der Aufschluß mit einer Ultraschallbehandlung (vier mal 30 sec, duty cycle 50\% und level 7). Die aufgeschlossenen Bakterien wurden erneut mit 0,1 mM PMSF versetzt und 30 min bei $4^{\circ} \mathrm{C}$ mit 2 mg DNAse pro Liter Ausgangskultur behandelt. Danach wurde entweder 6M Harnstoff für 6xHis-Fusionsproteine oder 0,5\% TritonX-100 für GST-Fusionsproteine zugegeben, gut gemischt (eventuell mit einem Handmixer) und die Zelltrümer wurden bei $4^{\circ} \mathrm{C}$ abzentrifugiert (2x15 min bei $\left.27000 \mathrm{~g}\right)$. Zu dem Überstand wurden dann Kügelchen mit der entsprechenden Affinitätsmatrix hinzugegeben (s. Tab. 2) und 3 Stunden bei $4^{\circ} \mathrm{C}$ rotierend inkubiert. Danach wurden die Kügelchen in eine Säule gepackt, mit Waschpuffer (s. Tab. 2) gewaschen und in mehreren Fraktionen mit dem entsprechenden Elutionspuffer (s. Tab. 2) eluiert, bis kein Protein mehr im Eluat zu detektieren war.

Für die anschließende Ionenaustauschchromatographie wurden die eluierten Proteine auf Niedrigsalz (50-100 mM NaCl) durch Dialyse gebracht. Während der Dialyse wurde bei Bedarf der Expressionstag abgeschnitten. Die Spaltung des Expressionstags verlief über Nacht bei $4^{\circ} \mathrm{C}$ mit 1-10 U Thrombin (Calbiochem) pro mg rekombinantes Protein.

Alle Proteine wurden anschließend entweder duch Anionen- bzw. Kationenaustauschchromatographie (monoS- bzw. monoQ-Säule von Amersham Pharmacia Biotech) mit dem ÄKTA-System gereinigt. Die Bindung an die Säule erfolgte in Niedrigsalzpuffer (je nach Löslichkeit des Proteins in Salzlösungen wurden unterschiedliche Konzentrationen eingesetzt, immer unter $100 \mathrm{mM} \mathrm{NaCl}$ ), die Elution erfolgte durch einen von 0 auf $1 \mathrm{M}$ ansteigenden Natriumchloridgradienten in $20 \mathrm{mM}$ Tris mit Zugabe von $1 \mathrm{mM}$ EDTA. Außerdem wurde $1 \mathrm{mM}$ DTT zugesetzt, wenn Cysteine vorhanden waren. Die Peakfraktionen (verfolgt über die UV-Absorption bei 230 und $280 \mathrm{~nm}$ ) wurden auf einem Coomassie gefärbten SDS-Gel analysiert und die saubersten Fraktionen vereinigt.

\begin{tabular}{|c|c|c|}
\hline & 6xHis-Fusionsproteine & GST-Fusionsproteine \\
\hline Vektor & pET-Serie & pGEX-Serie \\
\hline Antibiotikum & Kanamyzin $(100 \mu \mathrm{g} / \mathrm{ml})$ & Ampizilin $(25 \mu \mathrm{g} / \mathrm{ml})$ \\
\hline Induktionstemperatur & $37^{\circ} \mathrm{C}$ & $25^{\circ} \mathrm{C}$ \\
\hline Nährmedium & TB & LB \\
\hline Aufschluß & $\begin{array}{l}\text { denaturierend mit 6M } \\
\text { Harnstoff }\end{array}$ & $\begin{array}{l}\text { Nativ, mit 0,5\% TritonX- } \\
100\end{array}$ \\
\hline
\end{tabular}




\begin{tabular}{|l|l|l|}
\hline Affinitätsmatrix & $\mathrm{Ni}^{2+}$-NTA-Agarose & Glutathion-Sepharose-4B \\
\hline Resuspensionspuffer & $\mathrm{T}_{20} \mathrm{~N}_{500} \mathrm{I}_{8} \mathrm{pH}=7,4$ & $\mathrm{~T}_{50} \mathrm{~N}_{100} \mathrm{E}_{1}\left(\mathrm{D}_{1}\right) \mathrm{pH}=7,4$ \\
\hline Waschpuffer & $\mathrm{T}_{20} \mathrm{~N}_{500} \mathrm{I}_{20} \mathrm{pH}=7,4$ & $\mathrm{~T}_{20} \mathrm{~N}_{100} \mathrm{E}_{1}\left(\mathrm{D}_{1}\right) \mathrm{pH}=7,4$ \\
\hline Elutionspuffer & $\mathrm{T}_{20} \mathrm{~N}_{500} \mathrm{I}_{400} \mathrm{pH}=7,4$ & $\mathrm{~T}_{50} \mathrm{~N}_{100} \mathrm{E}_{1}\left(\mathrm{D}_{1}\right) \mathrm{G}_{100} \mathrm{pH}=7,4$ \\
\hline & & \\
\hline
\end{tabular}

Tab.2 Unterschiede in Expressions- und Aufschlussbedingungen zwischen 6xHis- und GST-Fusionsproteinen. T- TRIS, N- NaCl, I- Imidazol, E- EDTA, D- DTT (nur bei Proteinen mit vorhandenen Cysteinen dazugegeben), G- Gluthation. Die Zahlen hinter den einzelnen Buchstaben indizieren die Konzentration in mM.

\subsection{CD-Spektroskopie}

Die CD- Spektren zwischen 195 und $250 \mathrm{~nm}$ wurden in Quarzküvetten von 0,1 cm Schichtdicke bei $50 \mathrm{~nm} / \mathrm{min}$ in 0,1 nm Schritten aufgenommen. Jedes Spektrum stellt den Mittelwert von 15 unabhängigen Messungen der gleichen Proteinprobe dar. Für die Messungen wurden Proteinkonzentration von $15 \mu \mathrm{M}$ in $20 \mathrm{mM}$ TRIS, $300 \mathrm{mM} \mathrm{NaCl}, 1 \mathrm{mM}$ EDTA, 1 mM DTT verwendet. Wenn durch Proteininteraktionen entstandene Änderungen in der Sekundärstruktur nachgewiesen werden sollten, wurden die potentiellen Interaktionspartner über Nacht bei $4^{\circ} \mathrm{C}$ miteinander inkubiert. Um die Änderungen im CDSpektrum einer Proteininteraktion zuzuordnen, wurden die gemessenen CD-Spektren mit der theoretischen Summe individueller CD-Spektren verglichen. Zur Berechnung dieser Summe wurde die Gleichung

$\left[\Theta_{\text {sum }}\right]=\Sigma c_{i} n_{i}\left[\Theta_{i}\right] / \Sigma c_{i} n_{i}$

benutzt, mit $\Theta_{\mathrm{i}}$ - molare Elliptizität pro Aminosäure, $c_{\mathrm{i}}$ - Proteinkonzentration und $\mathrm{n}_{\mathrm{i}}$ Anzahl der Aminosäuren im entsprechenden Protein.

Die Schmelzkurven wurden bei $220 \mathrm{~nm}$ in $0,5^{\circ} \mathrm{C}$-Intervallen mit einem Temperaturanstieg von $60^{\circ} \mathrm{C}$ pro Stunde aufgenommen. Wegen der starken Temperaturabhängigkeit des $\mathrm{pH}-$ Wertes des TRIS-Puffers wurden die Messungen in $40 \mathrm{mM} \mathrm{NaH} \mathrm{PO}_{4}, 300 \mathrm{mM} \mathrm{NaCl}, 1 \mathrm{mM}$ DTT $\mathrm{pH}=7,4$ vorgenommen.

\subsection{Multi-angle laser light scattering (MALLS)}

$60 \mu \mathrm{M}$ Protein in $20 \mathrm{mM}$ TRIS, $300 \mathrm{mM} \mathrm{NaCl}, 1 \mathrm{mM}$ DTT $\mathrm{pH}=7,4$ wurde zuerst über die HR-10/30 Superdex-200-Säule bei einer Flußrate von $0,5 \mathrm{ml} / \mathrm{min}$ gelfiltriert. Das Elutionsprofil wurde durch die Messungen von der UV-Absorption bei $280 \mathrm{~nm}$, der Lichtstreuung bei $632.8 \mathrm{~nm}$ und des Reflektionsindexes beobachtet. Die Analyse der 
Lichtstreuungsparameter und die Berechnung der daraus resultierenden molekularen Masse wurde mit Asta-Software von Wyatt Technology Corporation durchgeführt. Dazu wurde angenommen, daß die Änderung des Reflektionsindexes mit der Änderung der Proteinkonzentration in Lösungen $(d n / d c)$ einen konstanten Wert von 0,189 für alle Proteine hat (Wen et al., 1996).

\subsection{Kristallisation von Snapin}

Zur Herstellung von Kristallen wurde Snapin bei einer Konzentration von 2,5 mg/ml in 10 mM Hepes, 300 mM NaCl, 1 mM DTT verwendet. Kristalle wurden duch die ,,sitting drop”Methode bei $20^{\circ} \mathrm{C}$ mittels Dampfdiffusion gebildet. $2 \mu$ der Proteinlösung wurden mit $1 \mu \mathrm{l}$ Reservoirlösung (0.4 M ( $\left.\mathrm{NH}_{4}\right)_{2} \mathrm{SO}_{4}, 100 \mathrm{mM}$ Natriumcitrat $\left.\mathrm{pH}=5,0\right)$ versetzt. Das Reservoirvolumen betrug $500 \mu \mathrm{l}$.

Die Beugungsdaten wurden an der Beamline BW6 am DESY (Hamburg, Deutschland; http://wwwhasylab.desy.de/facility/experimental_stations/stations/BW6.htm) aufgenommen. Die Analyse der Diffraktionsdaten wurde mit dem Programm DENZO/SCALEPACK durchgeführt.

\subsection{Immunopräzipitationen}

PC12-Zellen oder postnuklearer Überstand eines Rattenhirnhomogenats wurden mit 2\% TritonX-100 bei $4^{\circ} \mathrm{C}$ unter Zugabe von Boehringer Proteaseninhibitorencocktail in $10 \mathrm{mM}$ Hepes, $150 \mathrm{mM} \mathrm{NaCl} \mathrm{pH}=7,0$ solubilisiert. Die Proteinkonzentration nach der Proteinbestimmung mit BCA-Assay wurde auf $2 \mathrm{mg} / \mathrm{ml}$ eingestellt und das in TritonX-100 unlösliche Material durch die Zentrifugation für 30 min bei 16000 g entfernt. Antikörper wurden während einer Stunde bei $4^{\circ} \mathrm{C}$ an ProteinG-Sepharose vorgebunden und anschließend mit frisch hergestellten Lysaten inkubiert.

Um SNAP-25 zu immunopräzipitieren, reichte eine zweistündige Inkubation aus, für eine komplette Immunopräzipitation von Snapin war eine Übernachtinkubation mit dem Antikörper nötig. Für $200 \mu \mathrm{g}$ Lysatprotein wurden $10 \mu \mathrm{g}$ affinitätsgereinigten Snapinserums bzw. $5 \mu$ SNAP-25-spezifischen monoklonalen 71.1 Antikörpers in Form von Aszites eingesetzt.

Nach drei Waschzyklen mit 1\% TritonX-100 in 10 mM Hepes, 150 mM NaCl pH= 7,0 wurde der Antikörper-Antigen-Komplex mit dem Laemmli-Puffer ohne reduzierende Agenzien von der ProteinG-Sepharose eluiert. Das ungebundene Material wurde mit Acetonpräzipitation konzentriert, so dass eine finale Proteinkonzentration von 1mg/ml erreicht wurde. Gleiche Volumina von gebundem und ungebundem Material, erhalten aus $20 \mu$ g Ausgangsmaterial 
(PC12 oder Rattenhirnlysat), wurden mit SDS-PAGE und anschließender Immunodetektion analysiert.

\subsection{Subzelluläre Fraktionierungen}

Subzelluläre Fraktionierung von Rattenhirnhomogenaten wurde wie beschrieben durchgeführt (Huttner et al., 1983).

TritonX-114-Verteilung erfolgte nach Bordier, 1981. Dazu wurden PC12-Zellen oder Rattenhirnhomogenat in $10 \mathrm{mM}$ Hepes, $150 \mathrm{mM} \mathrm{NaCl} \mathrm{pH}=7,0$, Boehringer Proteaseninhibitorencocktail mit $1 \%$ TritonX-114 (Pierce) verwendet. Die Proteinkonzentration betrug 1,5 mg/ml. In TritonX-114 unlösliches Material wurde durch eine Zentrifugation für 5 min bei 13000 g entfernt. Die Trennung von $200 \mu$ l Zellysat in die detergenzarme und detergenzreiche Phase, in der Membranproteine angereichert sind, erfolgte wie bei Bordier beschrieben durch Erwärmung der Probe auf $30^{\circ} \mathrm{C}$ und kurze Zentrifugation bei 1800 g. $20 \mu \mathrm{l}$ vom Ausgangsmaterial und den beiden Phasen nach der Trennung, die dem Ausgangsvolumen angeglichen worden waren, wurden auf SDS-Gel aufgetragen und anschließend mittels Immunoblot analysiert.

\subsection{Gewinnung von Synaptosomen}

2 Rattenhirne wurden aus erwachsenen Wistar Ratten isoliert und in eiskalter $320 \mathrm{mM}$ Saccharoselösung aufgenommen. Anschießend wurden sie mit 8 Hüben bei 800 rpm in einem Glasteflonhomogenisierer zerkleinert. Das Homogenat wurde zuerst bei $3000 \mathrm{~g}$ für 2 min und dann der Überstand der ersten Zentrifuagation bei 14500 g für 12 min abzentrifugiert. Das Pellet wurde in $2 \mathrm{ml} 320 \mathrm{mM}$ Saccharose, $5 \mathrm{mM}$ HEPES $\mathrm{pH}=7,4$ pro Rattenhirn resuspendiert. Das resupendierte Pellet wurde auf einen Ficoll-Gradienten (4 ml 13\% (w/v), 1 $\mathrm{ml}$ 9\% (w/v), $4 \mathrm{ml}$ 6\% (w/v) Ficoll in $320 \mathrm{mM}$ Saccharose, $5 \mathrm{mM}$ HEPES $\mathrm{pH}=7,4$ ) geladen und für 35 min bei 87000 g zentrifugiert. Die Synaptosomen flotieren als deutlich sichtbare weiße Doppelbande in der 9\% Ficollfraktion. Diese Bande wurde vorsichtig abgenommen, im flüssigen Stickstoff schockgefroren und bei $-80^{\circ} \mathrm{C}$ gelagert.

\subsection{Gewebeextrakte}

Organe wurden aus erwachsenen männlichen Wistar-Ratten isoliert und im eiskalten $10 \mathrm{mM}$ Hepes-Puffer pH=7,0 mit $150 \mathrm{mM} \mathrm{NaCl}$ und Proteaseinhibitoren (1 mM EDTA, 0,1 mM PMSF, $10 \mu \mathrm{g} / \mathrm{ml}$ Aprotinin, $10 \mu \mathrm{g} / \mathrm{ml}$ Leupeptin, $1 \mu \mathrm{g} / \mathrm{ml}$ Pepstatin) aufgenommen. Die Homogenisierung von Geweben erfolgte entweder mit einem Ultratorax-Gerät (Herz, 
Skelettmuskel, Unterkieferspeicheldrüse) oder mit einem Glasteflonhomogenisierer mit 10 Hüben bei 800 rpm (alle anderen Gewebe).

\subsection{Interaktionsstudien mit GST-Fusionsproteinen und Hirnextrakten}

Rattenhirne von erwachsenen Wistar-Ratten wurden in $10 \mathrm{mM}$ Hepes $\mathrm{pH}=7,4,320 \mathrm{mM}$ Saccharose und Proteaseinhibitoren (0,1 mM PMSF, $10 \mu \mathrm{g} / \mathrm{ml}$ Aprotinin, $1 \mu \mathrm{g} / \mathrm{ml}$ Pepstatin) homogenisiert und bei 12000 g für 15 min abzentrifugiert. Der Überstand wurde mit $10 \mathrm{mM}$ Hepes $\mathrm{pH}=7,4150 \mathrm{mM} \mathrm{NaCl}, 1 \%$ TritronX-100 auf die finale Proteinkonzentration von 1 $\mathrm{mg} / \mathrm{ml}$ gebracht und solubilisiert. Das nichtlösliche Material wurde bei $100000 \mathrm{~g}$ für $1 \mathrm{~h}$ abzentrifugiert. Nach der Zentrifugation wurden 15 mg des Überstandes mit $200 \mu g$ des potentiellen Bindungspartners als GST-Fusionsprotein inkubiert. Nach 2 h wurde GluthationSepharose dazugegeben und erneut $2 \mathrm{~h}$ inkubiert.

Die Elution erfolgte in 1/100 des Ausgangsvolumens mit dem Laemmli-Probenpuffer. Die Proben wurden für $5 \mathrm{~min}$ bei $95^{\circ} \mathrm{C}$ gekocht und gleiche Volumina an Gluthation-Sepharose gebundenen und ungebundenen Materials mit SDS-PAGE und Immunoblot analysiert.

\subsection{Limitierte Proteolyse}

Limitierte Protelolyse von Snapin wurde in $10 \mathrm{mM}$ Hepes pH=7.8, $300 \mathrm{mM} \mathrm{NaCl}, 1 \mathrm{mM}$ DTT bei Raumtemperatur durchgeführt. Dazu wurden folgende Proteasen benutzt: Proteinase K (Sigma), Pronase E (Sigma) und Carboxypeptidase Y (Roche). Angegebene Verhältnisse Snapin zu Protease beziehen sich immer auf Gewichtsanteile. Die proteolytische Reaktion wurde durch Zugabe von Laemmli-Probenpuffer und Inkubation für 5 min bei $95^{\circ} \mathrm{C}$ gestoppt.

\subsection{Biochemische Standardmethoden}

SDS-PAGE (15 \%ige Gele) und Immunoblot wurden wie beschrieben durchgeführt (Laemmli, 1970; Towbin et al., 1979). Der Laemmli-Probenpuffer bestand aus 10\% w/v SDS, 18 mM TRIS pH=6,8, 30\% w/v Glycerin, 0,05 w/v Bromphenolblau.

Proteinkonzentrationen wurden mit dem BCA-Assay (Pierce) bestimmt. Hierbei diente BSA als Proteinstandard. Wenn besonders genaue Konzentrationsangaben nötig waren, wurde der Extinktionskoeffizient des jeweiligen rekombinanten Proteins aus der Aminosäurensequenz mit dem Peptide Calculator (Version 1, http://www.basic.nwu.edu/biotools/ProteinCalc.html) ermittelt und die Konzentration aus der Absorption bei 280 nm nach dem Lambert-BeerGesetz berechnet. 
Acetonpräzipitation von verdünnten Proteinlösungen wurde wie folgt durchgeführt: Die Proteinlösung wurde mit 4 Volumina kalten Acetons vermischt, 1 Stunde bei $-20^{\circ} \mathrm{C}$ inkubiert und bei 16000 g 10 min präzipitiert. Der Überstand wurde schnell abgesaugt und das Pellet im Laemmli-Probenpuffer aufgenommen. Die DNS-Proben wurden durch Elektrophorese auf einem 1\%igen Agarosegel in TAE analysiert.

\subsection{Computergestüzte Sequenzanalyse}

Alle Programme, die zur Strukturvorhersage benutzt wurden (Transmembrandomänen, $\alpha$ helikale Strukturen, Coiled-coil-Domänen) sind bei dem Expasy-Server (http://www.expasy.org/tools/) erhältlich. Sequenzvergleiche wurden mit ClustalW (http://www.ebi.ac.uk/clustalw/) mit Standardeinstellungen gemacht. Im Folgenden sind Organismen aufgelistet, von den die benutzte Snapin-homologe Sequenzen mit den dazugehörenden Datenbankidentifikationsnummern abstammen: Rattus norvegicus (gi:41017816), Mus musculus (gi:4206090), Bos taurus (gi:107610), Sus scrofa (gi:37798214), Homo sapiens (gi:4206088), Xenopus laevis (gi:15274523), Dario rerio (zfish/TC250152), Ciona intestinalis (gi:24821347), Apis mellifera (gi:48103117), Drosophila melanogaster (gi:17861576), Caenorhabditis elegans (gi:17538398). 


\section{Ergebnisse}

\subsection{Reinigung von rekombinantem Snapin und Snapinfusionsproteinen}

Die meisten in dieser Studie vorgenommen biochemischen und strukturellen Untersuchungen erforderten rekombinantes Protein vom höchsten Reinheitsgrad und oft in größeren Mengen. Deshalb wurde zunächst ein Überexpressions- und Reinigungsverfahren etabliert, das hochreines Protein in Milligrammengen lieferte. Dazu sollte die Sequenz von Snapin aus $R$. norvegicus in einen Vektor für bakterielle Überexpression kloniert werden. Zu Beginn dieser Studie war nur die Sequenz von Snapin aus M. musculus und $H$. sapiens publiziert und lediglich eine homologe Sequenz aus $R$. norvegicus (EST189206) konnte durch BLASTSearch identifiziert werden. Sie zeigte 100\% Identität auf Aminosäurenebene zu den Aminosäuren 4 bis 136 von Snapin aus M. musculus. Die fehlenden N-terminalen Aminosäuren wurden durch die Aminosäuren aus der Sequenz von M. musculus ergänzt. Dieser Bereich scheint unter Säugern konserviert zu sein, weil er 100\% Homologie zu humanem Snapin aufweist (Vergl. Abb.11 und Abb.12). Kürzlich ist die komplette Sequenz von Snapin aus R. norvegicus publiziert worden. Diese Sequenz (gi:27692724) stimmt mit der von uns erstellten vollkommen überein.

Snapin wurde in E. coli als N-terminales 6xHis-Fusionsprotein exprimiert und anschließend in zwei Schritten durch $\mathrm{Ni}^{2+}$-Affinitätschromatographie und Ionenaustauschchromatographie gereinigt. Die Ausbeute betrug 30 mg Protein pro Liter Bakterienkultur. Diese hohe Ausbeute konnte erst durch den Aufschluß von Bakterien unter denaturierenden Bedingungen (in $6 \mathrm{M}$ Harnstoff) erreicht werden, da der lösliche Anteil von 6xHis-Snapinfusionsprotein unter 10\% lag. Im Gegensatz dazu war das GST-Snapinfusionsprotein vollkommen löslich. Der Harnstoff wurde durch Dialyse entfernt und die Rückfaltung des Proteins durch CD-Studien bestätigt (s. Abschnitt 3.4.2). Nach der $\mathrm{Ni}^{2+}$-Affinitätschromatographie wurde Protein erhalten, dessen Reinheit anhand der Coomassie-Färbung auf einem SDS-Gel auf 90\% geschätzt wurde. Danach wurde der nun überflüssige 6xHis-Tag mit Thrombin abgeschnitten. Klonierungsbedingt ergaben sich 3 zusätzliche Aminosäuren (GlySerHis) am N-terminus von rekombinantem Snapins nach dem Abschneiden des Expressionstags. Als nächster Reinigungsschritt wurde Ionenaustauschchromatographie eingesetzt. Das typische Reinigungsprofil ist in der Abb. 4 dargestellt. 
A

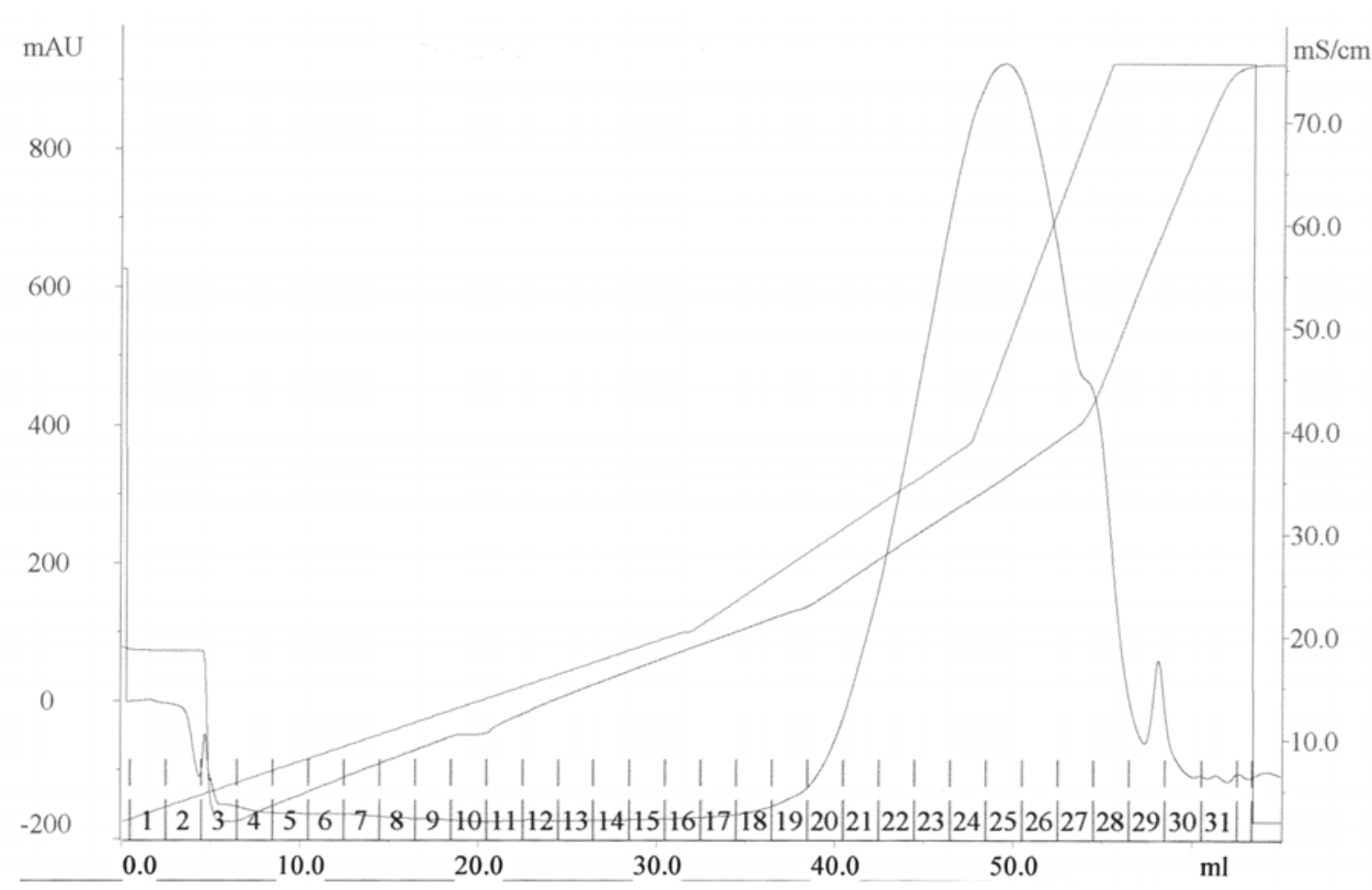

B

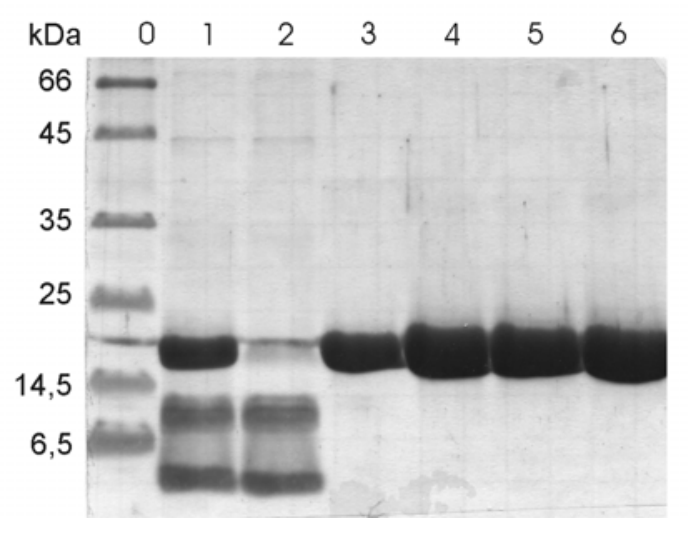

Abb. 4 Reinigung von rekombinantem Snapin. A, Elutionsprofil von Snapin während Kationenaustauschchromatographie. Glockenförmige Kurve - Absorption bei $280 \mathrm{~nm}$ (linke Ordinate), obere geneigte Kurve - Salzgradient von 0 bis $1 \mathrm{M} \mathrm{NaCl}$, untere geneigte Kurve Leitfähigkeit (rechte Ordinate). Die Abszisse zeigt die Fraktionsnummern und die entsprechende Milliliterzahl. B, Analyse des Elutionsprofils mit Coomassie gefärbtem 15\%igem SDS-Gel. Pro Spur wurden $5 \mu$ l Probe geladen. 0 - Molekulargewichtsstandard, 1 Ausgangsmaterial: mit $\mathrm{Ni}^{2+}$-Affinitätschromatographie gereinigtes Snapin, geschnitten mit Thrombin, 2 - Säulendurchfluß, 3 - Fraktion 22, 4 - Fraktion 23, 5 - Fraktion 24, 6 Fraktion 25.

Während der Kationenaustauschromatographie eluierte Snapin in einem einzelnen symmetrischen Peak, der abgeschnittene Expressionstag befand sich im Durchfluß. Die Reinheit des Proteins lag über 98\%, (abgeschätzt von einem mit Commasie gefärbten Gel). 
Neben der monoS-Sepharose von Amersham Pharmacia Biotech wurde auch Carboxymethyl-Kationenaustauscher (CM-Säule von Poros) getestet. Snapin kann auch an diesen schwachen Kationenaustauscher binden und der Reihnheitsgrad nach dem Säulenlauf ist vergleichbar.

Nach der Reinigung wurde die Proteinkonzentration auf 2,5 mg/ml eingestellt. Höher konzentrierte Proteinproben waren metastabil und fielen spätestens nach einem EinfrierAuftauen-Zyklus aus.

Leicht alkalische pH-Werte (zwischen 7, 8 und 8) und erhöhte Salzkonzentration (300 mM $\mathrm{NaCl}$ ) stabilisierten das Protein. Zugabe von Detergenz (z. B 0,1\% ß-Octylglukosid) erlaubte es, Snapin auf die Konzentration von über $10 \mathrm{mg} / \mathrm{ml}$ zu bringen, ohne dass sich Präzipitate bildeten.

Denaturierende Bedingungen bei der Reinigung können unter Umständen zu einem komplett oder teilweise denaturiertem Protein führen. Allerdings haben CD-Studien und MALLSAnalyse (s. Abschnitte 3.4.2 bzw. 3.4.4) gezeigt, dass auf diese Weise gereinigtes rekombinantes Snapin einen hohen Anteil an $\alpha$-helikalen Strukturen aufweist und zu ProteinProtein-Interaktionen fähig ist, da es als Dimer vorliegt.

Die Reinigung von GST-Snapin verlief nach dem Standardprotokoll für GST-Fusionsproteine (s. Material und Methoden). Das GST-tag verleiht dem Snapin erhöhte Löslichkeit und verhindert die Präzipitation. Der Nachteil dieses Fusionsproteins ist, dass einige C-terminale Abbruchprodukte bei der Expression trotz niedriger Induktionstemperatur und proteasedeffizienten E. coli Stammes entstehen. Diese Abbau- oder Abbruchprodukte zeigen ein ähnliches chromatographisches Verhalten in allen Reinigungsschritten wie das komplette GST-Snapin-Fusionsprotein und konnten nicht vollständig von ihm abgetrennt werden. Deshalb wurde GST-Snapin nur für Interaktionsstudien mit Proteinen aus Rattenhirnextrakten benutzt. Für alle weiteren Untersuchungen wie CD-Spektroskopie, MALLS, Kristallisation wurde über die $\mathrm{Ni}^{2+}$-Affinitätschromtographie und Kationenaustauschchromatographie gereinigtes Snapin (so wie es auf der Abb. 4 zu sehen ist) benutzt.

Die Reinigung der phosphomimetischen Mutante Snapin S50D als 6xHis- und GSTFusionsprotein verlief unter den gleichen Bedingungen und mit ähnlicher Ausbeute. Allerdings musste die Konzentration des tagfreien Proteins weiter verringert werden, damit es nicht aggregierte. Der GST-Tag erhöhte die Löslichkeit der phosphomimetischen Mutante beträchtlich. 


\subsection{Antikörper gegen Snapin und Snapinfragmente}

In dem Artikel von Ilardi et al., 1999, in dem Snapin zum ersten mal beschrieben wurde, untersuchten die Autoren auch die Domänenstruktur von Snapin (s. Abb. 5). Laut ihrer Darstellung beinhaltet Snapin eine N-terminale hydrophobe Sequenz, die als eine Transmembrandomäne interpretiert wurde, weiterhin eine Region, die zur Beteiligung an Coiled-coil-Interaktionen fähig ist, und direkt an diese anschließend ein Fragment, das für die Interaktion mit SNAP-25 verantwortlich ist. Basierend auf diesen Daten wurden vier verschiedene Snapinfragmente zum Immunisieren von Kaninchen eingesetzt :

1. SN (Ala26-Tyr81) beihaltet das Fragment zwischen der hydrophoben Region und der Coiled-Coil-Domäne;

2. SPSN (Thr117-Lys136) ist die putative SNAP25-Bindungsstelle

3. SC (Lys83-Arg120) entspricht der Coiled-coil-Domäne, die für andere Proteininteraktionen außer der mit SNAP-25 verantwortlich sein könnte.

4. Snapin entspricht dem Protein in voller Länge.

Die Korrelation zwischen diesen Antigenen und der beschrieben Domänenstruktur von Snapin ist auf der Abb. 5 dargestellt.

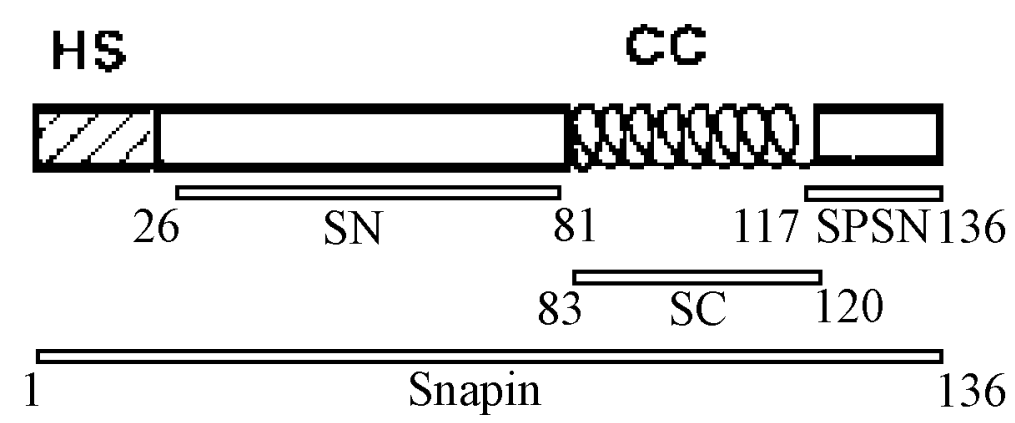

Abb.5 Domänenstruktur von Snapin und als Antigene benutzte Fragmente (verändert nach Ilardi et al., 1999). HS, hydrophobe Sequenz; CC, putative Coiled-coil-Domäne. Snapin, SN, SC, SPSN sind Antigenbezeichnungen.

Das Serum wurde nach jeder Abnahme (alle 6 Wochen) zuerst auf der LP2-Fraktion (angereicherte synaptische Vesikel) aus Rattenhirn im Immunoblot getestet. Später wurde die LP2-Fraktion durch Synaptosomen ersetzt, weil keine spezifische Anreichrung von Snapin in dieser Fraktion zu finden war (s. Abschnitt 3.3). Zusätzlich wurden die Antikörper auf PC12- 
Zellysaten getestet, da diese Zellinie ein höheres Expressionsniveau von endogenem Snapin aufweist. Das SC-Fragment erwies sich als wenig immunogen und rief in 2 getesteten Kaninchen auch nach mehrmals wiederholten Immunisierungen kaum eine Immunantwort hervor. Die restlichen drei Antiseren erkannten rekombinantes Snapin und eine Bande in der gleichen Größe im nativen Material. Das SN-Serum hatte einen deutlich niedrigeren Titer als das Snapin- und das SPSN-Serum (s. Abb. 6).

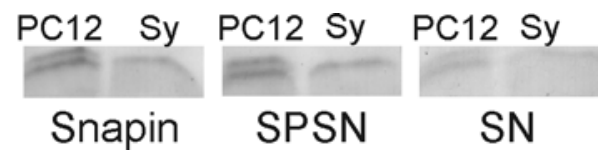

Abb.6 Immunoblot mit drei verschiedenen Snapin-Antisera. $30 \mu$ g PC12-Zellysat (PC12) oder Synaptosomen (Sy) wurden pro Spur auf ein 15\%iges SDS-Gel aufgetragen. Die Immunodetektion erfolgte bei der 1:300fachen Verdünnung des jeweiligen Serums (Snapin, SPSN, SN (s. Abb. 5). Die Nachweisreaktion wurde mit der alkalischen Phosphatase durchgeführt. Die Entwicklungszeit betrug 20 min.

Alle Antiseren detektieren eine Bande von der richtigen Größe in Synaptosomen und eine Doppelbande in PC12-Zellen. Diese Doppelbande konnte nur dann deutlich aufgelöst werden, wenn die Nachweisreaktion mit der alkalischen Phosphatase erfolgte. Zur Verstärkung des Signals wurden später HRP-gekoppelte sekundäre Antikörper eingesetzt. Bei diesem Detektionsverfahren ist die Doppelbande nur bedingt sichtbar.

Das SPSN-Serum erkennt noch zusätzliche Banden von einem höheren Molekulargewicht als Snapin. Alle immunreaktiven Banden konnten durch Vorinkubation des Serums mit dem Antigen (SPSN-Peptid) eliminiert werden (s. Abb. 7).

In allen weiteren Experimenten wurde das SPSN-Serum für Immunodetektion von Snapin eingesetzt, für Immunopräzipitationen wurde das affinitätsgereinigte Snapin-Serum benutzt. 


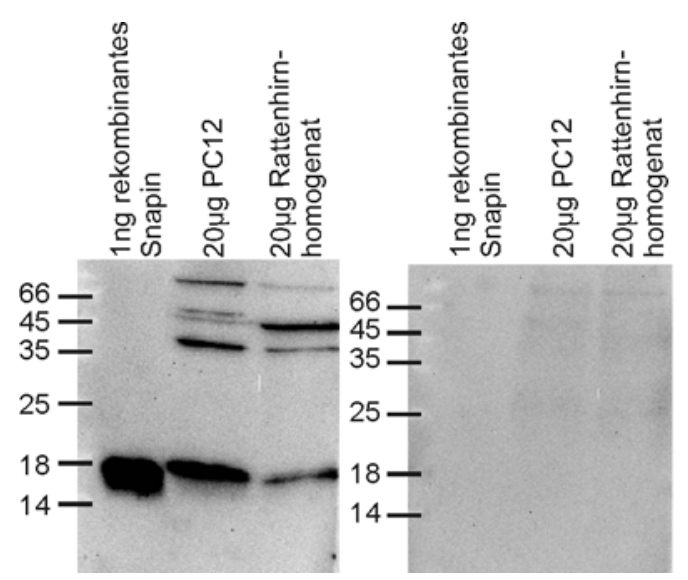

Abb. 7 Kompetitationsexperiment mit dem SPSN-Serum und seinem Antigen. Links, das affinitätsgereinigte SPSN-Antiserum erkennt natives und rekombinantes Snapin. Rechts, das Signal auf dem Immunoblot kann durch Zugabe von löslichem Antigen eliminiert werden.

\subsection{Gewebeverteilung und subzelluläre Verteilung von Snapin}

Mit den nun zur Verfügung stehenden Antikörpern konnte die Verteilung von Snapin im Organismus und in der Zelle ausführlich charakterisiert werden. Die Entdeckung, dass mit dem Snapin-Antikörper auch eine Immunreaktivität in der richtigen Größe in PC12-Zellen zu finden war, ließ die Frage nach der Gewebeverteilung erneut aufkommen, obwohl Ilardi und Kollegen Snapin bereits als hirnspezifisches Protein beschrieben hatten.

Snapin erwies sich als ubiquitäres Protein ohne eine spezifische Anreicherung im Hirn (s. Abb.8). Außerdem wurden bei der Datenbanksuche viele zu Snapin homologe Sequenzen gefunden, die als EST aus nicht neuronalem Gewebe (z.B. Lunge, Herz) kloniert worden sind. Auch Buxton et al., 2003 konnten sowohl bei M. musculus als auch bei R. norvegicus Snapin in mehreren Geweben detektieren. Wie sich aus dem Vergleich der Bandenstärke von rekombinantem (2 ng) und nativem Snapins (10 $\mu \mathrm{g}$ Gesamtprotein) auf der Abb.8 ergibt, scheint das Expressionsniveau von Snapin grundsätzlich niedrig zu sein und unter $0.001 \%$ des Gesamtproteins zu liegen. Allerdings kann nicht ausgeschlossen werden, dass der Antikörper rekombinantes und natives Snapin unterschiedlich gut erkennt oder dass Snapin in der Zelle zusätzlich noch in hochmolekularen oder detergenzunlöslichen Proteinkomplexen vorliegt und sich deshalb der Detektion durch Immunoblotting entzieht. 


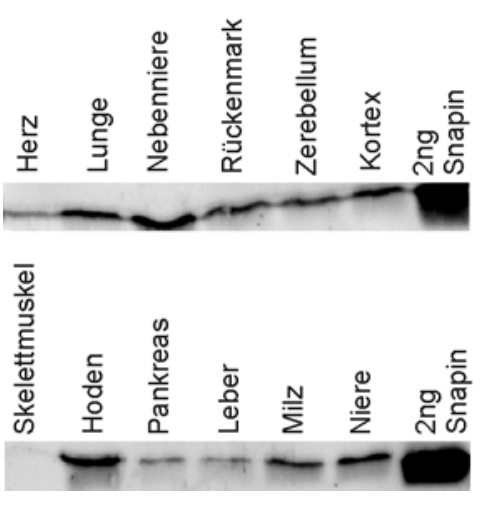

Abb. 8 Gewebeverteilung von Snapin. Pro Spur wurden $10 \mu \mathrm{g}$ Gesamtprotein eines Gewebehomogenats aufgetragen. Die jeweils letzten Spuren zeigen 2 ng rekombinantes Snapin als Referenz.

Als nächstes wurde die subzelluläre Verteilung von Snapin im Rattenhirnhomogenat untersucht. Die subzelluläre Fraktionierung nach Huttner et al., 1983 ergibt durch differentielle Zentrifugation folgende wichtige Fraktionen (s. Abb.9):

H - Rattenhirnhomogenat, S1 und P1 - postnuklearer Überstand (S1) mit dem dazugehörenden Pellet (P1), P2 - angereicherte Synaptosomen, LS1 - nach der osmotischen Lyse von Synaptosomen erhaltener Überstand, LP1 - Synaptosomenmembranpellet, LS2 Synaptosomenzytosol, LP2 - angereicherte synaptische Vesikel, S3 - Zytosol, P3 Mikrosomenfraktion.

Ilardi und seine Kollegen fanden Snapin ausschließlich auf synaptischen Vesikeln. Unsere subzelluläre Verteilung ergab, dass sich Snapin, im Gegensatz zu Synaptophysin als Markerprotein für synaptische Vesikel, auch auf lösliche Fraktionen verteilt. Auch die Fraktion S3 zeigt eine deutliche Snapinbande, obwohl sie keine Membranen mehr enthält. Dies ist aus der Abwesenheit von NMDAR und Synaptophysin ersichtlich.

Diese Ergebnisse widersprechen der Behauptung von Ilardi et al., 1999, dass Snapin ein Membranprotein ist. Zur Klärung dieser Frage wurden noch zwei weitere unabhängige Methoden außer der subzellulären Verteilung von Rattenhirnhomogenaten herangezogen: TritonX-114-Verteilung und computergestützte Analyse der Aminosäurensequenz von Snapin. 


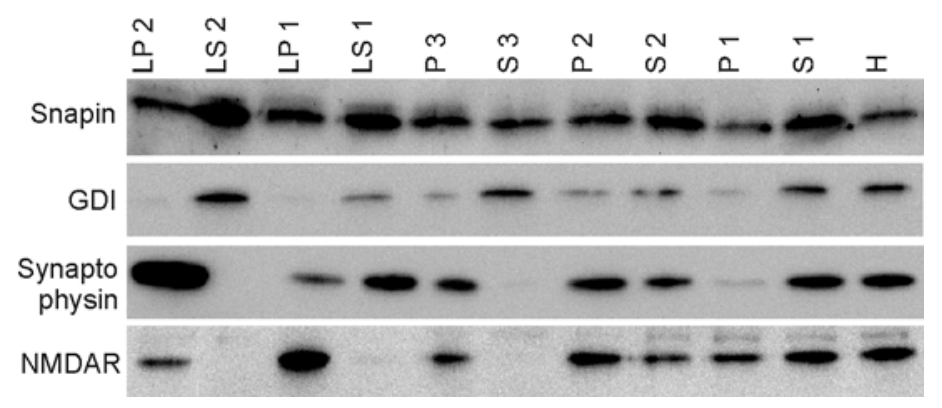

Abb. 9 Subzelluläre Verteilung von Snapin. $10 \mu$ g pro Spur subzellulärer Fraktionen (HHomogenat, S - lösliche Fraktionen, $\mathrm{P}$ - angereicherte Membranfraktionen, für Details s. Matherial und Methoden) wurden mit Antkörpern gegen Snapin, gegen einen zytosolischen Marker (GDI), gegen einen Marker für synaptische Vesikel (Synaptophysin) und gegen einen Plasmamembranmarker (NMDAR) analysiert.

1981 beschrieb Bordier eine einfache Methode, die es erlaubt lösliche Proteine von Membranproteinen zu trennen. Sie basiert auf der Eigenschaft von TritonX-114-Lösungen, oberhalb des Detergenzwolkenpunkts, der nur bei $20^{\circ} \mathrm{C}$ liegt, zwei Phasen zu bilden: eine Mizellenphase und eine detergenzarme Phase. In TritonX-114-Zellysaten verteilen sich Proteine dementsprechend: lösliche Membranproteine bleiben in der detergenzarmen Phase und hydrophobe Membranproteine kondensieren zusammen mit dem Detergenz. Abb. 10 zeigt die TritonX-114-Verteilung von Snapin im Vergleich mit einem zytosolischen Protein und einem Membranprotein.

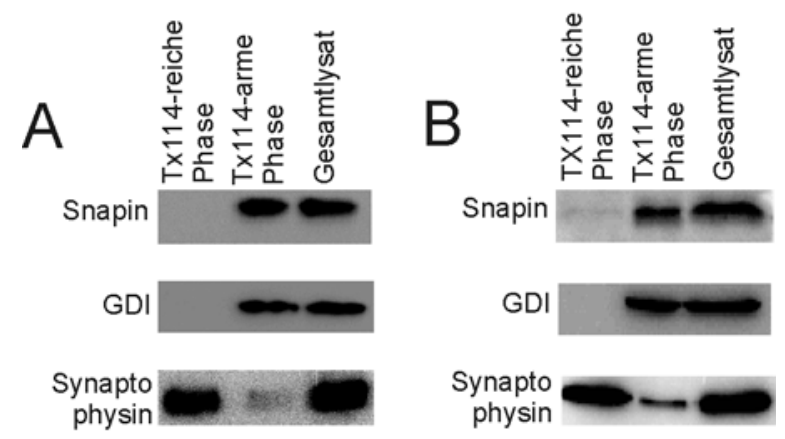

Abb.10 TritonX-114-Verteilung von Snapin in PC12-Lysaten (A) und Rattenhirnlysaten (B). Immunoblot mit $10 \mu \mathrm{g}$ Gesamtprotein pro Spur zeigt, dass Snapin sich in der TritonX114-Verteilung wie ein zytosolisches Protein (Koverteilung mit GDI) verhält. 
Während das Membranprotein Synaptophysin fast auschließlich in der detergenzreichen Phase zu finden ist, zeigt Snapin genau so wie das zytosolische Protein GDI eine Anreicherung in der mizellenarmen Phase.

Alle getesten Pogramme, die Transmembrandomänen anhand der Aminosäurensequenz vorhersagen, konnten keine putative Transmembrandomäne identifizieren. Und nicht zulezt weist die Stabilität von rekombinantem Snapin auch in detergenzfreien Lösungen darauf hin, dass dieses Protein keine Transmembrandomäne besitzt. Allerdings zeigt eine erhöhte Löslichkeit von Snapin in 0,1 \% ß-Octylglukosid, dass dieses Protein hydrophobe Bereiche besitzt, die Aggregation verursachen können.

\subsection{Unterusuchungen zur Struktur von Snapin: von der Primärstruktur zu Kristallen}

\subsubsection{Primäre Struktur: Konservierung von Snapin im Tierreich}

Snapin wurde von Ilardi und Kollegen aus M. musculus kloniert. Eine Suche nach homologen Sequenzen in Nukleotid- und Proteindatenbanken ergab eine hohe Konservierung von Snapin unter Säugern. Die Snapin-Sequenzhomologie zwischen z.B $M$. musculus und einem der einfachsten Chordatiere C. intestinalis beträgt 72\% über einen zentralen Abschnitt von 100 Aminosäuren bei einer Gesamtlänge des Proteins von 136 Aminosäuren. Bis jetzt (Stand 08.2004) wurde Snapin in H. sapiens, R. norvegcus, M. musculus, B. taurus und S. scrofa gefunden. Die Sequenzkonservierung auf der Aminosäurenebene liegt bei Säugern bei fast 100 \%. Auch unter den Chordatieren ist sie sehr hoch: (s. Abb. 11).

Bemerkenswerterweise ist das der Sequenzabschnitt zwischen Aminosäuren 117 und 136, der für elektrophysiologische Effekte von Snapin und Bindung an SNAP-25 verantwortlich sein soll (Ilardi et al., 1999), zwischen den aus Säugern stammenden Sequenzen und SnapinHomolog aus $X$. laevis nicht konserviert ist. Auch bei Fischen (Sequenz von D. rerio) ist hier die Konservierung deutlich niedriger als im zentralen Bereich.

Außerdem konnten Snapin-ähnliche Sequenzen in D. melanogaster, A. mellifera und C. elegans gefunden werden. Diese Sequenzen zeigen eine signifikante Homologie zu der Konsensus-Sequenz von Chordatieren (s. Abb 12).

Kürzlich wurde auch im Pflanzenreich eine Sequenz gefunden, die eine signifikante Homologie zu Snapin aufweist (hypothetisches Protein von A. thaliana (Datenbanknummer YUP8H12R.31) mit 49 \% Homologie über 99 Aminosäuren). 


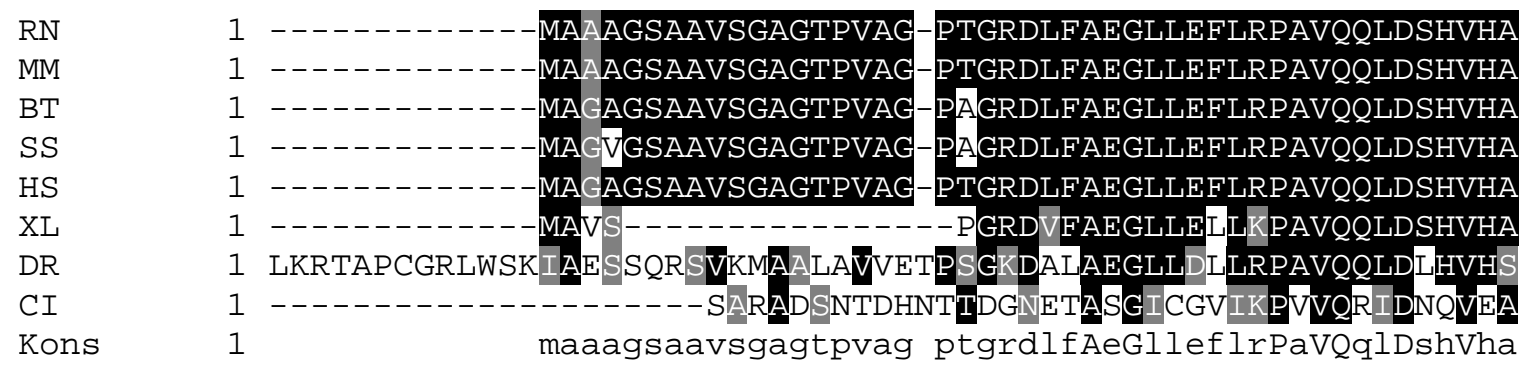

\begin{tabular}{|c|c|c|}
\hline RN & 47 & VRESQVELREQIDNLATELCRINEDQKVALDLDPYVKKLLNARF \\
\hline MM & 47 & VRESQVELREQIDNLATELCRINEDQKVALDLDPYVKKLLNARF \\
\hline BT & 47 & VRESQVELREQIDNLATELCRINEDQKVALDLD \\
\hline SS & 47 & VRESQVELREQSDNLATELCRINEDQKVALDLD \\
\hline HS & 47 & VRESQVELREQIDNLATELCRINEDQKVALDLDPYVKKLLNA \\
\hline $\mathrm{XL}$ & 32 & VRESQVDLREHIDNLASELCKINEDQKVALDLL \\
\hline DR & 61 & VRESQVELREHIDNLASELCRINEF \\
\hline CI & 40 & VRKSQLELRVKIEEVSSDLQRISE \\
\hline Kons & 61 & QvelReqidnlateLcrinE \\
\hline RN & 104 & ERLRRLNHSVAKETARRRAMLDSG \\
\hline MM & 104 & ERLRRLNHSVAKETARRRAMLDSG-VYPPGSPSK- - - - 136 \\
\hline BT & 103 & ERLRRLNHSVAKETARRRAMLDSG \\
\hline SS & 104 & ERLRRLNHSVAKETARRRAMLDSG-VYPPGSPS \\
\hline HS & 104 & ERLRRLNHSVAKETARRRAMLDSG-IYYPPGSPGK \\
\hline $\mathrm{XL}$ & 89 & ERLRLNHSVAKETARRRAMLDSGSHHPPASPNK \\
\hline DR & 118 & ERLRLNHNVAKETARRKTMLEASGAFTPRSPSKP \\
\hline CI & 97 & DRLERLQR $\overline{S A E Q E T N R V K T I V Q A E S A L I ̄ N V T Q V V T S D P S ~} 135$ \\
\hline Kons & 121 & $\overline{\mathrm{RL}} \overline{\mathrm{R}}$ rlnhsvaketarrramldsg vyppgspsk \\
\hline
\end{tabular}

Abb. 11 Sequenzvergleich von aus Chordatieren stammenden Sequenzen mit Homologien zu Snapin aus $\boldsymbol{R}$. norvegicus. Das Sequenzalignment wurde mit dem ClustalW-Programm (http://www.ebi.ac.uk/clustalw/) aufgestellt. RN - Rattus norvegicus, MM - Mus musculus, BT - Bos taurus, SS - Sus scrofa, HS - Homo sapiens, XL - Xenopus laevis, DR - Dario rerio, CI - Ciona intestinalis. Kons - von ClustalW berechnete Konsensussequenz. Identische Aminosäuren sind schwarz, konservierte Aminosäuren sind grau unterlegt. Die Abbildung wurde mit Boxshade erstellt. 

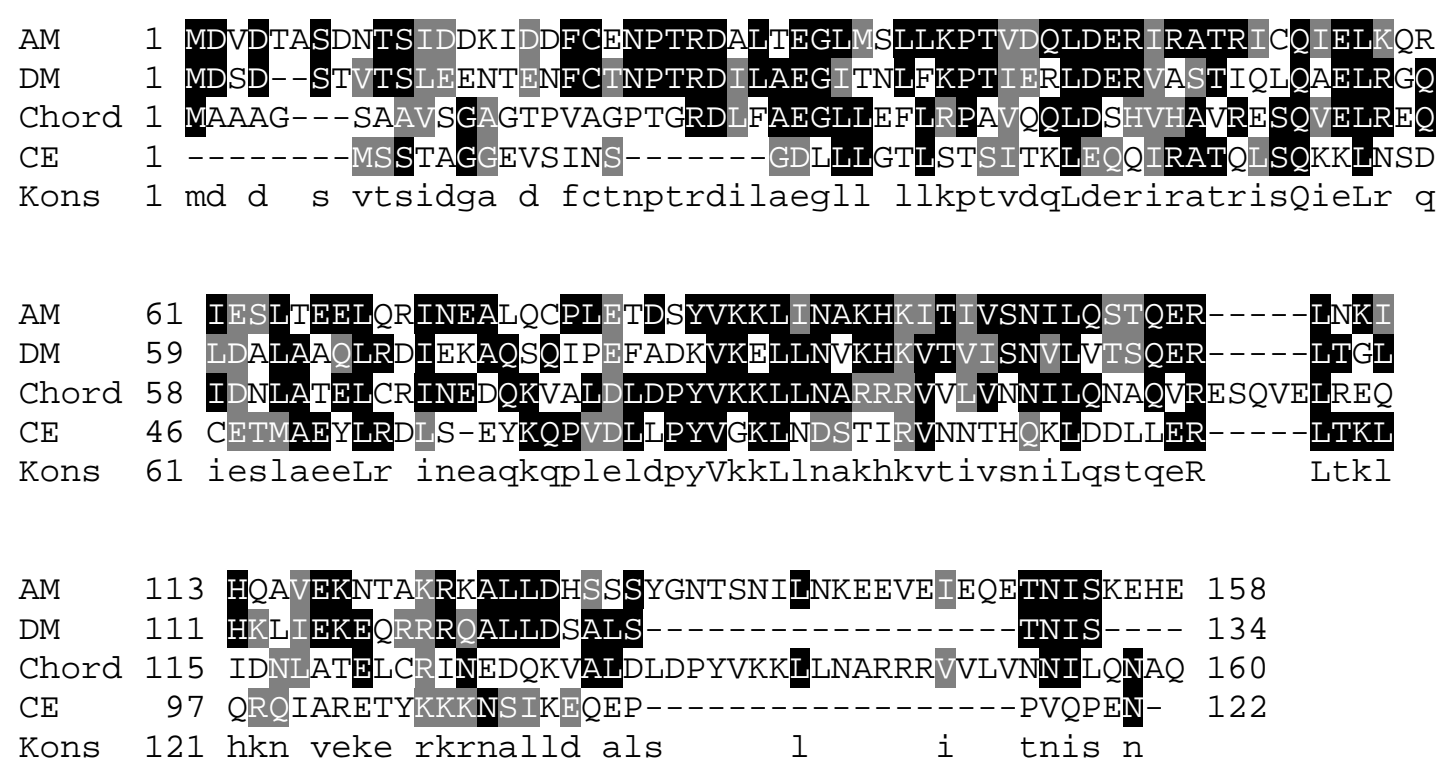

Abb. 12 Sequenzvergleich von tierischen Sequenzen mit Homologien zu Snapin aus $\boldsymbol{R}$. norvegicus. AM - Apis mellifera, DM - Drosophila melanogaster, Chord -

Konsensussequenz für Chordatiere aus der Abb. 8, CE - Caenorhabditis elegans, Kons - Kons - von ClustalW berechnete Konsensussequenz. Identische Aminosäuren sind schwarz, konservierte Aminosäuren sind grau unterlegt. Die Abbildung wurde mit Boxshade erstellt.

21 GRDLFAEGLLEFLRPAVQQLDSHVHAVRESQVELREQIDNLATELCRINEDQKVALDLDP $\mathrm{G}+\mathrm{A} \mathrm{GL} \quad \mathrm{L}++$ DS SQ EL +D L EL ++ E+ + +

33 GGEAMARGLSAMLESVIKDFDSKALDTLNSQDELSGSLDRLVQELDQLLENAPLPFIVQ-

81 YVKKLLNARRRVVLVNNILQNAQERLRRLNHSVAKETAR 119

$++++++\mathrm{RV}+\mathrm{N}+\mathrm{L}++\mathrm{Q} \mathrm{R}+++\mathrm{H}++\mathrm{T}+$

92 HASRISSVKQRVSSLNLVLKSVQRRIDNIDHMLSANTTQ 130

Abb. 13 Sequenzalignment zwischen Snapin von $R$. norvegicus (obere Sequenz) und einem Protein von $A$. thaliana (untere Sequenz). Die mittlere Zeile stellt konservierte Aminosäuren dar. Mit entsprechenden Buchstaben werden identische, mit ,,+” ähnliche Aminosäuren dargestellt. Die Zahlen indizieren die Position der ersten und letzten Aminosäure aus dem Alignment in der Originalsequenz. 


\subsubsection{Sekundäre Struktur: computergestützte Analyse der Aminosäurensequenz von Snapin und Studien mittels CD-Spektroskopie}

Arbeit mit rekombinantem Protein und Auswertung von spektroskopischen und chromatographischen Daten bedarf oft genauer Kenntnisse seiner biophysikalischen Eigenschaften. In diesem Abschnitt wird eine auf der Aminosäurensequenz basierende Charakterisierung von Snapin beschrieben.

Rekombinantes Snapin ist ein verhältnismäßig kleines Protein von 139 Aminosäuren und 15,2 kDa Molekulargewicht. Die ersten 3 Aminosäuren (Gly-Ser-His) sind klonierungsbedingt zur nativen Sequenz hinzugekommen. Das Protein ist stark basisch (pI=9,4) und ist deshalb bei physiologischen pH-Werten mehrfach positiv geladen. Es besitzt wenige aromatische Aminosäuren und sein Extinktionskoeffizient beträgt $3,2 \quad 1 /\left(\mathrm{mM}^{*} \mathrm{~cm}\right)$. Das Hydrophobizitätsprofil nach Kyte und Doolittle identifiziert am N-Terminus eine durchgehend hydrophobe Sequenz von etwa 18 Aminosäuren (s. Abb. 14). Interessanterweise führt die bakterielle Expression von einem Snapinfragment mit deletierten 20 N-termnalen Aminosäuren zu einem vollkommen unlöslichen Protein. Alle benutzten Programme zur Vorhersage der Sekundärstruktur anhand der Aminosäurensequenz finden in Snapin fast durchgehend $\alpha$-helikale Strukturen mit der Fähigkeit, Coiled-coil-Interaktionen einzugehen. Zum Beispiel besitzt Snapin laut der Strukturvorhersage durch das Programm PredictProtein (http://cubic.bioc.columbia.edu/predictprotein/) einen hohen Gehalt an $\alpha$-Helicies von 80\%, dadrunter eine Coiled-coil-Domäne von Leu85 bis Ser126. Allerdings konnten keine für Coiled-coil-Domänen typischen Heptaden-Wiederholung mit hydrophoben Aminosäuren in den Positionen $a$ und $d$ gefunden werden. 


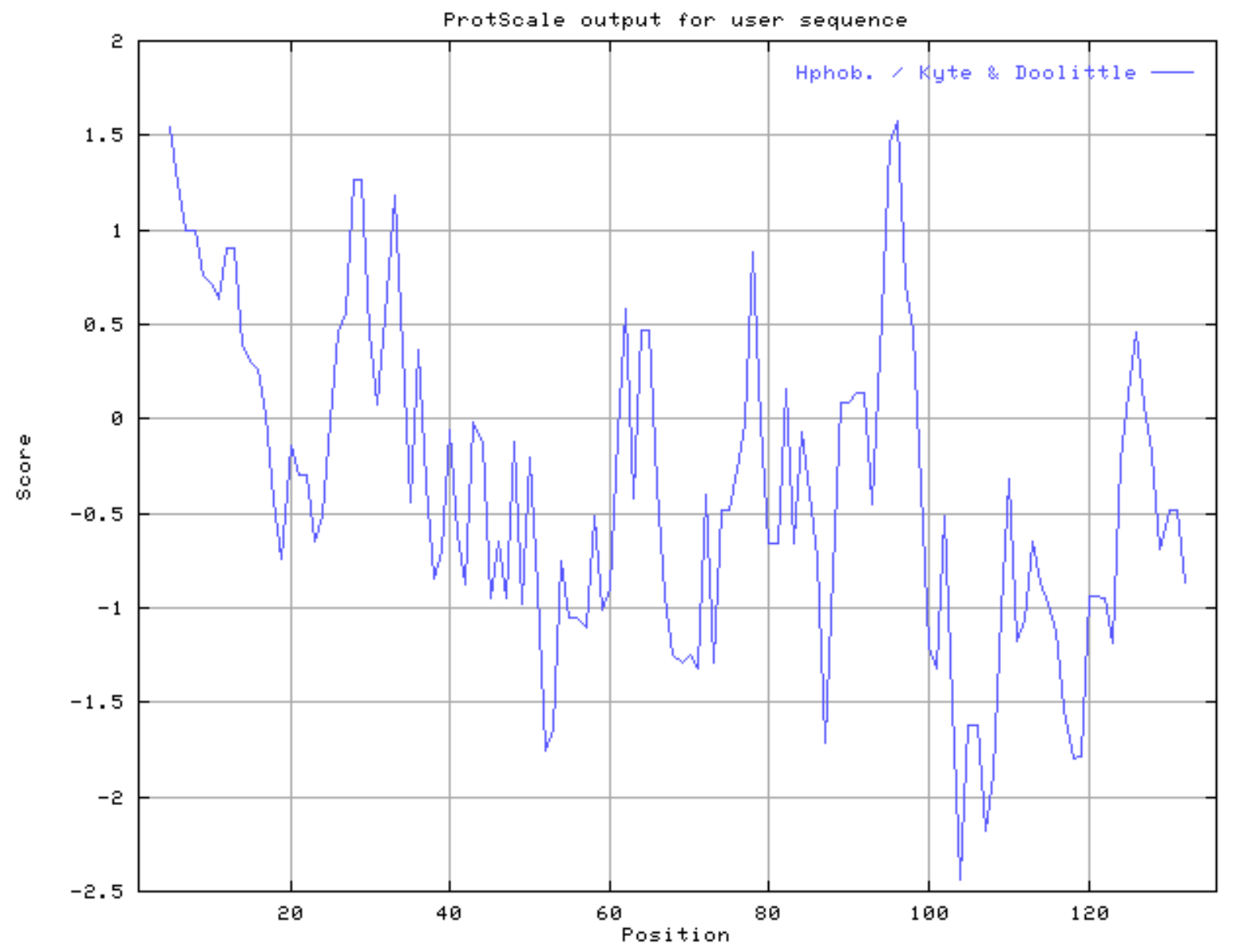

MAAAGSAAVSGAGTPVAGPTGRDLFAEGLLEFLRPAVQQLDSHVHAVRESQVELREQIDNLATELCRINEDQKVALDLDPYVKKLL CCCCCCCEECCCCCCCCCCCHHHHHHHHHHHHHHHHHHHHHHHHHHHHHHHHHHHHHHHHHHHHHHHHHHHHHHHCHCHHHHHHH

NARRRVVLVNNILQNAQERLRRLNHSVAKETARRRAMLDSGVYPPGSPSK HHHHHEEHHHHHHHHHHHHHHHHHHHHHHHHHHHHHHHHCCCCCCCCCCC

Abb. 14 Computergestüzte Analyse der Aminosäurensequenz von Snapin aus $R$. norvegicus. A, Hydrophobizitätsplot nach Kyte und Doolittle, erstellt mit der Fenstergröße von 9 Aminosäuren. Werte über 0 bedeuten hydrophobe Bereiche, Werte unter 0 bedeuten hydrophile Bereiche. Unter dem Plot befindet sich die Aminosäurensequenz von Snapin mit der dazugehörenden Sekundärstrukturvorhersage. H - Helix, C - ,,random coil’’, ungefalteter Bereich, E - ß-Sheet.

Die Reinigung von rekombinantem Snapin fand unter denaturierenden Bedingungen in $6 \mathrm{M}$ Harnstoff statt. Anschließend wurde Harnstoff durch Dialyse und danach während der Ionenaustauschchromatographie komplett entfernt. Um den Faltungszustand des gereinigten Proteins zu überprüfen, wurde CD-Spektroskopie durchgeführt. Die $\alpha$-Helizität eines Peptids kann mit CD-Spektroskopie im nahen UV-Bereich gemessen werden, da $\alpha$-helikale Bereiche bei $208 \mathrm{~nm}$ und $222 \mathrm{~nm}$ negative Absorptionsmaxima von zirkulär polarisiertem Licht aufweisen. Das CD-Spektrum von rekombinantem Snapin ist in der Abb. 12 dargestellt. Snapin zeigt ein für Proteine mit $\alpha$-helikalen Bereichen typisches Spektrum (Abb. 10A). Aus diesen Daten lässt sich nach der Formel (Chen et al., 1974) 


$$
\left[\Theta_{222}\right]_{\text {snapin }} /\left[\Theta_{222}\right]_{\max }=\left[\Theta_{222}\right]_{\text {snapin }} /\left(36300 *\left(1-2,57 / \mathrm{N}_{\mathrm{as}}\right)\right)
$$

der Gesamtgehalt an $\alpha$-Helix berechnen, mit

$\left[\Theta_{222}\right]_{\text {snapin }}$ - molare auf Aminosäurenzahl normierte Elliptizität von Snapin bei $222 \mathrm{~nm}$

$\left[\Theta_{222}\right]_{\max }$ - molare auf Aminosäurenzahl normierte Elliptizität eines zu 100\% $\alpha$-helikalen Proteins mit Aminosäurenzahl $\mathrm{N}_{\mathrm{as}}$. Somit beläuft sich der Gesamtgehalt an $\alpha$-Helix von rekombinantem Snapin auf 64\%.

Der neuronale und endosomale SNARE-Komplexe, die auch durch a-helikale Strukturen gebildet werden, zeigen eine enorme Stabilität (Schmelztemperatur über $80^{\circ} \mathrm{C}$ ) und eine Hysterese im Faltungs-Rückfaltungs-Zyklus (Fasshauer et al., 2002). Unter diesem Aspekt wurde die Stabilität von Snapin mit CD-Spektroskopie untersucht. Das Protein wurde thermal denaturiert und anschließend wieder abgekühlt, um die Rückfaltung zu erlauben. Als Äquivalent des Faltungszustandes wurde die Elliptizität bei 222 nm mit einem CDSpektrometer gemessen. Die $\alpha$-helikalen Bereiche können sich nach der thermalen Entfaltung komplett neu bilden. Die Schmelzkurve ist mit der Rückfaltungskurve fast identisch. Sie zeigen beide eine Überganstemperatur von $58^{\circ} \mathrm{C}$, bei der $50 \%$ der $\alpha$-helikalen Bereiche entfaltet sind (s. Abb.15B).

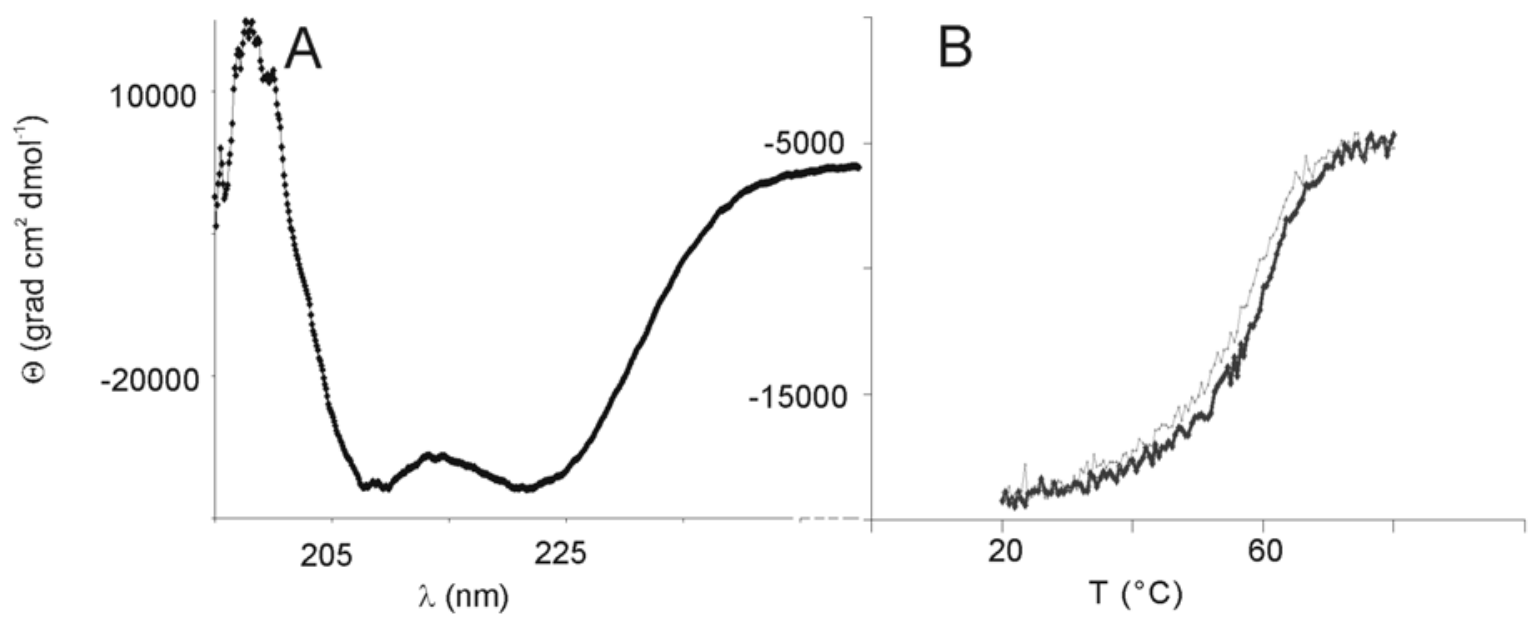

Abb. 15 CD-Spektroskopie mit rekombinantem Snapin. A, CD-Spektrum im weiten UVBereich. B, termale Schmelz- (schwarz) und Rückfaltungskurve (grau). $\Theta$ - molare auf Aminosäurenzahl normierte Elliptizität, $\lambda$ - Wellenlänge, $\mathrm{T}$ - Temperatur. 
Diese Daten zeigen, dass gereinigtes Snapin stabile $\alpha$-helikale Strukturen besitzt, die sich autonom falten können. Der Gesamtgehalt an $\alpha$-Helix leicht unter dem von den Computerprogrammen vorhergesagtem Wert von 80\%. Möglicherweise werden zusätzliche $\alpha$-helikale Strukturen durch seine Bindungspartner induziert oder die bakterielle Expression und denaturierende Reinigungsbedingungen führten teilweise $\mathrm{zu}$ einer Proteinfaltung, die nicht mit der nativen Proteinfaltung komplett identish ist.

\subsubsection{Tertiäre Struktur: limitierte Proteolyse}

Während eines proteolytischen Abbaus stellen ungefaltete, exponierte Bereiche bevorzugte Angriffsstellen für Proteasen dar. Deshalb wird limitierte Proteolyse zur Kartierung von gefalteten Domänen und Bindugsstellen benutzt. $\mathrm{Zu}$ diesem Zwecke werden relativ unspezifische Proteasen eingesetzt. Snapin wurde mit Pronase E, Proteinase K, Carboxypeptidase Y und Aminopeptidase M für indizierte Zeiten bei Protease zu Substrat Verhältnis zwischen 1:200 und 1:500 (Gewichstanteile) behandelt. Aminopeptiodase M konnte Snapin auch nach einer längeren Zeit nicht proteolytisch abbauen. Auch für Carboxypeptidase Y war Snapin ein schlechtes Substrat. Proteinase K und Pronase E ergaben ein charakterisches Bandenmuster wie in der Abb. 16 dargestellt.

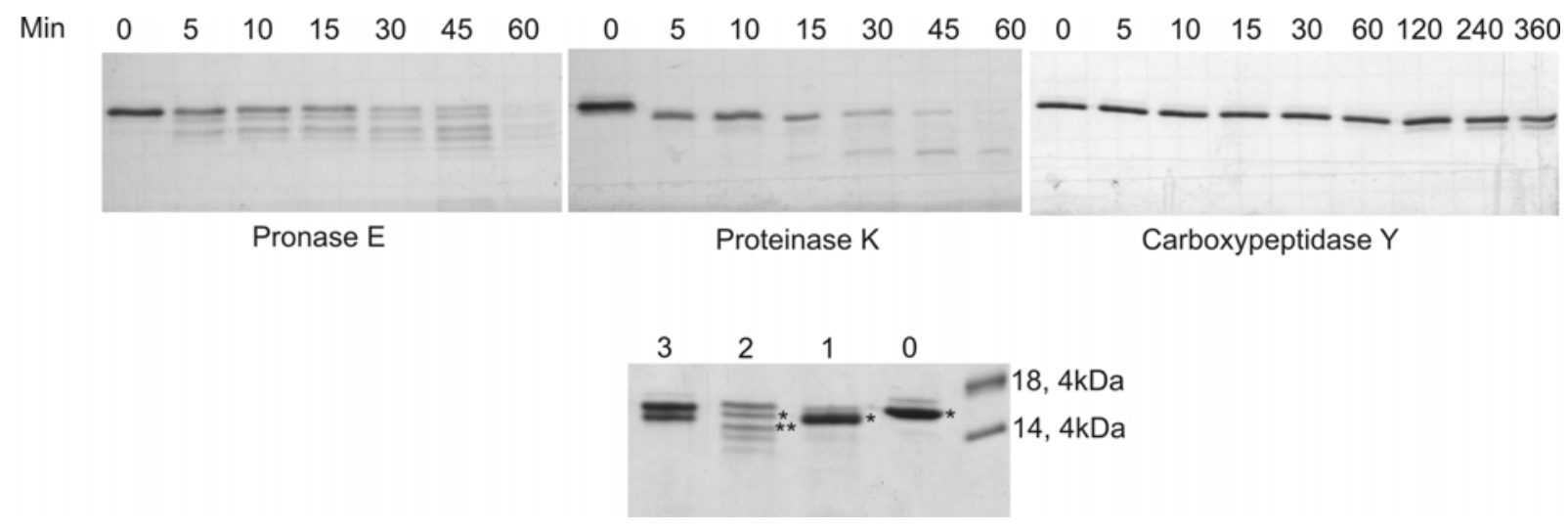

\footnotetext{
Abb. 16 Limitierte Proteolyse von rekombinantem Snapin. Snapin wurde mit Pronase E (im Gewichtsverhältnis 1:200), Proteinase K (1:500) und Carboxypeptidase Y (1:200) für angegebene Zeit behandelt. Der untere Teil der Abbildung zeigt den proteolytischen Abbau in Zusammenfassung: 0 - Snapin unverdaut, 1 - Verdau mit Proteinase K (1:500, 15 min), 2 - Verdau mit Pronase E (1:200, 40 min), 3 - Verdau mit Carboxypeptidase Y (1:200, 120 min). Mit , ${ }^{*}$ sind Banden markiert, die zum N-terminalen Sequenzieren eingesetzt worden sind. Alle Abbildungen zeigen mit Coomassie gefärbte 15\%ige SDS-Gele.
} 
Mit Sternchen markierte Banden wurden aus dem Gel ausgeschnitten und N-terminal ansequenziert. Daraus ergab sich, dass Proteinase K Snapin zuerst zwischen Ser10 und Gly11 hydrolisiert. Pronase E spaltet das Protein zwischen Ala8 und Val9 und Pro15 und Val16. Der N-Terminus von nicht behandeltem Snapin wurde zu GSHMA bestimmt. Dies bedeutet, dass das rekombinante Protein nicht schon bereits vorher N-terminal abgebaut war. Diese Ergebnisse weisen darauf hin, daß zumindest zwischen Ser10 und Val16 ein ungefalteter Bereich vorliegt. Das stimmt sehr gut mit der Vorhersage der Snapinstruktur überein. Anhand des Hydrophobizitätsprofils nach Kyte-Doolittle ist ersichtlich (Abb.14), dass der N-Termins hoch hydrophob ist und deshalb nicht auf der Oberfläche exponiert und von Proteasen geschützt sein wird. Unterschiedliche Programme sagen fast durchgehende $\alpha$-helikale Struktur für Snapin voraus, die ihre größte Unterbrechung zwischen Ser10 und Leu24 hat. Im guten Einklang mit diesen biochemischen Daten zeigt die limitierte Proteolyse, dass dieser Aminosäurenabschnitt die bevorzugte Angriffsstelle für Pronase E und Proteinase K darstellt.

\subsubsection{Quartiäre Struktur: Dimerisierung von rekombinantem Snapin}

Coiled-coil-Domänen vermitteln oft Homo- und Heterooligomerisierung von Proteinen. Um den Olgomerizationszustand von rekombinantem Snapin $\mathrm{zu}$ überprüfen, wurde frisch gereinigtes Protein (s. Abb.4) mit Gelfiltration und anschließender MALLS analysiert. Snapin eluierte von der Säule in einem einzelnen symmetrischen Peak (s. Abb. 17A). Aus den Lichtstreuungsdaten ergab sich, dass Snapin bei der gegebenen Konzentration $(60 \mu \mathrm{M})$ ausschließlich als Dimer vorliegt. Das aus den MALLS-Daten berechnete Molekulargewicht betrug 29 $\pm 1,45 \mathrm{kDa}$, während das theoretisch kalkulierte Molekulargewicht für ein Snapindimer bei 30,4 kDa liegt. Interessanterweise konnte eine Dimerisierung von rekombinantem Snapin auch im Gel beobachtet werden (s. Abb.17B). Bei einer längeren Lagerung (über 14 Tage) des Proteins bei $4^{\circ} \mathrm{C}$ oder bei Raumtemperatur ohne Zugabe von reduzierenden Agenzien (ursprünglich beinhaltet der Puffer, in dem Snapin gelagert wird, 1 mM DTT) entsteht eine zusätzliche Bande, die zwischen 25 und 35 kDa läuft. Wird diese Bande aus dem Gel ausgeschnitten und nach einem tryptischen Verdau in MALDI eingesetzt, zeigt sich, dass sie auch Snapin enthält. Allerdings wird das Peptid Glu49-Arg90, das in der Monomerbande leicht zu detektieren ist, in der Dimerbande nicht mehr gefunden. Dieses Peptid beinhaltet Cys66, das einzige Cystein von Snapin aus $R$. norvegicus. Daraus kann man schließen, dass zumindest diese Art von Dimerisierung über Crosslinking von Cysteinen stattfindet. 
A

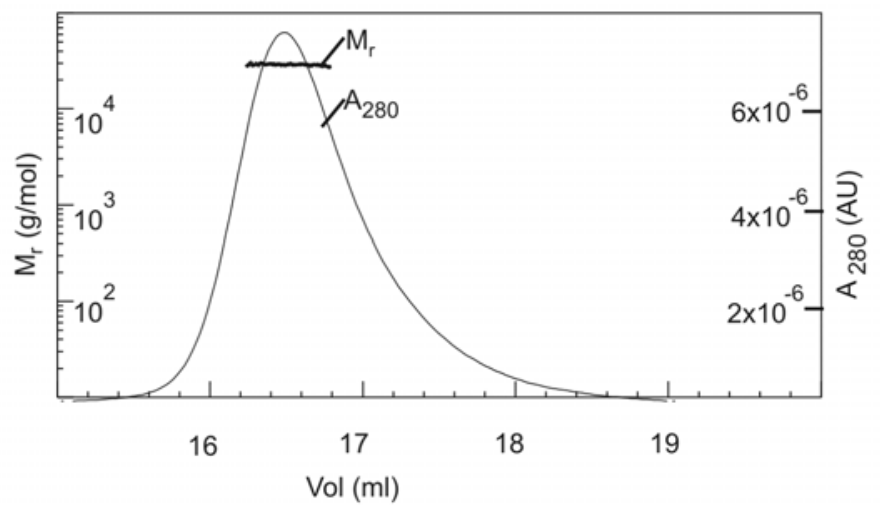

B

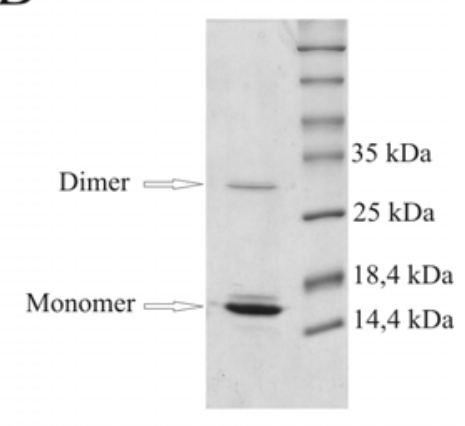

Abb.17 Dimerisierung von Snapin. A, Die glockenförmige Kurve stellt das Elutionsprofil von Snapin von der Gelfiltrationssäule (siehe rechte Ordinate) dar und die gerade Linie durch den Peak zeigt die Berechnung des Molekulargewichts des eluirenden Proteins (siehe linke Ordinate) aus den MALLS-Daten. B, SDS-resistente Dimerisierung von Snapin unter oxidierenden Bedingungen auf einem 15\% SDS-Gel. Vergleiche Abb. 4, auf der Snapin direkt nach der Reinigung dargestellt ist.

\subsubsection{Snapinkristalle}

Um detaillierte Information über die Struktur von Snapin zu bekommen, wurde eine kristallographische Untersuchung initiert. Erste Kristallizationsversuche wurden mit kommerziellen „Incomplete Factrorial Screens” (Crystal Screens I und II von Hampton Research) bei $20^{\circ} \mathrm{C}$ und bei $4^{\circ} \mathrm{C}$ durchgeführt. Snapin wurde in einer Konzentration von 2 $\mathrm{mg} / \mathrm{ml}$, die schon an der Saturierungsgrenze liegt, in $10 \mathrm{mM}$ Hepes $\mathrm{pH}=7,8,300 \mathrm{mM} \mathrm{NaCl}, 1$ mM DTT eingesetzt. Je nach Screen und Temperatur bildeten sich in 67\% bis 86\% Ansätze Präzipitate. Die ersten Mikrokristalle wurden nach ungefähr 2 Wochen unter der folgenden Reservoirbedingung beobachtet: 0,5 $\mathrm{M}\left(\mathrm{NH}_{4}\right)_{2} \mathrm{SO}_{4}, 1 \mathrm{M} \mathrm{Li}_{2} \mathrm{SO}_{4}, 0,1 \mathrm{M}$ Natriumcitrat $\mathrm{pH}=5,6$, inkubiert bei $20^{\circ} \mathrm{C}$. Die anfängliche Kristallisationsbedingung wurde durch die Variation der Temperatur, Salzkonzentration, des pH-Wertes und durch Zugabe unterschiedlicher Additive weiter verfeinert. Im Rasterscreen Ammoniumsulfatkonzentration gegen $\mathrm{pH}$-Wert zeigte sich, dass Kristalle in einem Fenster von nur 0,2 pH-Einheiten unter eher niedrigen Salzonzentrationen unterhalb von 0,6 M gebildet wurden. Die derzeit besten Reservoirbedingungen für die Kristallisation von Snapin sind:

0,4 M $\left(\mathrm{NH}_{4}\right)_{2} \mathrm{SO}_{4}, 0,1 \mathrm{M}$ NaCitrat $\mathrm{pH}=5,0$ (alternativ 0,5 $\mathrm{M} \quad\left(\mathrm{NH}_{4}\right)_{2} \mathrm{SO}_{4}, 0,1 \mathrm{M}$ NaCitrat $\mathrm{pH}=5,1$ oder $0,6 \mathrm{M}\left(\mathrm{NH}_{4}\right)_{2} \mathrm{SO}_{4}, 0,1 \mathrm{M}$ NaCitrat $\left.\mathrm{pH}=5,1-5,2\right), 20^{\circ} \mathrm{C}$.

Die Anhebung der Proteinkonzentration von 2 auf 2,5 mg/ml wirkte sich günstig auf die Kristallgröße aus. Auf diese Weise entstandene Snapin-Kristalle sind auf der Abb. 18 zu 
sehen. Kristalle erreichten ihre maximale Größe nach 2-3 Wochen und hatten die Form vonhexagonalen Stäbchen.
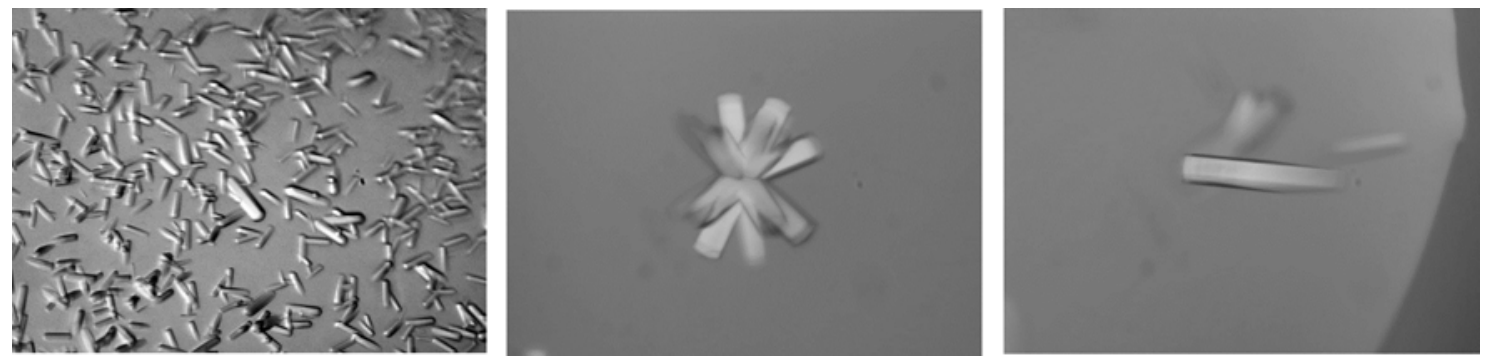

Abb.18 Kristalle aus rekombinantem Snapin

Die größten Kristalle erreichten eine Länge bis zu $200 \mu$ m, hatten scharfe Kanten, waren in Wasser stabil und verhielten sich stark doppelbrechend im Polarisationsmikroskop. Obwohl diese optische Aktivität eine anisotrope Materienverteilung anzeige und damit möglicherweise eine systematische Molekülanordnung im Kristall andeute, war die beobachtete Beugungskraft der Kristalle nur schwach. Auch an einer starken Synchrotronquelle konnten nur Reflexe bis ca. 5,5 A Auflösung beobachtet werden. Die Auswertung einzelner Beugungsbilder deutet auf eine trigonale oder hexagonale Raumgruppe mit ungefähren Zellkonstanten von $100 \AA, 100 \AA, 171 \AA, 90^{\circ}, 90^{\circ}, 120^{\circ}$ hin. Diese Indizierung ist gut mit der äußeren hexagonalen Form der Kristalle vereinbar. Nimmt man die höchstmögliche Symmetrie (hexagonal P622) und normale Packungsdichte an, so erwartet man ca. 50 kDa pro asymmetrische Einheit, was 3 bis 4 Snapin-Molekülen entspricht.

Zum Nachweis, dass diese Kristalle wirklich aus Snapin bestanden, wurden 10-12 davon aus der Mutterlauge herausgenommen, mehrmals in Reservoirlösung gewaschen, in LaemmliProbenpuffer aufgenommen und auf ein SDS-Gel aufgetragen (s. Abb.19). 


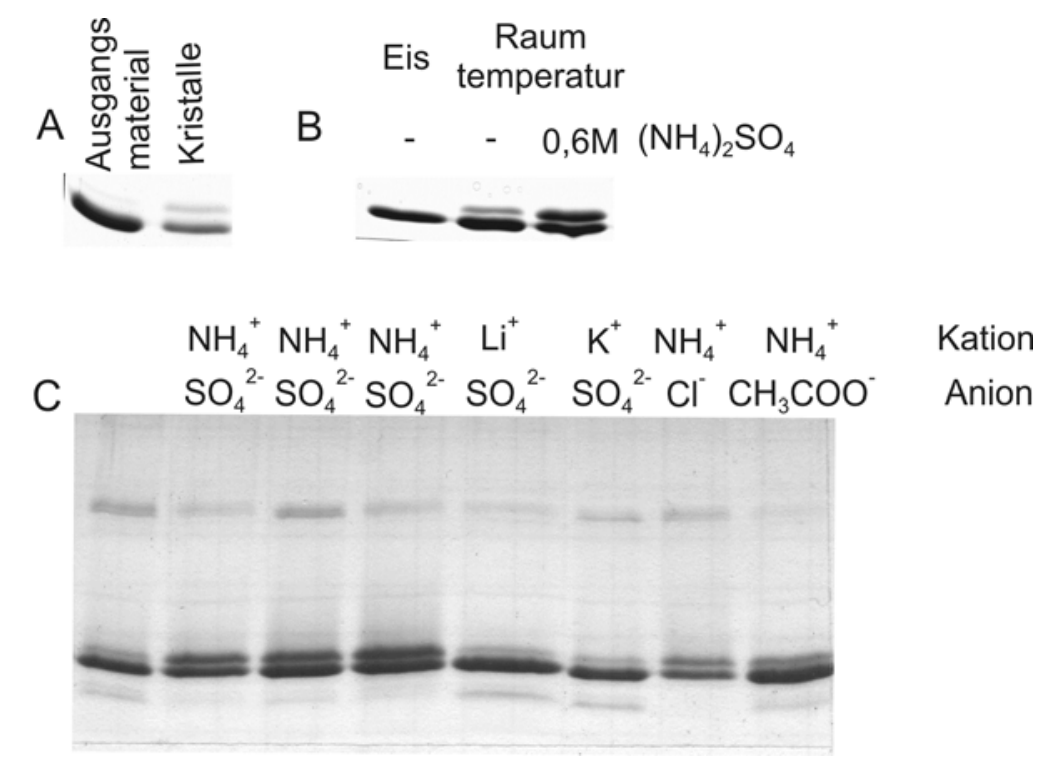

Abb.19 Modifikation von Snapin durch Ammoniumsulfat. A, SDS-Gel zum Vergleich zwischen zur Kristallisatisation eingesetztem Snapin (Ausgangsmaterial) und Material aus den entstandenen Kristallen. B, Induktion einer Modifikation in Snapin, die sich durch eine zusätzlichen Bande manifestiert, durch Zugabe von Ammoniumsulfat in Lösung. C, Wirkung von verschiedenen Anionen und Kationen auf die Entsehung einer zusätzlichen Bande. Snapin wurde im Verhältnis 2:1 mit entsprechender Salzlösung vermischt und 3 Wochen bei Raumtemperatur inkubiert.

Der direkte Vergleich zwischen dem Ausgangsmaterial und den Kristallen zeigte, dass die Kristalle anscheinend aus zwei verschiedenen Proteinspezies bestanden, während nur eine Proteinbande in einer frischen Snapinpräparation. Diese zweite (obere) Bande konnte alleine durch Zugabe von Ammoniumsulfat induziert werden (Abb. 19B). Andere Sulfate wie z.B. Lithium und Kaliumsulfat hatten diese Wirkung nicht, andere Ammoniumsalze hatten diese Wirkung in abgeschwächter Form (s. Abb.19C). Wie aus der ersten Spur auf der Abb. 19C ersichtlich, kann diese zweite Bande auch ohne Salzzugabe nach einer längeren Inkubation bei Raumtemperatur entstehen. Zwei verschiedene Spezies im Kristall könnten eine Quelle von Unordnung und damit eine Ursache für die geringe Beugungskraft der Kristalle sein. Um diese zwei Proteinspezies zu identifizieren, wurden die Banden ausgeschnitten und entweder direkt oder nach einem tryptischen Verdau mit MALDI-MS charakterisiert. Durch den Vergleich mit Proteindatenbanken konnten beide Banden eindeutig Snapin aus $R$. norvegicus zugeordnet werden. Sie beinhalteten Snapin in voller Länge und keine weiteren Proteine (zumindest nicht in der nr-Datenbank des NCBI-Servers vorhandene, Stand 04.2003). MALD-MS Analysen von unverdautem Protein, dass aus den Banden extrahiert worden war ergab ein Molekulargewicht von 15185 Da für die untere Bande und ein Molekulargewicht von 15285 Da für die obere Bande. Während das niedrige Molekulargewicht eindeutig dem 
rekombinanten Snapin mit oxidierten Methioninen entspricht, sind die zusätzlichen 100 Da im Molekulargewicht der oberen Bande keiner bekannten Proteinmodifikation zuzuordnen. Die exakte chemische Identität der oberen Bande konnte daher auf diese Weise nicht geklärt werden.

\subsection{Interaktion zwischen Snapin und SNARE-Proteinen}

Snapin wurde ursprünglich von Ilardi und seinen Kollegen (Ilardi et. al, 1999) als ein Protein beschrieben, das spezifisch an SNAP-25 aber nicht an SNAP-23 bindet und außerdem die Bindung des SNARE-Komplexes an Synaptotagmin verstärkt. Diese Interaktionen wurden zunächst nur phänomenologisch beschrieben. Eine genaue Charakterisierung und Klärung ihrer Mechanismen stand noch aus. Dies wurde zu einem der Hauptziele dieser Studie. Es standen gereinigte rekombinante Proteine und Rattenhirn- und PC12-Zellysate als Quelle für native Proteine und eine Reihe von gut etablierten Gleichgewichts- und Ungleichgewichtsmethoden zum Studium von Proteininteraktionen zur Verfügung.

\subsubsection{Immunopräzipitationen aus Lysaten von PC12 Zellen und Rattenhirnen}

Die Interaktionsstudien zwischen Snapin und den neuronalen SNARE-Proteinen wurden von Ilardi und seinen Kollegen entweder ausschießlich mit rekombinanten Proteinen (pull downs) oder mit den nativen SNARE-Protienen aus dem Synaptosomenextrakt und beigemischten rekombinantem Snapin (Immunopräzipitationen) durchgeführt. Somit wurde die Existenz dieser Komplexe in vivo nicht endgültig bewiesen. In Vorversuchen hat sich gezeigt, dass das von mir hergestellte Snapin-Antiserum (s. Abschnitt 3.2) Snapin immunpräzipitieren kann. Das Serum wurde affinitätsgereinigt und zu Immunopräzipitationen von Snapin aus Lysaten von PC12-Zellen und Rattenhirnen eingesetzt. Durch den Einsatz eines Überschusses an Snapin-Antiserum und verlängerte Inkubationszeiten (über Nacht bei $4^{\circ} \mathrm{C}$ ) konnte fast das gesamte Snapin immunopräzipitiert werden, was durch den Vergleich von an den Antikörper gebundenen und im Überstand verbliebenen Snapin auf der Abb. 20 zu sehen ist. 


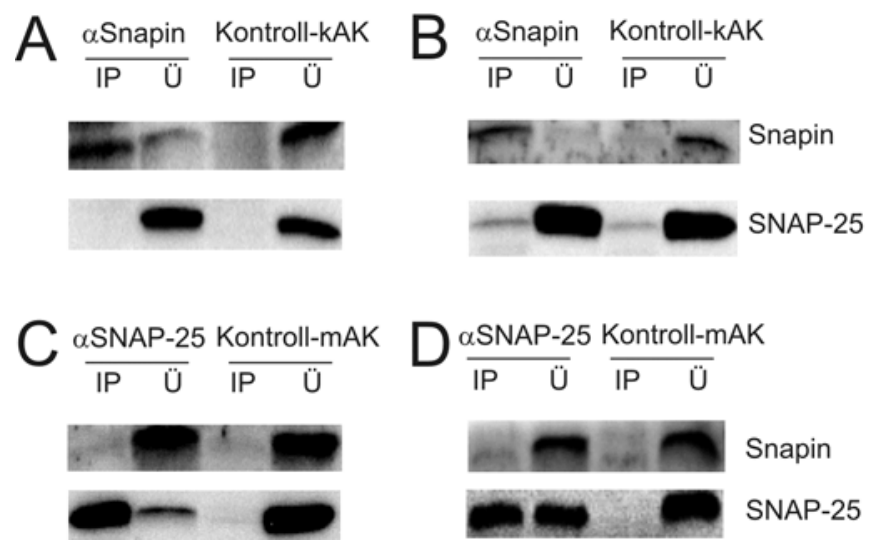

Abb. 20 Interaktion zwischen Snapin und SNAP-25 analysiert durch Immunopräzipitationen aus Lysaten von PC12-Zellen und Rattenhirnhomogenaten. A und B, Immunopräzipitationen mit affinitätsgereinigtem Snapin-Serum. C und D, Immunopräzipitationen mit monoklonalem $\alpha$ SNAP-25 Antikörper. Immunopräzipitationen wurden mit Lysaten von PC12-Zellen (A und C) und Rattenhirnhomogenaten (B und D) durchgeführt. Alle Proben wurden auf gleiches Volumen gebracht und mit SDS-PAGE und Immunoblot analysiert. Ü - Überstand nach der Immunopräzipitation, IP immunopräzipitiertes Material, Kontroll-kAK - Kontroll-Kaninchenserum ( $\alpha$ Doc), KontrollmAK - Kontroll-Ascides (monoklonaler Antikörper 7.2, $\alpha$ Synaptophysin).

Obwohl Snapin komplett an den Antikörper gebunden wurde, konnte kein SNAP-25 koimmunopräzipitiert werden. Auch bei den Präzipitationen von SNAP-25 wurde kein Snapin in der an den Antikörper gebundenen Fraktion detektiert. Allerdings war es in diesem Falle nicht möglich, trotz eines deutlichen Antikörperüberschusses SNAP-25 komplett zu immunopräzipitieren. Diese Ergebnisse wurde in beiden Fällen mit Lysaten aus PC12-Zellen und Rattenhirn erhalten. Der eingesetzte monoklonale Antikörper 71.1 erkannte nur ein Pool von diesem extrem abundanten Protein (1\% des Gesamtproteins im Hirn, Walch-Solimena et al., 1995). Es wurden drei weitere polyklonale aSNAP-25 Antikörper aus diesem Labor (Casanova, Ying und Yang) für Immunopräzipitationen eingesetzt. Aber auch in diesem Fall wurde keine Koimmunopräzipitation von Snapin beobachtet (Daten nicht gezeigt).

Es ist bekannt, daß der monoklonale Antikörper 71.1 freies SNAP-25 aber nicht SNAP-25 im ternären SNARE-Komplex erkennt (Xu et al., 2000). Um die Möglichkeit auszuschließen, dass Snapin in vivo auschließlich mit dem SNARE-Komplex interagiert und dass dies der Grund dafür ist, dass ich keine Koimmunopräuzipitation mit freiem SNAP-25 fand, wurde der ternäre SNARE-Komplex mit dem monoklonalen $\alpha$ Synaptobrevin-Antikörper 69.1 immunopräzipitiert, von dem bekannt ist, dass seine Bindung an Synatobrevin keinen Einfluss auf die Formation des SNARE-Komplexes hat. In Abb. 18 ist dargestellt, dass auch in diesem 
Fall kein Komplex zwischen Snapin und den SNARE-Proteinen detektiert werden konnte. Synaptobrevin konnte fast komplett an den Antikörper gebunden werden und ein Komplex mit SNAP-25 ist deutlich nachweisbar.

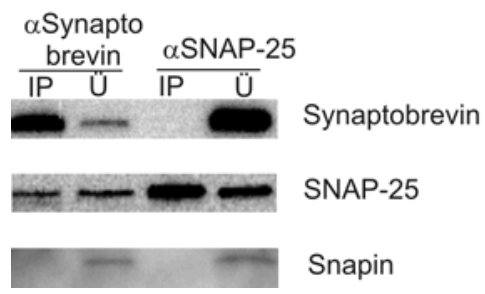

Abb. 21 Interaktion zwischen Snapin und dem neuronalen SNARE-Komplex analysiert durch Immunopräzipitationen aus Lysaten von Rattenhirnhomogenaten. Ü - Überstand nach der Immunopräzipitation, IP - immunopräzipietirtes Material.

Diese Ergebnisse zeigen, dass auch durch Immunopärzipitationen keine Assozation von Snapin mit SNAP-25 oder mit dem neuronalen SNARE-Komplex weder im Hirn noch in PC12-Zellen nachgewiesen werden konnte.

\subsubsection{Interaktionsstudien mit GST-Fusionsproteinen und Rattenhirnlysaten}

Zusätzlich zu Immunopräzipitationen wurde versucht, die Bindung zwischen Snapin und SNAP-25 mit GST-pulldowns nachzuweisen. Dazu wurden folgende Proteine als GSTFusionsproteine exprimiert: Snapin, SNAP-23, SNAP-25a, SNAP-25b, SNAP-29, Syntaxin 1a (zytosolische Domäne), Synaptobrevin 2 (zytosolische Domäne). Der ternäre SNAREKomplex wurde aus SNAP-25a, Synaptobrevin 2 und GST-Syntaxin 1a assembliert. Als Quelle für native Proteine diente der TritonX-100-Extrakt aus Rattenhirnhomogenaten. Um auch schwache Interaktionen detektieren zu können, wurden die GST-Fusionsproteine im deutlichen Überschuß eingesetzt und die an die GST-Proteine gebundene Fraktion 100fach gegenüber dem Überstand und dem Ausgangsmaterial ankonzentriert. Zunächst wurde GSTSnapin als Interaktionspartner für Proteine aus dem Rattenhirnextrakt angeboten. Wie in Abb. 22A zu sehen ist, konnte ein Teil von SNAP-25 an GST-Snapin gebunden werden. Auch weitere Proteine SNAP-23, Syntaxin und Synaptobrevin konnten in der gebundenen Fraktion detektiert werden. Dieses Ergebnis und der 100fache Konzentrationsfaktor der gebundenen Fraktion gegenüber dem Überstand mit ungebundenen Proteinen lassen die Frage nach der Spezifität dieser Bindung aufkommen. Das reverse Experiment, in dem natives Snapin aus 
dem Rattenhirnextrakt und diverse SNARE-GST-Fusionsproteine und GST-SNAREKomplex als Interaktionspartner getestet wurden, ergab keine detektierbare Bindung (s. Abb. 22B). Als interne Positivkontrolle wurde die Bindug von nativem Complexin I und II, die selektiv an den SNARE-Komplex aber nicht an einzelne SNARE-Proteine (Pabst et al., 2000) binden, getestet. Die Dissoziation von Complexin vom SNARE-Komplex verläuft extrem schnell (Pabst et al., 2001), deshlab ist die Bindung trotz eines Überschusses am SNAREKomplex nicht quantitativ.
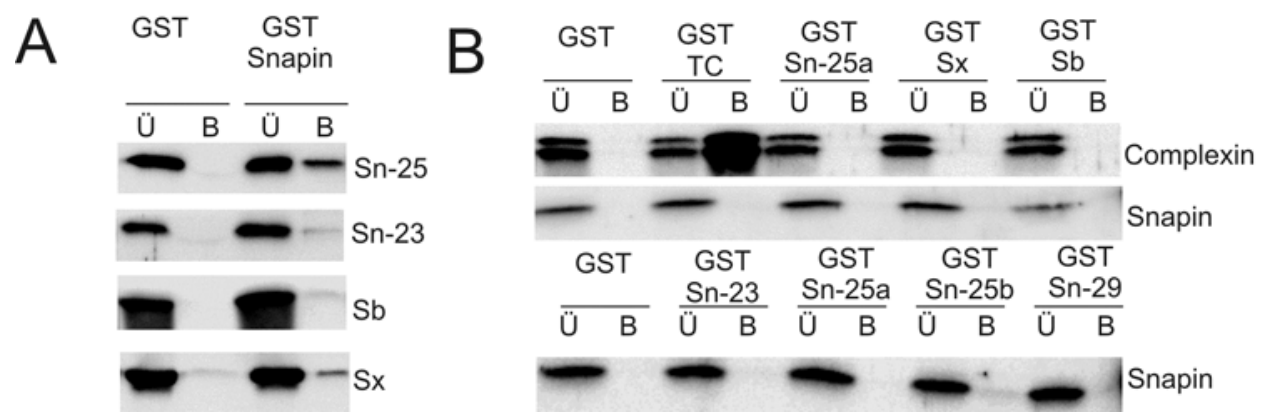

Abb.22 Interaktionsstudien mit GST-Fusionsproteinen und Rattenhirnlysaten als Quelle für native SNARE-Proteine bzw. natives Snapin. Die an GST-Fusionsproteine gebundene Fraktion wurde 100fach ankonzentriert und gleiche Volumina des Überstands nach dem Pelletieren der Gluthationsepharose (Ü) und der gebundenen Fraktion (B) wurden mit SDSPAGE und Immunoblot analysiert Recht von jedem Bild steht das detektierte Protein, oberhalb die als Interaktionspartner angebotene GST-Proteine. Sn - SNAP, Sb Synaptobrevin 2, Sx - Syntaxin 1, TC - ternärer SNARE-Komplex.

\subsubsection{Untersuchungen mittels CD-Spektroskopie}

Immunopräzipitationen und Interaktionsstudien mit GST-Fusionsproteinen gehören beide zu den sogenannten Ungleichgewichtsverfahren. Zum Studium von Interaktionen mit niedriger Affinität eignen sich besser Gleichgewichtsverfahren, bei denen z.B. die Gefahr nicht existiert, das gebundene Protein durch extensives Waschen zu verlieren. CD-Spektoskopie wurde schon mehrmals erfolgreich zum Studium von Interaktion zwischen SNARE-Proteinen und viralen Proteinen, die an der Membranfusion beteiligt sind, eingesetzt. Man macht sich dabei zunutze, dass Proteine durch die Bindung aneinander eine neue Konformation einnehmen. Dies ist besonders leicht mit CD-Spektoroskopie zu detektieren, wenn es sich um eine Änderung im $\alpha$-helikalan Gehalt handelt. Bei SNARE-Proteinen kommt das Phänomen der Induktion von neuen Konformationen besonders deutlich zum Vorschein. Die neuronalen SNARE-Proteine (außer der N-terminalen Domäne von Syntaxin) sind unstrukturiert, solange 
sie einzeln und nicht in Komplexen vorliegen (Fasshauer et al., 1997). Bei der Formation eines SNARE-Komplexes beobachtet man einen massiven Gewinn an $\alpha$-Helizität. Diese Methode wurde zur Untersuchung der Interaktion zwischen Snapin und SNAP-25 benutzt. In Abb. 23A sieht man individuelle Spektren von Snapin und SNAP-25 (hier wurde die Isoform SNAP-25a eingesetzt). Im Gegensatz zu Snapin zeigt SNAP-25 keine für $\alpha$-helikale Bereiche typischen Absorptionsmaxima bei 208 und 222 nm. Inkubiert man die zwei Proteine im äquimolaren Verhältnis über Nacht, so findet man keine Zunahme in der $\alpha$-Helizität der Mischung. Das ist erkennbar durch den Vergleich (Abb. 23B) des gemessenen Spektrums der Mischung aus den beiden Proteinen nach einer Übernachtinkubation und des theoretischen berechneten Spektrums, das durch einfaches Summieren der individuellen Spektren, wie sie in Abb. 20A dargestellt sind, entsteht. Auch mit der anderen Isoform von SNAP-25, SNAP25b, konnte keine Änderung im $\alpha$-helikalen Gehalt nach dem Mischen von Snapin und SNAP25 gefunden werden (Daten nicht gezeigt). Im Gegensatz dazu wurde wie bereits beschrieben (Fasshauer et al., 1997) eine massive Zunahme an $\alpha$-Helizität nach der Zugabe von Syntaxin zu SNAP-25 gefunden.

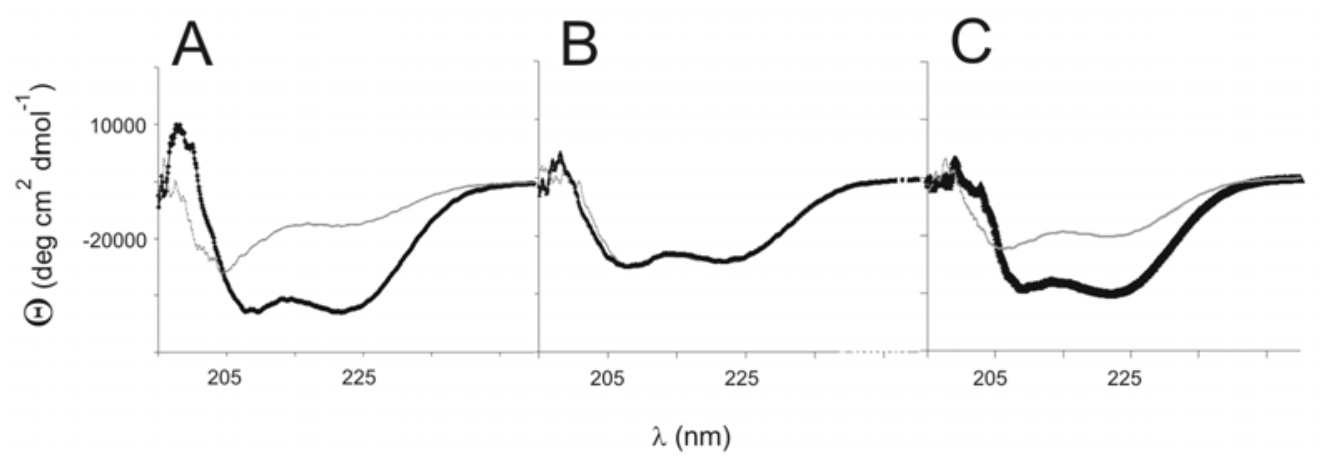

Abb.23 Interaktionsstudien zwischen Snapin und SNAP-25 mit Hilfe von CDSpektroskopie. A, individuelles CD-Spektrum von Snapin (schwarz) und SNAP-25a (grau). B, CD-Spektrum einer äquimolaren Mischung aus Snapin und SNAP-25a nach einer Übernachtinkubation (schwarz). Zum Vergleich wird die theoretische Summe der individuellen Spektren von SNAP-25 und Snapin gezeigt (grau). C, CD-Spektrum einer äquimolaren Mischung aus Syntaxin und SNAP-25a (schwarz). Die theoretische Summe der individuellen Spektren dieser Proteine ist in grau dargestellt. $\Theta-$ molare auf Aminosäurenzahl normierte Elliptizität, $\lambda$ - Wellenlänge.

Wie es aus den MALLS-Daten und der thermalen Schmelzkurve von Snapin hervorgeht, liegt rekombinantes Snapin in der Lösung als ein extrem stabiles Dimer vor. Ob diese Dimerisierung auch in vivo stattfindet, ist nicht erforscht. Wenn das nicht der Fall ist, könnte 
sie der Grund dafür sein, dass die Interaktion zwischen Snapin und SNAP-25 in vitro blockiert ist. Deshalb wurde als nächstes die thermale Entfaltungs- und Rückfaltungskurve von Snapin in Anwesenheit von SNAP-25 untersucht. Als Äquivalent des Faltungszustandes wurde die Elliptizität bei $222 \mathrm{~nm}$ mit einem CD-Spektrometer gemessen. Wie in Abb. $24 \mathrm{zu}$ sehen ist, sind die Entfaltungs- und Rückfaltungskurven fast identisch und der gesamte Vorgang zeigt keine Hysterese auf. Eine Hysterese würde man erwarten, wenn sich nach dem Schmelzen von Snapin bei der Rückfaltung ein neuer Komplex mit SNAP-25 entstehen würde. Der Gesamtgehalt der Proteinmischung an $\alpha$-Helix gleicht nach dem Abschluss der Rückfaltung dem Ausgangswert.

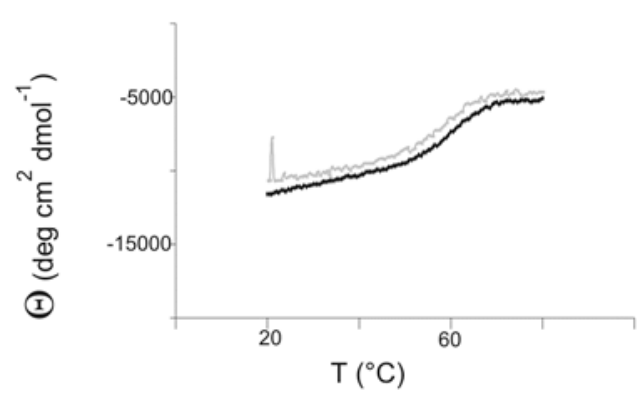

Abb. 24 Denaturierung und Zurückfaltung von Snapin in Anwesenheit von SNAP-25. Äquimolare Mischung aus Snapin und SNAP-25 wurde thermal entfaltet (schwarze Kurve) und anschließend zurückgefaltet (graue Kurve). Der Vorgang wurde durch die Messung der Elliptizität $(\Theta$, molare Elliptizität normiert auf die Aminosäurenzahl) bei $220 \mathrm{~nm}$ beobachtet.

Zusätzlich zur CD-Spektroskopie wurden Anisotropiemessungen mit an drei verschiedenen Positionen (Cys20, 48 oder 200) markiertem SNAP-25 und Snapin durchgeführt. Auch hier konnten keine Hinweise auf eine Interaktion erhlalten werden.

\subsubsection{Vergleichsstudien mit Wildtyp-Snapin und SnapinsS50D}

Chheda und Kollegen publizierten 2001, dass Snapin von der PKA an Ser50 phosphoryliert werden kann, und dass diese Phosphorylierung einen dreifachen Anstieg in der Menge des an Snapin gebundenen SNAP-25 verursacht. Auch die Interaktion zwischen Synaptotagmin und dem SNARE-Komplex soll dadurch verstärkt werden. Allerdings handelt es sich hier um einen Faktor von 1,5. In dieser Arbeit wurde eine phosphomimetische Mutante Ser50Asp beschrieben, die die Eigenschaften des phosphorylierten Snapins widerspiegelt. Ich habe diese 
Mutante (weiterhin als SnapinS50D bezeichnet) hergestellt und ihre Bindungseigenschaften im Vergleich zum Wildtyp-Snapin unterucht. Diese Mutante ließ sich unter den gleichen Bedingungen wie Wildtyp-Snapin exprimieren und reinigen.

Als erstes wurde kontrolliert, ob die eingefügte Mutationen die Struktur von Snapin beeinflusste. Soweit man das anhand des CD-Spektrums von SnapinS50D, das sich vom Wildtyp-Spektrum nicht unterscheidet (s. Abb. 25A), beurteilen kann, wurden durch die Mutation keine massiven Störungen in der Sekundärstruktur verursacht.

Genauso wie der Wildtyp induzierte diese Mutante keine Strukturänderung in SNAP-25 (s. Abb. 25B). In den Interaktionststudien zwischen GST-Fusionsproteinen und Rattenhirnlysaten als Quelle für native SNARE-Proteine konnte kein Unterschied in der Bindung von SNAP-25 und folglich auch des SNARE-Komplexes gefunden werden (s. Abb. 25C)
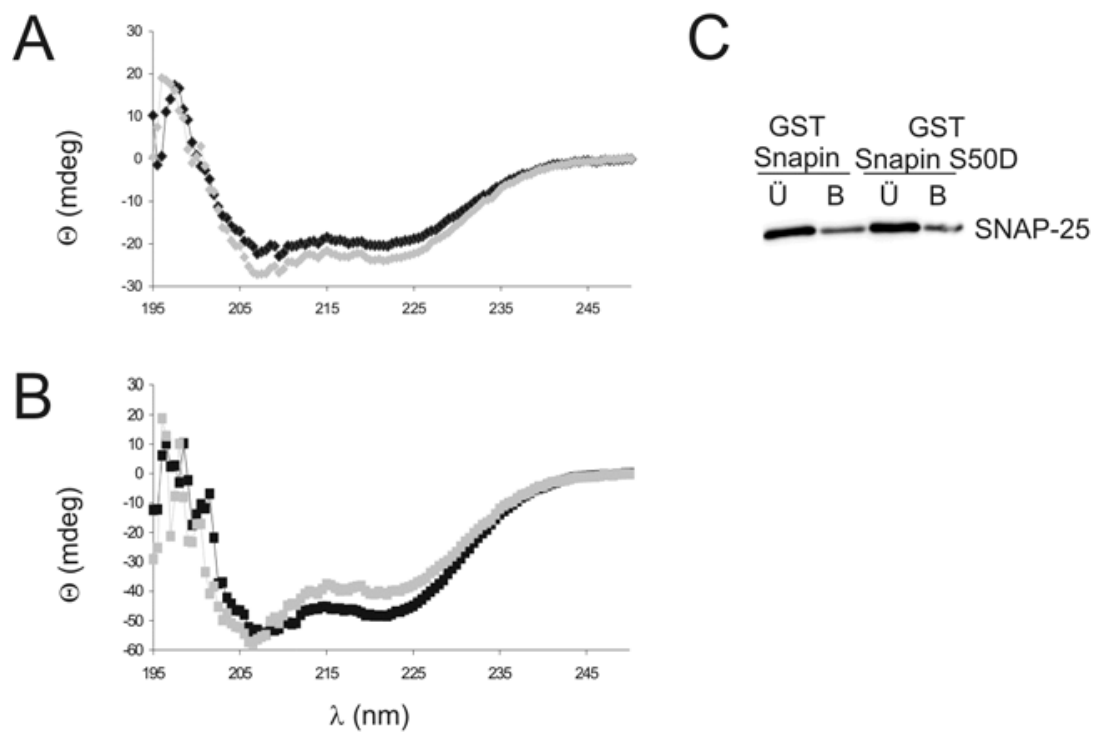

\section{Abb.25 Vergleichsstudien mit Wildtyp-Snapin und SnapinsS50D}

A, CD-Spektrum von Snapin (schwarz) und SnapinS50D (grau). B, CD-Spektrum einer äquimolaren Mischung aus SnapinS50D und SNAP-25 nach einer Übernachtinkubation (schwarz). Das theoretisch berechnete Summenspektrum beider Proteine ist in grau dargestellt. C, Interaktion zwischen Snapin und SnapinS50D als GST-Fusionsproteine und SNAP25 aus Rattenhirnhomogenat. Die an GST-Fusionsproteine gebundene Fraktion wurde 100fach ankonzentriert und gleiche Volumina des Überstands nach dem Pelletieren der Gluthationsepharose (Ü) und der gebundenen Fraktion (B) wurden mit SDS-PAGE und Immunoblot analysiert. 


\section{Diskussion}

\subsection{Gewebeverteilung und subzelluläre Lokalisation von Snapin}

In dieser Studie wurde gezeigt, dass Snapin ein ubiquitäres Protein ist, das in der Zelle sowohl im Zytosol als auch membranassoziert vorliegt. Diese Ergebnisse widersprechen den Daten von Ilardi et al., 1999, stimmen aber gut mit allen anderen Publikationen überein, die sich mit der Gewebeverteilung und subzellulärer Lokalisation von Snapin auseinandersetzten. So zeigten Buxton et al., 2003 anhand eines RNS-Blots und Immunoblots, dass Snapin in vielen anderen Geweben das gleiche Expressionsniveau wie im Hirn erreicht. Stracevic und Dell'Angelica, 2004 konnten Snapin als Bestandteil des BLOC-Komplexes aus der Rinderleber isolieren. Mehrmals wurde Snapin als EST oder durch Zwei-Hybrid-Verfahren aus nichtneuronalen Geweben oder Zellinien kloniert (z.B. Buxton et al., 2003 fanden Snapin in einer cDNS-Bibliothek aus der Adipozyten-Zellinie 3T3-L1). Die Assoziation von Snapin mit der Membran lässt sich nicht durch eine Transmembrandomäne erklären, wie Ilardi et al., 1999 behaupteten. Buxton et al., 2003 konnten zeigen, dass die Assoziation mit dem Membranpool fast vollständig durch Waschen mit $1 \mathrm{M}$ Harnstoff oder $1 \mathrm{M}$ Natriumchlorid aufgehoben werden kann. Das weist darauf hin, dass Snapin über andere Proteine an die Membran gebunden ist. Interessanterweise sind viele der vorgeschlagenen Interaktionspartner von Snapin membranassozierte Proteine (SNAP-23, SNAP-25, RGS7) oder Proteine mit eigenen Transmembrandomänen (Vanilloidrezeptor, Adenylatcyclase VI). Snapin scheint nicht nur an die Plasmamembran gebunden zu sein, sondern auch an andere intrazelluläre Membrankomartimente. Das zeigen die in dieser Studie durchgeführte subzelluläre Fraktionierung von Rattenhirnlysaten und konfokale Immunfluoreszenzaufnahmen von Adipozyten und Snapin überexprimierenden COS-7 Zellen (Buxton et al., 2003). In diesen Aufnahmen ist sowohl eine diffuse zytosolische Färbung als auch die Färbung eines perinuklearen Kompartementes zu sehen. Chou et al., 2004 untersuchten die Expression von Snapin im Hirn. Snapin konnte in mehreren Hirnarealen detektiert werden. Seine Lokalisation in Neuronen war dendritisch und somatisch, auch das Ende des Wachstumskegels war deutlich gefärbt. Die Färbung ergab ein punktiertes Muster und kolokalisierte teilweise mit der Färbung für die Adenylatcyclase VI. Die zelluläre Lokalisation von Snapin änderte sich nicht nach einer Stimulation der Neuronen mit 56 mM Kaliumlösung. Zwar wurden keinen direkten Kolokalisationsstudien zwischen Snapin und SNAP-25 oder SNAP-23 durchgeführt, aber aus den früheren Arbeiten ( Chen et al., 1999, Tao-Cheng et al., 2000, Feng et al., 2002) ist bekannt, dass SNAP-23 und SNAP-25 eine deutliche Plasmamembranfärbung zeigen, wobei SNAP-25 an der axonalen und synaptischen 
Membran und SNAP-23 an der somatischen Plasmamembran angereichert ist. Außerdem zeigt der SNAP-25-Antikörper die Färbung eines perinukliären Kompartiments.

Zusammenfassend lässt sich sagen, dass diese Daten die Rolle von Snapin in der neronalen Exozytose nicht komplett ausschließen, weisen aber deutlich darauf hin, dass es kein wichtiger Bestandteil der exozytoschen Maschine ist, da es wieder an der Plasmamembran noch auf synaptischen Vesikeln angereichert ist und höchstens eine regulatorische Rolle in der neuronalen oder konstitutiven Exozytose hat.

\subsection{Dimerisierung von Snapin}

Die im Rahmen dieser Studie durchgeführte MALLS-Analyse zeigte, dass rekombinantes Snapin als Dimer vorliegt. Dabei kann nicht ausgeschlossen werden, dass es sich um ein in vitro Artefakt handelt und die Dimerisierung von Snapin Interaktionen mit anderen Proteinen erschwert. In einem Zwei-Hybrid-Screen konnten Starcevic und Dell-Angelica, 2004 keine Interaktion von Snapin mit sich selber feststellen. In derselben Arbeit wurde eine Gelfiltration von Leberzytosol durchgeführt, wobei Snapin in zwei Pools eluierte. Ein hochmolekularer Pool entspricht dem BLOC-1 Komplex, da hier alle Komponenten des Komplexes koeluiren.

Der zweite Pool eluiert zwischen den Markerprotein von $29 \mathrm{kDa}$ und $66 \mathrm{kDa}$ Molekulargewicht. Monomeres Snapin konnte nicht detektiert werden.

\subsection{Rolle von Snapin in der neuronalen Exozytose}

\subsubsection{Interaktionsstudien mit rekombinanten und nativen SNARE-Proteinen}

\subsubsection{Unteruchungen mit Ungleichgewichtsassay}

Diese Studie beschäftigte sich eingehend mit der Interaktion von Snapin und SNAREProteinen, insbesondere mit der binären Interaktion zwischen Snapin und SNAP-25. Ilardi et al., 1999 und Buxton et al., 2003 konnten durch Pull-down-Experimente mit rekombinanten Proteinen eine Assoziation zwischen Snapin und SNAP-25 bzw. SNAP-23 finden. Dabei wurde Snapin als 6xHis-getaggtes Protein eingesetzt. In diesem Zusammenhang ist es wichtig zu erwähnen, dass wir eine deutliche Diskripanz im Verhalten von 6xHis-Snapin und Snapin ohne 6xHis-Tag beobachtet haben. Das getaggte Protein neigte deutlich stärker zu Aggregation als das Protein, von dem der Tag bereits abgeschnitten wurde. 6xHis-Snapin konnte nur durch Zugabe von Detergenzien und Erhöhnung des Salzgehaltes auch bei Konzentrationen unter $1 \mathrm{mg} / \mathrm{ml}$ in Lösung gehalten werden. Zwar wirkten diese Bedingungen sich auch auf das Aggregatiosverhalten von Snapin ohne 6xHis-Tag günstig aus, jedoch war es möglich, dieses Protein bei physiologischen Salzkonzentrationen und ohne Detergenz bei 
Proteinkonzentrationen bis zu $2 \mathrm{mg} / \mathrm{ml}$ in Lösung zu halten. Diese starke Neigung zu Aggregationen von 6xHis-Snapin weist auf die auf der Oberfläche exponierten hydrophoben Bereiche und eine partielle Entfaltung des Proteins hin. Deshalb ist es nicht weiter verwunderlich, dass diese exponierten hydrophoben Bereiche eine Affinität zu solchen Proteinen mit Coiled-Coil-Domänen wie SNAP-25 und SNAP-23 besitzen. Obwohl Ilardi und seine Kollegen in ihren Interaktionsstudien (Immunopräzipitationen und „Pulldown”Experimente) die ungebundene und gebundene Fraktion nicht direkt verglichen, zeigten sie, dass $1 \mu \mathrm{g}$ ( 0,4 nmol) GST-SNAP-25 bereits bei $100 \mathrm{nM}$ Snapin (hier wurde die CoiledCoil-Domäne von Snapin benutzt) abgesättigt ist. Daraus lässt sich schließen, dass das äquimolare Verhältnis bei der Bindung nicht erreicht wird. Protein-Protein-Interaktionen werden aber von der 3-D-Struktur der Interaktionspartner bestimmt und sind stoechiometrisch, solange keine Heterogenität in der Proteinkonformation vorliegt oder die Bindung durch die Immobilization des Proteins oder durch seinen Tag beeinflusst wird. Folglich sollte die Bindung quantitativ sein, solange sie nicht so schwach ist, dass der Ligand durch Waschen verloren geht. Interessanterweise konnte Buxton et al., 2003 im Gegensatz zu Ilardi und seinen Mitarbeitern auch eine Bindung zwischen Snapin und SNAP-23 detektieren. Das einzige Experiment, bei dem wir eine Assozation zwischen Snapin und den beiden SNAP-Proteinen feststellten, war der „Pull-down’-Versuch mit GST-Snapin und Rattenhirnlysaten als Quelle für native SNARE-Proteine. Obwohl GST-Snapin im deutlichen Überschuß eingesetzt worden ist, musste das gebundene Material gegenüber dem Überstand mit ungebundenen Proteinen 100fach ankonzentriert werden. Die Assoziation zwischen SNAP-25 und Snapin war etwas stärker als die zwischen SNAP-23 und Snapin, was vielleicht die Diskripanz zwischen den Daten von Ilardi et al., 1999 und Buxton et al., 2003 erklären könnte.

Im reversen Experiment, bei dem verschiendene SNARE-Proteine und der neuronale SNARE-Komplex durch den GST-tag immobilisiert wurden, konnte kein Snapin in der gebundenen Fraktion detektiert werden.

Auch Immunopräzipitationen mit SNAP-25- und Snapin-Antikörpern aus PC12- und Rattenhirnlysaten konnten keinen Komplex zwischen diesen Proteinen detektieren. Ilardi und seine Kollegen führten Immunopräzipitationen mit rekombinanten Proteinen durch und Buxton et al., konnten SNAP-23 und Snapin nicht koimmunopräzipitieren, solange nicht mindestens ein Interaktionspartner überexprimiert war. 
Zusammengefasst weisen unsere Daten darauf hin, dass die Interaktion zwischen Snapin und SNARE-Proteinen, falls sie existiert, einen transienten und niedrigaffinen Charakter hat oder unter ganz speziellen Bedingungen stattfindet.

\subsubsection{Untersuchungen mit Gleichgewichtsverfahren}

Mehrere Gründe können dafür verantwortlich sein, dass die oben beschriebenen Bindungsstudien, keinen Komplex zwischen Snapin und SNAP-25 detektieren konnten:

1. Rekombinante Proteine entsprechen in ihrer Konformation nicht dem nativen Zustand und dies könnte zur verminderten Bindungsfähigkeit führen. Dies wurde mit Kontrolle der Proteinfaltung, Bindung von anderen Proteinen und abwechselnden Anbieten von nativen Proteinen als Liganden für rekombinante Proteine ausgeschlossen.

2. Komplexe von Proteinen mit einer niedrigen Abundanz können aus kinetischen Gründen in Pull-down-Versuchen nicht gebunden werden. Snapin stellt so einen Fall dar: seine abgeschätzte Konzentration im Hirn ist mindestens 100fach niedriger als die von SNAP-25. Diese Fehlerquelle konnte zumindest bei Immunorpäzipitationen durch quantitative Bindung von Snapin an seinen Antikörper und somit durch komplette Depletierung des Lysats beseitigt werden.

3. Komplexe mit anderen Proteinen, die bereits in der Zelle vorliegen und artifiziell entstehende Komplexe durch Zellsolubilisierung können die Menge des frei verfügbaren Interaktionspartners deutlich herabsetzen.

4. Niedrige Affinität der Interaktion hat zur Folge, dass der Interaktionspartner bei Waschschritten verloren geht.

Einige dieser Problemen können durch die Messung von Interaktionen unter Gleichgewichtsbedingungen umgangen werden. Zwei Ansätze wurden benutzt, um Hinweise auf die Interaktion zwischen Snapin und SNAP-25 unter Gleichgewichtsbedingungen zu bekommen. Estens wurde das Anisotropieverhalten von 3 an verschiedenen Stellen positionierten Aminosäuren von SNAP-25 in Anwesenheit von Snapin untersucht. Snapin hatte keinen Einfluß auf die Anisotropie von diesen Aminosäuren. Zweitens wurde in dieser Studie CD-Spektroskopie eingesetzt, die durch eine Komplexbildung eventuell entstandene Änderungen in der Sekundärstruktur detektiert. Für SNAP-23 wie auch für SNAP-25 wurde die C-terminale Coiled-Coil-Domäne von Snapin als die Bindungsdomäne bestimmt (Buxton et al., 2003, Ilardi et al., 1999). SNAP-25 besitzt ebenfalls zwei konservierte Coiled-CoilDomänen, verbunden durch ein flexibles Linkerfragment (Fasshauer et al, 1998). CoiledCoil-Proteine bilden miteinander Komplexe durch Heterooligomerisierung ihrer Coiled-Coil- 
Domänen (Übersicht bei Burkhard et al., 2001). Alle bis jetzt beschrieben Komplexe von SNAP-25 oder seinen Homologen stellen tetramere parallele Coiled-Coil-Strukturen dar (Sutton et al., 1998, Misura et al., 2001, Freedman et al., 2003). Fasshauer et al., 1997 konnten mittels CD-Spektroskopie zeigen, dass SNAP-25 in der Lösung als unstrukturiertes Monomer vorliegt und dass die prominenten $\alpha$-helikalen Strukturen erst in ausgebildeten Komplexen zustande kommen. Basierend auf diesen Beobachtungen wurde angenommen, dass Snapin beim Binden an SNAP-25 ebenfalls eine Zunahme in der $\alpha$-Helizität induzierend sollte. Entgegen diesen Erwartungen wurde nach einer Übernachtinkubation der beiden Proteine miteinander keine Änderung in der Sekundärstruktur festgestellt.

Weder mit Hilfe von CD-Spektroskopie noch Anisotropiemessungen konnten Hinweise auf die Interaktion zwischen Snapin und SNAP-25 gefunden werden. Jedoch kann man die Interaktion auch hier durch die erhaltenen negativen Ergebnisse nicht komplett ausschließen:

Bei der Anisotropie zeigt sich erst dann eine deutlich Änderung im Verhalten nach der Bindung des Interaktionspartners, wenn die markierte Aminosäure in der Bindungssequenz liegt oder in einer Sequenz die eine neue Konformation eingenommen hat. Die CDSpektroskopie detektiert nur eine Änderung in der $\alpha$-helikalen Struktur. Es kann aber nicht ausgeschlossen werden, dass die Bindung über eine andere Struktur oder über ein nicht strukturiertes Peptid verläuft oder dass die Änderung in der Struktur so klein sind, dass wir sie nicht detektieren können.

\subsubsection{Elektrophysiologische Daten}

Die Rolle von Snapin in der neuronalen Exozytose wurde mehrmals mit elektrophysiologischen Methoden untersucht. Es wurde der Einfluss von injizierten Snapinfragmenten auf Exozytose in Neuronen (Ilardi et al., 1999) erforscht und Überexpressionstudien von Snapin und seinen Mutanten in Chromaffinzellen (Chheda et al., 2001) und Neuronen (Thakur et al., 2004 und Vites et al., 2004) durchgeführt. Allerdings ergeben diese Daten in einer Zusammenstellung kein einheitliches Bild.

Direkte Injektion von Snapin-Fragmenten, die von Ilardie et al., 1999 als mit SNAP-25 interagierende Domäne (Snapin-CT, AA 80-136) bzw. interagierendes Peptid (W4, AA 117136) beschrieben wurden, führte zu einer Reduktion der Amplitude von postsynaptischen Potentialen um 30\%. Hier sollte angemerkt werden, dass diese Reduktion im Falle von Snapin-CT transient war und die normale Amplitude nach 60-80 Minuten beobachtet wurde. Außerdem konnte ein zweites Peptid von Snapin, W2 (AA 83-92) auch eine 20\%ige Reduktion von postsynaptischen Potentialen bewirken, obwohl es nicht mit der Bindung von 
Snapin an SNAP-25 wie W4 kompetitiert. Diese Ergebnisse wurden von den Autoren so interpretiert, dass injizierte Snapin-Fragmente die Bindung von nativem Snapin an SNAP-25 verhindern und somit die Exozytose beeinflussen. Daraus würde folgen, dass Snapin außer der C-terminalen Domäne noch N-teminale Domänen hat, die an der Regulation der neuronalen Exozytose beteiligt sind. Aus den biochemischen Daten folgt, dass der NTerminus für die Snapin-vermittelte Bindung von Synaptotagmin an den SNARE-Komplex notwendig ist.

Im Gegensatz zu hier beobachteten Effekten hatte die Überexpression von Snapin-CT (Vites et al., 2004) in Neuronen keine Auswirkung weder auf die Amplitude noch auf andere Charakteristika der postsynaptischen Antwort wie die Größe von RRP, spontane Neurotransmitterfreisetzung und ,,short time depression’'.

In einer anderen Arbeit (Thakur et al., 2004) wurden Effekte der Überexpression von Snapin (AA 1-136) in Hippocampus-Neronen untersucht. Hier beobachtete man eine Reduktion der Amplitude von postsynaptischen Potentialen um mehr als 30\%. Wenn natives Snapin in einer Mischung aus phosphorylierter und nicht-phosphorylierter Form vorliegt, muss eine der Formen, die durch die Mutanten wiedergegeben werden, für diese Wirkung verantwortlich ist. Erstaunlicherweise hatte keine der in der gleichen Studie eingesetzten Mutanten SnapinS50D (phosphomimetisch) und SnapinS50A (nicht-phosphomimetisch) einen solchen Effekt. Die Überexpression der nicht-phosphomimetischen Mutante zeigte eine leicht verstärkte Antwort auf die hypertonische Saccharoselösung $(0,72 \pm 0,15$ nC gegenüber $0,47 \pm 0,1$ nC der Kontrollzellen) die von den Autoren als nicht signifikant eingestuft wurde. Die hypertonische Saccharoselösung stimmuliert die Freisetzung von Vesikeln aus dem ,,ready releasable pool’. Die phosphomimetische Mutante zeigte dagegen eine Reduktion der postsynaptischen Antwort nach der presnaptischen Anwendung der hypertonischen Saccharoselösung $(0,29 \pm 0,04$ nC gegenüber $0,48 \pm 0,08$ nC der Kontrollzellen). Die Wirkung der überexprimierten phosphomimetischen Mutante wurde mit der Überexpression des WildtypProteins unter Zugabe eines PKA-Aktivators verglichen. Hier wurde kein Unterschied in der postsynaptichen Antwort auf die hypertonische Saccharoselösung gefunden. Wildtyp-Snapin und nicht-phosphomimetische Mutante hatten keine weiteren Auswirkungen auf die analysierten Parameter der postsynaptischen Antwort. Die beiden Situationen, die entweder den phosphorylierten Zustand von Snapin mimikrierten (SnapinS50D) oder ihn herbeiführten (Wildtyp mit gleichzeitiger PKA-Aktivierung) verursachten eine Reduktion von mit hypertonischer Saccharoselösung induzierer Exozytose und als Folge davon eine zweifach erhöhte Freisetzungswahrscheinlichkeit von Neurotransmittervesikeln. 
Dieselbe Arbeitsgruppe untersuchte die Überexpression von SnapinS50D und SnapinS50A auch in Chromaffinzellen. Im Gegensatz zu Neuronen beobachtete man hier in beiden Fällen eine deutliche Verstärkung in der langsamen Phase der Exozytose. Die phosphomimetische Mutante verstärkte zusätzlich auch leicht die schnelle Phase der Exozytose.

In der folgenden Tabelle sind Ergebnisse dieser Untersuchungen zusammengefasst.

\begin{tabular}{|c|c|c|c|c|}
\hline Publikation & Snapin-Fragment & Modellsystem & EPSC/EPSP & RRP \\
\hline Ilardie et al., 1999 & AS 80-136 & $\begin{array}{l}\text { Injektion in SCG- } \\
\text { Neuronen }\end{array}$ & $\begin{array}{l}\text { Transiente } \\
\text { Reduktion um 30\% }\end{array}$ & Nicht untersucht \\
\hline Ilardie et al., 1999 & AS 83-92 & $\begin{array}{l}\text { Injektion in SCG- } \\
\text { Neuronenn }\end{array}$ & Reduktion um 20\% & Nicht untersucht \\
\hline Ilardie et al., 1999 & AS 117-136 & $\begin{array}{l}\text { Injektion in SCG- } \\
\text { Neuronen }\end{array}$ & Reduktion um 30\% & Nicht untersucht \\
\hline Vites et al., 2004 & AS 80-136 & $\begin{array}{l}\text { Überexpression in } \\
\text { Hippocampus- } \\
\text { Neuronen }\end{array}$ & Kein Effekt & Kein Effekt \\
\hline Chheda et al., 2001 & $\begin{array}{l}\text { SnapinS50D } \\
\text { AS 1-136 }\end{array}$ & $\begin{array}{l}\text { Überexpression in } \\
\text { Chromaffinzellen }\end{array}$ & Nicht untersucht & $\begin{array}{l}\text { Schnelle Phase um } \\
\text { 25\% erhöht, } \\
\text { langsame Phase } \\
\text { 2fach erhöht }\end{array}$ \\
\hline Chheda et al., 2001 & $\begin{array}{l}\text { SnapinS50A } \\
\text { AS 1-136 }\end{array}$ & $\begin{array}{l}\text { Überexpression in } \\
\text { Chromaffinzellen }\end{array}$ & Nicht untersucht & $\begin{array}{l}\text { Schnelle Phase um } \\
\text { 21\% reduziert, } \\
\text { langsame Phase } \\
\text { 2fach erhöht }\end{array}$ \\
\hline Thakur et al., 2004 & AS 1-136 & $\begin{array}{l}\text { Überexpression in } \\
\text { Neuronen }\end{array}$ & Erhöht um 35\% & Kein Effekt \\
\hline Thakur et al., 2004 & $\begin{array}{l}\text { SnapinS50D } \\
\text { AS 1-136 }\end{array}$ & $\begin{array}{l}\text { Überexpression in } \\
\text { Hippocampus- } \\
\text { Neuronen }\end{array}$ & Kein Effekt & $\begin{array}{l}\text { Reduktion des } \\
\text { gesamten Pools um } \\
40 \%\end{array}$ \\
\hline Thakur et al., 2004 & $\begin{array}{l}\text { SnapinS50A } \\
\text { AS 1-136 }\end{array}$ & $\begin{array}{l}\text { Überexpression in } \\
\text { Hippocampus- } \\
\text { Neuronen }\end{array}$ & Kein Effekt & $\begin{array}{l}\text { Kein Effekt } \\
\text { bzw. leichte } \\
\text { Erhöhung des } \\
\text { gesamten Pools }\end{array}$ \\
\hline
\end{tabular}

Tab.3 Einfluß auf Exozytose durch Snapin und seine Mutanten. EPSC/EPSP ,excitatory postsynaptic current/potential’', RRP- ,,readily releasable pool”, SCG - ,,superior cervical ganglion’’.

Bei genauer Betrachtung dieser Daten fällt einem auf, dass die in Neuronen und Chromaffinzellen erhaltene Ergebnisse widersprüchlich sind. Die Widersprüchlichkeit der Daten und die geringen Effekte auf unterschiedliche Charakteristika der Exozytose lassen Zweifel an der biologischen Signifikanz dieser Daten aufkommen. Außerdem lässt die von Ilardi et al., 1999 beschrieben Immunopräzipitation eines rekombinanten SNARESynaptotagmin-Komplexes zusammen mit rekombinantem Snapin auf eine direkte Interaktion zwischen diesen Proteinen schließen. Die Interaktion zwischen Synaptotagmin und dem SNARE-Komplex zählt zu den späten Schritten in der exozytotischen Reaktionsfolge, 
während die beobachteten elektrophysiologischen Effekte auf eine regulatorische Funktion in Priming/Docking schließen lassen.

Eine andere Arbeit (Morenilla-Palao et al., 2004), die sich mit der Interaktion zwischen Snapin und dem Vanilloidrezeptor-1 (TRPV-1) beschäftigt, beschreibt ein anderes Phänomen, dass eine Rolle von Snapin in der regulierten Exozytose impliziert. PKC hatte zwei Effekte auf die Aktivität von TRPV-1. Erstens sensitivierte die PKC-abhängige Phosphorylierung den Rezeptor und zweitens verstärkte die PKC die SNARE-abhängige Exozytose, was zur Erhöhten Expression von TRPV-1 auf der Zelloberfläche führte. Gleichzeitige Überexpression von TRPV-1 und Snapin in Froschoozyten führt teilweise zur Aufhebung der PKC-Wirkung auf den Vanilloidrezeptor, die durch Exozytose vermittelt wird. Den gleichen Effekt hat auch Botulinumneurotoxin A. Dabei scheint Snapin direkt an den N-Terminus von TRPV-1 zu binden und damit die PKC-induzierte Exozytose zu verhindern.

Die Bindung von Snapin an TRPV-1 selbst hat keine Auswirkung auf die Aktivität dieses Rezeptors. Setzt man für Snapin eine direkte Rolle in der Exozytose über die Interaktion mit SNARE-Proteinen voraus, so erscheint Snapin in diesen Versuchen als ebenso potenter Blocker wie Botulinumneurotoxin A. Dies lässt sich aber nicht mit den milden Effekten, die in Neuronen und Chromaffinzellen durch Snapin vermittelt wurden, in Einklang bringen. Eine andere mögliche Erklärung ist, dass Snapin ein Teil der Signaltransduktionskaskade ist, die zur PKC-abhängigen Aktivierung der regulierten Exozytose führt. So zeigten Chou et al., 2004, dass Snapin die PKC-vermittelte Inhibition von Adenylatcyclase VI aufheben kann.

In Anbetrachtet der von mir vorgelegten Studie und der kritischen Betrachtung anderer Publikationen muß die Rolle von Snapin in der neuronalen Exozytose in Frage gestellt. Snapin scheint nicht der essentielle Bestandteil des Fusionsapparatus zu sein und übernimmt mit Sicherheit andere zusätzliche Aufgaben innerhalb von nicht-neuronalen Zellen.

\subsection{Snapin-Homologe in anderen Organismen}

Snapin-homologe Proteine wurden auch in D. melanogaster und C. elegans gefunden. Über die Funktion von Snapin in diesen Proteinen ist wenig bekannt. In beiden Fällen handelt es sich um Proteine mit zwei Coiled-Coil-Domänen mit moderater Homologie zum SäugerSnapin.

Snapin aus D. melanogaster wurde in einem genomweiten Screen nach synaptischen Proteinen identifiziert (Lloyd et al., 2000). Das Snapingen liegt in dergleichen genomischen Region (22F-23B,160 kB) wie andere Gene, deren Genprodukte wie dynamin-2, synaptotagmin 1 und HRS an Transportvorgängen innerhalb der Zelle beteiligt sind. Snapin 
ist verstärkt während der Embryonalenwicklung exprimiert (http://genome.med.yale.edu/Lifecycle/query_gen.php?input1=FBgn0031455). Bei einem Zwei-Hybrid-Screen mit 10623 vorhergesagten Transkripten hat man eine starke Interaktion zwischen Snapin und dem D. melanogaster Homolog von BLOS-2 gefunden (Giot et al., 2003). Es wurde keine Interaktion zwischen Snapin und synaptischen Proteinen gefunden, was leicht dadurch zu erklären ist, das Standad-Zwei-Hybrid-Verfahren sich für Membranproteine nicht eignen.

Das Snapin-Homolog in C.elegans zeigt eine deutlich verstärkte Expression im embryonalen Stadium (Hill et al., 2000) und eine Anreicherung in Oozyten (Piano et al., 2002). Zwei RNAi-Studien wurden mit dem Snapin-Homolog in C. elegans durchgeführt. Ein Verfahren (Kamath et al, 2003) basierte auf dem Füttern von erwachsenen Tieren mit Bakterien, die doppelsträngige RNS exprimierten. In diesem Fall wurde kein Phenotyp gefunden. Piano et al., 2002 injzierten doppelsträngige RNS direkt in die Tiere. Auch hier wurde kein ausgeprägtes Phenotyp gefunden: Eine von neun Platten war zu 60\% embryonisch lethal.

Somit lässt sich hier aus diesen Daten keine Funktion für Snapin-Homologe in C.elegans und D. melanogaster erschliessen.

\subsection{Perspektiven}

Snapin ist ein ubiquitäres, evolutiv hoch konserviertes Protein. Homologe Proteine wurden in Chordatieren, Invertrebrata und Pflanzen, aber nicht in Hefe gefunden. Mehrere Interaktionspartner wurden für Snapin identifiziert. Anhand der bekannten Rollen seiner Interaktionspartner lässt sich Beteiligung von Snapin an drei verschiedenen zellulären Vorgänge vermuten:

1. Kalziumabhängige und konstitutive Exozytose (über Interaktionen mit SNAP-23, SNAP-25)

2. Signaltransduktion über Proteinkinasen und G-Protein gekoppelte Rezeptoren (über Interaktionen mit Adenylatzyklase VI , RGS7 und Vanilloidrezeptor)

3. Biogenese von spezialisierten Organellen des lysosomal-endosomalen Systems (als Komponente des BLOC-1 Komplexes)

Am besten belegt ist die Beteiligung von Snapin am BLOC-1 Komplex. Mutationen in anderen Komponenten des BLOC-1 Komplexes verursachen das Hermansky-PudlakSyndrom, eine genetische Krankheit, die mit Hypopigmentation und Blutungsneigung assoziiert ist. Es wäre interessant zu sehen, ob Snapindeletion in einem Mausmodell zum ähnlichen Phänotyp führt. Zwar lässt sich den Mutationen ein Phänotyp zuordnen, aber der 
zelluläre Mechanismus, der diesem Phänotyp zugrunde liegt, ist weitgehend unklar. In diesem Zusammenhang ist es wichtig zu erwähnen, dass zwei Komponenten des BLOC-1 Komplexes mit SNARE-Proteinen interagieren können. Eine Interaktion zwischen Pallidin und Syntaxin 13 (Burkhard et al., 2001) und eine Interaktion zwischen Snapin und SNAP-23 (Buxton et al., 2003) wurde berichtet. Deshalb wird ein Zusammenhang zwischen intrazellulären Transportvorgängen und Biogenese der speziallisierten lysosomalen Organellen vermutet. Pallidin und Snapin haben beide wie auch SNARE-Proteine Coiled-coil-Domänen, die für die Protein-Protein-Interaktionen verantwortlich sind. Bedenkt man, dass SNARE-Proteine zu promiskuitiven Interaktionen in vitro neigen, sollte die Spezifität auch anderer Interaktionen, die über Coiled-Coil-Domänen vermittelt wird, überprüft werden. Unter diesem Gesichtspunkt sollte man zum Beispiel Interaktion von Pallidin mit anderen Proteinen der Syntaxin-Familie und die von Snapin mit anderen Proteinen der SNAP-25-Familie untersuchen. Ein Zusammenhang zwischen Syntaxin 13 und SNAP-23 ist aus den vorliegenden Daten nicht direkt erkennbar: Syntaxin 13 befindet sich auf frühen und ,, recycling', Endosomen (Prekeris et al., 1998) und ist an der homotypischen Fusion von frühen Endosomen (McBride et al., 1999) beteiligt; SNAP-23 ist in die konstitutive Exozytose involviert und zeigt eine starke Plasmamembranlokalization. Kein Komplex zwischen SNAP-23 und Syntaxin 13 wurde bis jetzt beschrieben.

Aus den Experimenten von Starcevic und Dell’Angelica, 2004 lässt sich schließen, dass Snapin in der Leber außer BLOC-1 noch in einem zweiten Komplex vorliegt. Dieser zweite Komplex kofraktioniert nicht mit den restlichen Komponenten des BLOC-1 Komplexes und könnte somit noch einen anderen unbekannten zytosolischen Interaktionspartner von Snapin beinhalten.

Die Rolle von Snapin in der regulierten Exozytose ist durch diese Arbeit und durch die Widersprüchlichkeit der elektrophysiologischen Daten in Frage gestellt. In diesem Zusammenhang wäre es wichtig, elektrophysiologische Experimente auf dem genetischen Hintergrund eines Snapin Knock-outs zu wiederholen.

Interaktionen von Snapin mit anderen Proteinen wie RGS7 und Vanilloidrezeptor sind nicht ausreichend belegt: Sie basieren auf den Studien mit rekombinanten oder überexprimierten Proteinen. Diese Untersuchungen sollten durch Kolokalizationsstudien ergänzt werden und auf andere Isoformen/Familienmitglieder ausgedehnt werden. Snapin und Adenylatcyclase VI zeigen in der Arbeit von Chou et al., 2004 eine Kolokalization nicht auf der Plasmamembran, sondern in einem endosomalen-lysosomalen Kompartiment. Es wäre interessant zu überprüfen, ob Snapin an einen endosomal lokalisierten Mitglied der RGS-Familie, RGS-PX1 
(Zheng et al., 2001) bindet, das eine Homologie zwischen seiner PX-Domäne und der SnapinBindungs-Domäne vor RGS7 (Vites, nicht publizierte Daten) augweist.

Snapin wird mehrmals in Zusammenhang mit PKA und PKC gebracht. Es konnte gezeigt werden, dass Snapin ein Substrat für PKA darstellt (Chheda et al., 2001). Interaktion von Snapin mit Adenylatcyclase VI hebt die Inhibierung dieses Enzyms durch PKC auf (Chou et al., 2004). Koexpression von Snapin und Vanilloidrezeptor führt zur Inhibition der PKCinduizierten und SNARE-abhängigen Expression des Rezeptors auf der Oberfläche. Kenntnisse über den Phosphorylierugnszustand von Snapin in verschieden Geweben und unter verschiedenen Bedingungen und über die Phosphorylierung von Snapin in vivo durch die beiden Proteinkinasen würden zum Verständnis dieser Interaktionen beitragen. 


\section{Zusammenfassung}

Snapin wurde ursprünglich von Ilardi et., al 1999 als hirnspezifisches Protein beschrieben, das mit SNAP-25, einem zentralen Protein der neuronalen Exozytse, interagiert. Sowohl biochemische Daten über die Bindung an SNAP-25 und Einfluss von Snapin auf die Interaktion zwischen dem SNARE-Komplex und Synaptotagmin als auch elektrophysiologische Versuche mit Snapinfragmenten ließen für Snapin eine regulatorische Rolle in der neuronalen Exozytose vermuten. Im Rahmen dieser Doktorarbeit wurde Snapin biochemisch und in struktureller Hinsicht charakterisiert. Zwei Snapin-Antisera wurden hergestellt, die sowohl rekombinantes wie natives Snapin im gefalteten und denaturierten Zustand erkennen und somit in unterschiedlichen Immunotechniken einsetzbar sind. Mit diesen Antikörpern konnte gezeigt werden, dass Snapin ein ubiquitäres Protein ist, das sowohl im Zytoplasma wie membranassoziiert vorliegt. Die Membranassoziation ist nicht auf eine putative Trasmembrandomäne zurückzuführen, wie Computeranalysen, TritonX-114Verteilung und nicht zuletzt die Löslichkeit des rekombinanten Proteins in detergenzfreien Lösungen zeigen. Rekombinantes Snapin liegt in Lösung als Dimer vor. Das Protein besitzt einen $\alpha$-helikalen Gehalt von 64\%. Die $\alpha$-helikalen Bereiche weisen eine Übergangstemperatur von $58^{\circ} \mathrm{C}$ und können sich komplett nach einer chemischen oder thermischen Denaturierung zurückfalten. Erste Snapinkristalle in Form von hexagonalen Stäbchen mit scharfen Kanten bis $200 \mu \mathrm{m}$ Länge wurden erhalten. Allerdings ließ sich die Auflösung wahrscheinlich aufgrund einer intrinsischen Unordnung nicht mehr als auf 5,5 $\AA$ verbessern. Die kristallographischen Daten lassen eine trigonale oder hexagonale Raumgruppe vermuten.

Snapin ist ein evolutiv konserviertes Protein. Die Konservierung unter den Chordatieren beträgt 72\% über einen mittleren Bereich von 100 Aminosäuren (bei Gesamtlänge von 136 Aminosäuren). Homologe Proteine wurde auch in Invertebraten (Caenorhabditis elegans und Drosophila melanogaster) und Pflanzen Arabidopsis thaliana) gefunden. Die Funktion dieses Proteins ist noch nicht aufgeklärt. Daten aus dieser Studie zeigen, dass eine direkte spezifische Interaktion zwischen Snapin und SNAP-25 sowie eine Assoziation mit dem SNARE-Komplex weder in vivo noch in vitro nachgewiesen werden konnte. Auch andere Daten wie ubiquitäre Verteilung, fehlende evolutive Konservierung der Aminosäurensequenz, die für die Interaktion mit SNAP-25 und elektrophysiologische Effekte verantwortlich ist, und neu publizierte Interaktionspartner für Snapin, die nicht an der Neurotransmitterfreisetzung beteiligt sind, stellen die Rolle von Snapin in der neuronalen Exozytose in Frage und lassen andere zusätzliche Funktionen für dieses Protein vermuten. 


\section{Summary}

Snapin has been originally described by Ilardi et al., 1999 as a brain specific protein that interacts with SNAP-25, one of the central proteins in neuronal exocytosis. Biochemical data on the binding to SNAP-25, its influence on the interaction between the SNARE complex and synaptotagmin and electrophysiological data has led to the conclusion that snapin plays a role neuronal exocytosis. In this $\mathrm{PhD}$ thesis, snapin was characterized biochemically and from a structural point of view. Two snapin antisera were raised in rabbits, which can recognize recombinant and native snapin in its unfolded and native form, which make them suitable for a variety of immunotechniques. I could show with these antisera that snapin is an ubiquitiously expressed protein which distributes into cytosolic and membrane associated pools. The association with membranes cannot be explained by assuming the presence of a putative transmembrane domain, as shown with computer analysis of the amino acid sequence of snapin, TritonX-114 distribution and the solubility of the recombinant protein in detergent free solutions. Recombinant Snapin forms a dimer with a high $\alpha$-helical content of $64 \%$. These $\alpha$-helical regions have a single transition point at $58^{\circ} \mathrm{C}$ and can be completely refolded after chemical or thermal denaturation. First attemps at crystallizing snapin has provided crystals in form of hexagonal rods with sharp edges of $200 \mu \mathrm{m}$. Resolution higher than $6 \AA$ could not be achieved so far, perhaps due to an intrinsic disorder in the crystals. Initial crystallographic data indicate a trigonal or hexagonal space group.

Snapin is an evolutionary conserved protein with 72 \% homology in chordates over a central stretch of 100 amino acids (the full length of snapin is 136 aminoacides). Homolog proteins can be found in invertebrates (Caenorhabditis elegans and Drosophila melanogaster) and plants (Arabidopsis thaliana) as well. The function of snapin is still unclear. Data from this study based on a variety of methods (pulldown assays, immunoprecipitations and circular dichroism studies) failed to show a specific interaction between snapin and SNAP-25 or any association of snapin with the SNARE complex. Additionally, the poor conservation of the putative SNAP-25 interaction regions that had an effect in electrophysiological studies (Ilardi et al., 1999), and newly published data on snapin interacting proteins that do not participate in neurotransmitter release question the role of snapin in neuronal exocytosis and raise the possibility of alternate functions of snapin. 


\section{Literaturverzeichnis}

Aebersold, R., and Mann, M. (2003) Mass spectrometry-based proteomics Nature 422, 198207

Andrews, N. W. (2000) Regulated secretion of conventional lysosomes Trends Cell Biol 10, 316-321

Barnstable, C. J., Hofstein, R., and Akagawa, K. (1985) A marker of early amacrine cell development in rat retina Brain Res 352, 286-290

Blott, E. J., and Griffiths, G. M. (2002) Secretory lysosomes Nat Rev Mol Cell Biol 3, 122131

Bordier, C. (1981) Phase separation of integral membrane proteins in Triton X-114 solution J Biol Chem 256, 1604-1607

Brose, N., Huntley, G. W., Stern-Bach, Y., Sharma, G., Morrison, J. H., and Heinemann, S. F. (1994) Differential assembly of coexpressed glutamate receptor subunits in neurons of rat cerebral cortex J Biol Chem 269, 16780-16784

Bruns, D., Engers, S., Yang, C., Ossig, R., Jeromin, A., and Jahn, R. (1997) Inhibition of transmitter release correlates with the proteolytic activity of tetanus toxin and botulinus toxin A in individual cultured synapses of Hirudo medicinalis J Neurosci 17, 1898-1910

Burkhard, P., Stetefeld, J., and Strelkov, S. V. (2001) Coiled coils: a highly versatile protein folding motif Trends Cell Biol 11, 82-88

Buxton, P., Zhang, X. M., Walsh, B., Sriratana, A., Schenberg, I., Manickam, E., and Rowe, T. (2003) Identification and characterization of Snapin as a ubiquitously expressed SNAREbinding protein that interacts with SNAP23 in non-neuronal Biochem J Pt

Causier, B. (2004) Studying the interactome with the yeast two-hybrid system and mass spectrometryMass Spectrom Rev 23, 350-367 
Chen, Y. H., Yang, J. T., and Chau, K. H. (1974) Determination of the helix and beta form of proteins in aqueous solution by circular dichroism Biochemistry 13, 3350-3359

Chen, Y., Harry, A., Li, J., Smit, M. J., Bai, X., Magnusson, R., Pieroni, J. P., Weng, G., and Iyengar, R. (1997) Adenylyl cyclase 6 is selectively regulated by protein kinase A phosphorylation in a region involved in Galphas stimulation Proc Natl Acad Sci U S A 94, $14100-14104$

Chen, D., Minger, S. L., Honer, W. G., and Whiteheart, S. W. (1999) Organization of the secretory machinery in the rodent brain: distribution of the t-SNAREs, SNAP-25 and SNAP23 Brain Res 831, 11-24

Chern, Y. (2000) Regulation of adenylyl cyclase in the central nervous system Cell Signal 12, 195-204

Chiang, P. W., Oiso, N., Gautam, R., Suzuki, T., Swank, R. T., and Spritz, R. A. (2003) The Hermansky-Pudlak syndrome 1 (HPS1) and HPS4 proteins are components of two complexes, BLOC-3 and BLOC-4, involved in the biogenesis of lysosome-related organelles J Biol Chem 278, 20332-20337

Chheda, M. G., Ashery, U., Thakur, P., Rettig, J., and Sheng, Z. H. (2001) Phosphorylation of Snapin by PKA modulates its interaction with the SNARE complex Nat Cell Biol 3, 331-338

Chou, J. H., and Jahn, R. (2000) Binding of Rab3A to synaptic vesicles J Biol Chem 275, 9433-9440

Chou, J. L., Huang, C. L., Lai, H. L., Hung, A. C., Chien, C. L., Kao, Y. Y., and Chern, Y. (2004) Regulation of type VI adenylyl cyclase by snapin, a SNAP25-binding protein J Biol Chem

de Duve, C. (1963) Lysosomes. Ciba Foundation Symposium edited by A. V. S. de Reuck and M. P. Cameron. London: Churchill, 411-412. 
Edelmann, L., Hanson, P. I., Chapman, E. R., and Jahn, R. (1995) Synaptobrevin binding to synaptophysin: a potential mechanism for controlling the exocytotic fusion machine Embo $\mathrm{J}$ $14,224-231$

Fasshauer, D., Otto, H., Eliason, W.K., Jahn, R. and Brunger, A.T. (1997) Structural changes are associated with soluble N-ethylmaleimide-sensitive fusion protein attachment protein receptor complex formation. J. Biol. Chem., 272, 28036-41.

Fasshauer, D., Sutton, R. B., Brunger, A. T., and Jahn, R. (1998) Conserved structural features of the synaptic fusion complex: SNARE proteins reclassified as Q- and R-SNAREs. Proc Natl Acad Sci U S A 95, 15781-15786.

Fasshauer, D., Antonin, W., Margittai, M., Pabst, S., and Jahn, R. (1999) Mixed and noncognate SNARE complexes. Characterization of assembly and biophysical properties J Biol Chem 274, 15440-15446

Fasshauer, D., Antonin, W., Subramaniam, V., and Jahn, R. (2002) SNARE assembly and disassembly exhibit a pronounced hysteresis Nat Struct Biol 9, 144-151

Feng, D., Crane, K., Rozenvayn, N., Dvorak, A. M., and Flaumenhaft, R. (2002) Subcellular distribution of 3 functional platelet SNARE proteins: human cellubrevin, SNAP-23, and syntaxin 2 Blood 99, 4006-4014

Freedman, S. J., Song, H. K., Xu, Y., Sun, Z. Y., and Eck, M. J. (2003) Homotetrameric structure of the SNAP-23 N-terminal coiled-coil domain J Biol Chem 278, 13462-13467

Gallwitz, D., and Jahn, R. (2003) The riddle of the Sec1/Munc-18 proteins - new twists added to their interactions with SNAREs Trends Biochem Sci 28, 113-116

Gautam, R., Chintala, S., Li, W., Zhang, Q., Tan, J., Novak, E. K., Di Pietro, S. M., Dell'Angelica, E. C., and Swank, R. T. (2004) The Hermansky-Pudlak syndrome 3 (cocoa) protein is a component of the biogenesis of lysosome-related organelles complex-2 (BLOC-2) J Biol Chem 279, 12935-12942 
Jahn, R. (2004) Principles of exocytosis and membrane fusion Ann N Y Acad Sci 1014, 170178

Giot, L., Bader, J. S., Brouwer, C., Chaudhuri, A., Kuang, B., Li, Y., Hao, Y. L., Ooi, C. E., Godwin, B., Vitols, E., Vijayadamodar, G., Pochart, P., Machineni, H., Welsh, M., Kong, Y., Zerhusen, B., Malcolm, R., Varrone, Z., Collis, A., Minto, M., Burgess, S., McDaniel, L., Stimpson, E., Spriggs, F., Williams, J., Neurath, K., Ioime, N., Agee, M., Voss, E., Furtak, K., Renzulli, R., Aanensen, N., Carrolla, S., Bickelhaupt, E., Lazovatsky, Y., DaSilva, A., Zhong, J., Stanyon, C. A., Finley, R. L., Jr., White, K. P., Braverman, M., Jarvie, T., Gold, S., Leach, M., Knight, J., Shimkets, R. A., McKenna, M. P., Chant, J., and Rothberg, J. M. (2003) A protein interaction map of Drosophila melanogaster Science 302, 1727-1736

Greene, L. A., and Tischler, A. S. (1976) Establishment of a noradrenergic clonal line of rat adrenal pheochromocytoma cells which respond to nerve growth factor Proc Natl Acad Sci U S A 73, 2424-2428

Jahn, R., Schiebler, W., Ouimet, C., and Greengard, P. (1985) A 38,000-dalton membrane protein (p38) present in synaptic vesicles Proc Natl Acad Sci U S A 82, 4137-4141

Jahn, R. (2004) Principles of exocytosis and membrane fusion Ann N Y Acad Sci 1014, 170178

Ilardi, J. M., Mochida, S., and Sheng, Z. H. (1999) Snapin: a SNARE-associated protein implicated in synaptic transmission Nat Neurosci 2, 119-124

Ishii, M., and Kurachi, Y. (2003) Physiological actions of regulators of G-protein signaling (RGS) proteins Life Sci 74, 163-171

Huang, L., Kuo, Y. M., and Gitschier, J. (1999) The pallid gene encodes a novel, syntaxin 13interacting protein involved in platelet storage pool deficiency Nat Genet 23, 329-332

Hunt, R. A., Edris, W., Chanda, P. K., Nieuwenhuijsen, B., and Young, K. H. (2003) Snapin interacts with the N-terminus of regulator of $\mathrm{G}$ protein signaling 7 Biochem Biophys Res Commun 303, 594-599 
Huttner, W. B., Schiebler, W., Greengard, P., and De Camilli, P. (1983) Synapsin I (protein I), a nerve terminal-specific phosphoprotein. III. Its association with synaptic vesicles studied in a highly purified synaptic vesicle preparation J Cell Biol 96, 1374-1388

Kamath, R. S., and Ahringer, J. (2003) Genome-wide RNAi screening in Caenorhabditis elegans Methods 30, 313-321

Lai, H. L., Yang, T. H., Messing, R. O., Ching, Y. H., Lin, S. C., and Chern, Y. (1997) Protein kinase C inhibits adenylyl cyclase type VI activity during desensitization of the A2aadenosine receptor-mediated cAMP response J Biol Chem 272, 4970-4977

Laemmli, U. K. (1970) Cleavage of structural proteins during the assembly of the head of bacteriophage T4 Nature 227, 680-685

Li, W., Zhang, Q., Oiso, N., Novak, E. K., Gautam, R., O'Brien, E. P., Tinsley, C. L., Blake, D. J., Spritz, R. A., Copeland, N. G., Jenkins, N. A., Amato, D., Roe, B. A., Starcevic, M., Dell'Angelica, E. C., Elliott, R. W., Mishra, V., Kingsmore, S. F., Paylor, R. E., and Swank, R. T. (2003) Hermansky-Pudlak syndrome type 7 (HPS-7) results from mutant dysbindin, a member of the biogenesis of lysosome-related organelles complex 1 (BLOC-1) Nat Genet 35, 84-89

Li, W., Rusiniak, M. E., Chintala, S., Gautam, R., Novak, E. K., and Swank, R. T. (2004) Murine Hermansky-Pudlak syndrome genes: regulators of lysosome-related organelles Bioessays 26, 616-628

Lloyd, T. E., Verstreken, P., Ostrin, E. J., Phillippi, A., Lichtarge, O., and Bellen, H. J. (2000) A genome-wide search for synaptic vesicle cycle proteins in Drosophila Neuron 26, 45-50

Martina, J. A., Moriyama, K., and Bonifacino, J. S. (2003) BLOC-3, a protein complex containing the Hermansky-Pudlak syndrome gene products HPS1 and HPS4 J Biol Chem 278, 29376-29384 
Maxfield, F. R., and McGraw, T. E. (2004) Endocytic recycling Nat Rev Mol Cell Biol 5, 121-132

McBride, H. M., Rybin, V., Murphy, C., Giner, A., Teasdale, R., and Zerial, M. (1999) Oligomeric complexes link Rab5 effectors with NSF and drive membrane fusion via interactions between EEA1 and syntaxin 13 Cell 98, 377-386

von Mering, C., Krause, R., Snel, B., Cornell, M., Oliver, S. G., Fields, S., and Bork, P. (2002) Comparative assessment of large-scale data sets of protein-protein interactions Nature 417, 399-403

Misura, K. M., Scheller, R. H., and Weis, W. I. (2000) Three-dimensional structure of the neuronal-Sec1-syntaxin 1a complex Nature 404, 355-362

Mons, N., and Cooper, D. M. (1994) Selective expression of one Ca(2+)-inhibitable adenylyl cyclase in dopaminergically innervated rat brain regions Brain Res Mol Brain Res 22, 236244

Morenilla-Palao, C., Planells-Cases, R., Garcia-Sanz, N., and Ferrer-Montiel, A. (2004) Regulated exocytosis contributes to protein kinase $\mathrm{C}$ potentiation of vanilloid receptor activity J Biol Chem

Nagy, G., Matti, U., Nehring, R. B., Binz, T., Rettig, J., Neher, E., and Sorensen, J. B. (2002) Protein kinase C-dependent phosphorylation of synaptosome-associated protein of $25 \mathrm{kDa}$ at Ser187 potentiates vesicle recruitment J Neurosci 22, 9278-9286

Nagy, G., Reim, K., Matti, U., Brose, N., Binz, T., Rettig, J., Neher, E., and Sorensen, J. B. (2004) Regulation of releasable vesicle pool sizes by protein kinase A-dependent phosphorylation of SNAP-25 Neuron 41, 417-429

Nazarian, R., Falcon-Perez, J. M., and Dell'Angelica, E. C. (2003) Biogenesis of lysosomerelated organelles complex 3 (BLOC-3): a complex containing the Hermansky-Pudlak syndrome (HPS) proteins HPS1 and HPS4 Proc Natl Acad Sci U S A 100, 8770-8775 
Nguyen, T., Novak, E. K., Kermani, M., Fluhr, J., Peters, L. L., Swank, R. T., and Wei, M. L. (2002) Melanosome morphologies in murine models of hermansky-pudlak syndrome reflect blocks in organelle development J Invest Dermatol 119, 1156-1164

Pabst, S., Hazzard, J. W., Antonin, W., Sudhof, T. C., Jahn, R., Rizo, J., and Fasshauer, D. (2000) Selective interaction of complexin with the neuronal SNARE complex. Determination of the binding regions J Biol Chem 275, 19808-19818

Pabst, S., Margittai, M., Vainius, D., Langen, R., Jahn, R., and Fasshauer, D. (2001) Rapid and selective binding to the synaptic SNARE complex suggests a modulatory role of complexins in neuroexocytosis J Biol Chem 20, 20

Palade, G. (1975) Intracellular aspects of the process of protein synthesis. Science, 189, 34758.

Piano, F., Schetter, A. J., Morton, D. G., Gunsalus, K. C., Reinke, V., Kim, S. K., and Kemphues, K. J. (2002) Gene clustering based on RNAi phenotypes of ovary-enriched genes in C. elegans Curr Biol 12, 1959-1964

Pieroni, J. P., Harry, A., Chen, J., Jacobowitz, O., Magnusson, R. P., and Iyengar, R. (1995) Distinct characteristics of the basal activities of adenylyl cyclases 2 and $6 \mathrm{~J}$ Biol Chem 270, 21368-21373

Di Pietro, S. M., Falcon-Perez, J. M., and Dell'Angelica, E. C. (2004) Characterization of BLOC-2, a complex containing the Hermansky-Pudlak syndrome proteins HPS3, HPS5 and HPS6 Traffic 5, 276-283

Phizicky, E., Bastiaens, P. I., Zhu, H., Snyder, M., and Fields, S. (2003) Protein analysis on a proteomic scale Nature 422, 208-215

Prekeris, R., Klumperman, J., Chen, Y. A., and Scheller, R. H. (1998) Syntaxin 13 mediates cycling of plasma membrane proteins via tubulovesicular recycling endosomes $\mathrm{J}$ Cell Biol 143, 957-971 
Premont, R. T., Chen, J., Ma, H. W., Ponnapalli, M., and Iyengar, R. (1992) Two members of a widely expressed subfamily of hormone-stimulated adenylyl cyclases Proc Natl Acad Sci U S A 89, 9809-9813

Salim, S., Sinnarajah, S., Kehrl, J. H., and Dessauer, C. W. (2003) Identification of RGS2 and type V adenylyl cyclase interaction sites J Biol Chem 278, 15842-15849

Schneider, S. W. (2001) Kiss and run mechanism in exocytosis J Membr Biol 181, 67-76

Sinnarajah, S., Dessauer, C. W., Srikumar, D., Chen, J., Yuen, J., Yilma, S., Dennis, J. C., Morrison, E. E., Vodyanoy, V., and Kehrl, J. H. (2001) RGS2 regulates signal transduction in olfactory neurons by attenuating activation of adenylyl cyclase III Nature 409, 1051-1055

Sollner, T., Whiteheart, S. W., Brunner, M., Erdjument-Bromage, H., Geromanos, S., Tempst, P., and Rothman, J. E. (1993a) SNAP receptors implicated in vesicle targeting and fusion Nature 362, 318-324

Sollner, T., Bennett, M. K., Whiteheart, S. W., Scheller, R. H., and Rothman, J. E. (1993b) A protein assembly-disassembly pathway in vitro that may correspond to sequential steps of synaptic vesicle docking, activation, and fusio Cell 75, 409-418

Sorensen, J. B., Nagy, G., Varoqueaux, F., Nehring, R. B., Brose, N., Wilson, M. C., and Neher, E. (2003) Differential control of the releasable vesicle pools by SNAP-25 splice variants and SNAP-23 Cell 114, 75-86

Starcevic, M., and Dell'Angelica, E. C. (2004) Identification of Snapin and Three Novel Proteins (BLOS1, BLOS2, and BLOS3/Reduced Pigmentation) as Subunits of Biogenesis of Lysosome-related Organelles Complex-1 (BLOC-1) J Biol Chem 279, 28393-28401

Stinchcombe, J., Bossi, G., and Griffiths, G. M. (2004) Linking albinism and immunity: the secrets of secretory lysosomes Science 305, 55-59

Sudhof, T. C. (2004) The synaptic vesicle cycle Annu Rev Neurosci 27, 509-547 
Sun, W., Yan, Q., Vida, T. A., and Bean, A. J. (2003) Hrs regulates early endosome fusion by inhibiting formation of an endosomal SNARE complex J Cell Biol 162, 125-137

Sutton RB, Fasshauer D, Jahn R, Brunger AT (1993) Crystal structure of a SNARE complex involved in synaptic exocytosis at 2.4 A resolution. Nature, 1998 Sep 24;395(6700):347-53.

Swank, R. T., Novak, E. K., McGarry, M. P., Rusiniak, M. E., and Feng, L. (1998) Mouse models of Hermansky Pudlak syndrome: a review Pigment Cell Res 11, 60-80

Tao-Cheng, J. H., Du, J., and McBain, C. J. (2000) Snap-25 is polarized to axons and abundant along the axolemma: an immunogold study of intact neurons J Neurocytol 29, 67-77

Thakur, P., Stevens, D. R., Sheng, Z. H., and Rettig, J. (2004) Effects of PKA-mediated phosphorylation of Snapin on synaptic transmission in cultured hippocampal neuronsJ Neurosci 24, 6476-6481

Towbin, H., Staehelin, T., and Gordon, J. (1979) Electrophoretic transfer of proteins from polyacrylamide gels to nitrocellulose sheets: procedure and some applications Proc Natl Acad Sci U S A 76, 4350-4354

Vites, O., Rhee, J. S., Schwarz, M., Rosenmund, C., and Jahn, R. (2004) Reinvestigation of the role of snapin in neurotransmitter release J Biol Chem 279, 26251-26256

Walch-Solimena, C., Blasi, J., Edelmann, L., Chapman, E. R., von Mollard, G. F., and Jahn, R. (1995) The t-SNAREs syntaxin 1 and SNAP-25 are present on organelles that participate in synaptic vesicle recycling J Cell Biol 128, 637-645

Wen, J., Arakawa, T., and Philo, J. S. (1996) Size-exclusion chromatography with on-line light-scattering, absorbance, and refractive index detectors for studying proteins and their interactions Anal Biochem 240, 155-166

Xu, T., Rammner, B., Margittai, M., Artalejo, A. R., Neher, E., and Jahn, R. (1999) Inhibition of SNARE complex assembly differentially affects kinetic components of exocytosis Cell 99, 713-722 
Zerial, M., and McBride, H. (2001) Rab proteins as membrane organizers Nat Rev Mol Cell Biol 2, 107-117

Zheng, B., Ma, Y. C., Ostrom, R. S., Lavoie, C., Gill, G. N., Insel, P. A., Huang, X. Y., and Farquhar, M. G. (2001) RGS-PX1, a GAP for GalphaS and sorting nexin in vesicular trafficking Science 294, 1939-1942 
7 Anhang

\subsection{Abkürzungen}

Abbildung

BLOC

BSA

biogenesis of lysosomal-related organelle complex

CD

Rinderserumalbumin

$\mathrm{CNBr}$

circular dichroism

DTT

cyanogen bromide

EDTA

Dithiothreitol

EST

Ethylendiamintetraessigsäure

FCS

expressed sequence tag

GDI

fetal calf serum

GST

GDP dissociation inhibitor

HEPES

Glutathion-S-Transferase)

6xHis

N-(2-Hydroxyethyl-)piperazin-N`-2-Ethansulfonsäure

HRP

Histidin-Tag

IgG

Meerettichperoxidase

IPTG

$\mathrm{kb}$

Immunglobulin $\mathrm{G}$

Isopropyl-ß-D-Thiogalaktosid

$\mathrm{kDa}$

Kilobasenpaare

Kilodalton

$\mathrm{KLH}$

Keyhole limpet hemocyonin

LB

Luria-Bertani Medium

MALLS

MALDI-MS

multi-angle laser light scattering

matrix assisted laser desorption/ionization mass spectrometry

MBS

m-Maleimidobenzoicacid-N-hydoxysuccinimidester

NEM

$\mathrm{N}$-Ethylmaleimid

NMDAR

N-methyl-D-Aspartatrezeptor

NSF

N-ethylmaleimide-sensitive factor

OD

optische Dichte

PAGE

Polyacrylamidgelelectrophorese

PBS

phosphate bufferd saline

PCR

Polymerasekettenreaktion

PKA

Proteinkinase A 


$\begin{array}{ll}\text { PKC } & \text { Proteinkinase C } \\ \text { PMSF } & \text { Phenylmethylsulfonylfluorid } \\ \text { RGS } & \text { regulator of G-protein signaling } \\ \text { rpm } & \text { Umdrehungen pro Minute } \\ \text { SDS } & \text { Natriumdodecylsulfat } \\ \text { SDS-PAGE } & \text { SDS-Polyakrylamidgelelektrophorese } \\ \text { SNAP } & \text { soluble NSF attachment protein } \\ \text { SNAP-25 } & \text { synaptosomal associated protein of } 25 \mathrm{kDa} \\ \text { SNAP-23 } & \text { synaptosomal associated protein of } 23 \mathrm{kDa} \\ \text { SNARE } & \text { SNAP-receptor } \\ \text { Tab } & \text { Tabelle } \\ \text { TB } & \text { 'terrific broth' Medium } \\ \text { TBS } & \text { Tris bufferd saline } \\ \text { TRIS } & \text { Tris-(Hydroxymethyl)-Aminoethan } \\ \text { Vol } & \text { Volumen }\end{array}$




\subsection{Danksagung}

Mein besonderer Dank gilt Herrn Prof. Reinhard Jahn, dafür dass er mir die Durchführung der Doktorarbeit in seiner Abteilung ermöglicht hat, für seine jedmögliche Unterstützung und ansteckende Optimismus und Zuversicht.

Beim Professor Ralf Ficner bedanke ich mich für die Übernahme des Korreferats.

Bei dem Graduiertenkolleg 521 bedanke ich mich für die Unterstützung während der ersten drei Jahren meiner Doktorarbeit.

Bei Markus Wahl möchte ich mich für seine Betreuung und seinen Kampfgeist beim Kristallisieren von Snapin bedanken.

Sehr herzlich möchte ich mich bei dem guten Geist dieses Labors, Gottfried Mieskes, bedanken. Für seine enorme Geduld und Hilfsbereitschaft und Erfindungsgeist bei Lösung aller Probleme technischer und seelischer Art.

Ursel Ried danke ich ganz herzlich für die enorme Hilfe bei der Proteinexpression, Gordon Dowe danke ich für die Sequenzierung von unzähligen DNA-Konstrukten und Uwe Pleßmann für die Sequenzierung von Proteinfragmenten. Für die MALDI-MS-Analysen bedanke ich mich ganz herzlich bei Henning Urlaub.

Ich möchte mich bei Dirk Fasshauer für die Hilfe mit Anisotropiemessungen bedanken.

Dorothea Schierding gilt ganz besonderer Dank für die Korrektur dieser Doktorarbeit, die sie um einiges leserlicher gemacht hat.

Ich bedanke mich bei allen meinen Kollegen, alten und neuen, nicht nur aus dieser Abteilung, die mir in diesen Jahren mit viel Hilfsbereitschaft zur Seite gestanden haben.

Ich bedanke mich bei meinen Eltern, Großeltern und Freunden dafür, dass sie mich lieben. 


\subsection{Publikationen}

Teile dieser Studie wurden publiziert in

Vites, O., Rhee, J. S., Schwarz, M., Rosenmund, C., and Jahn, R. (2004) Reinvestigation of the role of snapin in neurotransmitter release J Biol Chem 279, 26251-26256 


\subsection{Lebenslauf}

Name:

Geburtsdatum:

Geburtsort:

Staatsangehörigkeit:

Schulbildung:

1982-1990

1990-1992

1992

1993

Dezember 1993

\section{Studium:}

1994-1999

Mai 1999-Nov. 1999

Nov. 1999

Nov.1999-Juli 2000

$\underline{\text { Doktorarbeit: }}$

seit August 2000 Doktorarbeit am Max-Planck-Institut für biophysikalische Chemie, Abteilung Neurobiologie, Göttingen
Olga Vites

09.11.1975

Odessa (Ukraine)

deutsch

mittlere Schule Nr. 35, Odessa

naturwissenschaftliches Lyzeum Nr. 36, Odessa

allgemeine ukrainische Hochschulreife

Studienkolleg Münster,

Fachabitur (Biologie, Medizin)

Studium Diplom Biologie an der Universität zu Köln

Diplomarbeit an der Universität zu Köln, Institut für Genetik Titel der Arbeit „Identifizierung und Charakterisierung $L$. monocytogenes spezifischer Genabschnitte mittels genomischer Subtraktion zwischen L. monocytogenes und L. innocua', Diplom in Biologie

Hauptfach: Genetik, Nebenfächer Biochemie und physikalische Chemie

Tätigkeit als wissenschaftliche Mitarbeiterin an der Universität zu Köln, Institut für Genetik 